\title{
Promotion of exclusive breastfeeding for six months in asthmatic families
}

Citation for published version (APA):

Gijsbers, B. (2007). Promotion of exclusive breastfeeding for six months in asthmatic families. [Doctoral Thesis, Maastricht University]. Universiteit Maastricht. https://doi.org/10.26481/dis.20071121bg

Document status and date:

Published: 01/01/2007

DOI:

$10.26481 /$ dis.20071121bg

Document Version:

Publisher's PDF, also known as Version of record

\section{Please check the document version of this publication:}

- A submitted manuscript is the version of the article upon submission and before peer-review. There can be important differences between the submitted version and the official published version of record.

People interested in the research are advised to contact the author for the final version of the publication, or visit the DOI to the publisher's website.

- The final author version and the galley proof are versions of the publication after peer review.

- The final published version features the final layout of the paper including the volume, issue and page numbers.

Link to publication

\footnotetext{
General rights rights.

- You may freely distribute the URL identifying the publication in the public portal. please follow below link for the End User Agreement:

www.umlib.nl/taverne-license

Take down policy

If you believe that this document breaches copyright please contact us at:

repository@maastrichtuniversity.nl

providing details and we will investigate your claim.
}

Copyright and moral rights for the publications made accessible in the public portal are retained by the authors and/or other copyright owners and it is a condition of accessing publications that users recognise and abide by the legal requirements associated with these

- Users may download and print one copy of any publication from the public portal for the purpose of private study or research.

- You may not further distribute the material or use it for any profit-making activity or commercial gain

If the publication is distributed under the terms of Article $25 \mathrm{fa}$ of the Dutch Copyright Act, indicated by the "Taverne" license above, 


\section{PROMOTION OF EXCLUSIVE BREASTFEEDING FOR SIX MONTHS IN ASTHMATIC FAMILIES}


Promotion of exclusive breastfeeding for six months in asthmatic families Barbara Gijsbers

ISBN: 978-90-9022302-5

Cover: "Borstvoeding", sculpture by Henny Lauwers

Lay-out: Barbara Gijsbers

Production: Gildeprint Drukkerijen B.V., Enschede

(C) 2007, Barbara Gijsbers

All rights reserved. No part of this thesis may be reproduced or transmitted in any form or by any means, electronic or mechanical, including photocopying, recording or any information storage or retrieval system, without permission in writing from the author.

The study presented in this thesis was funded by the Dutch Asthma Foundation (3.2.99.39) and the Netherlands Organization for Health Research and Development (ZonMw) (No 2300.0009).

Financial support for the printing of this thesis was kindly provided by the faculty of Health, Medicine and Life Sciences (Maastricht University), the Dutch Asthma Foundation and ZonMw. 


\title{
PROMOTION OF EXCLUSIVE BREASTFEEDING FOR SIX MONTHS IN ASTHMATIC FAMILIES
}

\author{
PROEFSCHRIFT \\ ter verkrijging van de graad van doctor \\ aan de Universiteit Maastricht, \\ op gezag van de Rector Magnificus, Prof.mr. G.P.M.F. Mols, \\ volgens het besluit van het College van Decanen, \\ in het openbaar te verdedigen \\ op woensdag 21 november 2007 om 14.00 uur
}

door

Barbara Gijsbers 


\section{Promotoren}

Prof.dr. C.P. van Schayck

Prof.dr. J.A. Knottnerus

Copromotor

Dr. I. Mesters

Beoordelingscommissie

Prof.dr. H. de Vries (voorzitter)

Prof.dr. P.J.E. Bindels, AMC Amsterdam

Dr. E. Dompeling

Prof.dr. R.A Hirasing, VUmc Amsterdam

Dr. T. van der Weijden 


\section{Contents}

$\begin{array}{lll}\text { Chapter } 1 \quad \text { General introduction } & 7\end{array}$

Chapter 2 Factors influencing breastfeeding practices in asthmatic families: results from an explorative study

(Patient Educ Couns 2005;57:15-21)

Chapter 3 The success of an educational programme to promote exclusive breastfeeding for six months

- a randomised controlled trial-

(Pediatr Asthma Allergy Immunol 2006;19:214-222)

Chapter 4 The effective breastfeeding educational programme: its content and why it may work-a RCT based analysis-

(Manuscript in preparation)

Chapter 5 Factors associated with the initiation of breastfeeding in asthmatic families:

the Attitude-Social Influence-self-Efficacy model

(Breastfeed Med 2006;1:236-246)

Chapter 6 Factors associated with the duration of exclusive

breastfeeding in asthmatic families

99

(Health Educ Res 2007;doi:10.1093/her/cym013)

Chapter $7 \quad$ General discussion

Summary

Samenvatting

Appendix: Breastfeeding booklet

Publications

Dankwoord

About the author 



\section{1}

General introduction 



\section{Introduction}

The research project described in this thesis originates from the PREVASC programme (PREVention of ASthma in Children). In this programme, women, in addition to other preventive recommendations, were encouraged to give breast milk exclusively for up to six months to prevent the development of asthma in their children. ${ }^{1}$ Since asthma is a multifactorial disease in which both genetics and environmental factors play a role, ${ }^{2}$ we assume that the development of asthma can be delayed or prevented by reducing exposure to both inhalant and food allergens simultaneously. Consequently, newborns with a predisposition for asthma should not be exposed to mite, pet allergens, environmental tobacco smoke (ETS) and food allergens (cow milk protein). However, prevention of exposure to cow milk proteins by exclusive breastfeeding for the entire first six months appears to be a very difficult recommendation to follow. ${ }^{1}$ According to the PREVASC study, only $10 \%$ of the women in the experimental group managed to breastfeed exclusively for the recommended period. ${ }^{1}$ Therefore, the main focus of this thesis is to find and validate a way to increase the percentage women who continue to breastfeed exclusively for the first six months of their infant's life. For this purpose a theory-based educational breastfeeding programme was developed. The other preventive measures, such as usage of anti-mite encasings for mattresses, cleaning recommendations and avoiding exposure to ETS were also performed by the participants, but will not be discussed in this thesis. ${ }^{3}$

To embed the different research questions of this research project, this chapter will present an overview of the prevalence of childhood asthma in the Netherlands, along with the different health benefits of breastfeeding (BF), especially the relationship between exclusive $\mathrm{BF}$ and prevention of childhood asthma. In addition, other BF promotion programmes will be discussed and the definition of $\mathrm{BF}$ that was used will be clarified. Furthermore, the factors that are associated with the initiation and continuation of exclusive $\mathrm{BF}$ according to the recent literature will be discussed, as well as the main theoretical model on which the educational programme was based. Finally, the outline of this thesis will be presented.

\section{Childhood asthma}

In recent decades the prevalence of asthma in children has increased substantially, ${ }^{4}$ but this trend seems not to have persisted into the twenty-first century. ${ }^{5-6}$ The prevalence of childhood asthma in the Netherlands is about $6 \%$ in $0-1$-year-old infants and decreases to $4 \%$ in $4-5$-year olds. ${ }^{7}$ Moreover, asthma is the most common chronic disease in childhood seen in general practice. Genetics as well as environmental factors play an important role in 
asthma development. ${ }^{8}$ Newborns with first-degree asthmatic blood relatives have a hereditary predisposition for such complaints and are, therefore, particularly at risk of developing asthma. This predisposition cannot be changed. However, reduction of exposure to environmental factors, such as mite or food allergens, could be an effective tool in preventing childhood asthma. Therefore, several birth cohort studies and intervention studies have been and are being carried out all over the world to explore the relationship between reduction of exposure to allergens and preventing asthma. ${ }^{9}$

\section{General health benefits of breastfeeding}

There is substantial evidence that BF over a longer period of time has many health benefits for mother and child. ${ }^{\text {e.g. } 10}$ Van Rossum et al. ${ }^{10}$ carried out a systematic literature review of published epidemiological studies conducted in the general ('western') population on the health effects of BF (taking the beneficial and harmful effects together) for mother and child.

In the overview, the strength of evidence for an association is qualified by four World Health Organisation (WHO) criteria derived from the 2003 report 'Diet, Nutrition and the Prevention of Chronic Diseases'. ${ }^{11}$

The criteria used to indicate the evidence's strength were:

- Convincing evidence: evidence based on epidemiological studies showing consistent associations between exposure and disease, with little or no evidence to the contrary. The available evidence is based on a substantial number of studies including prospective observational studies, systematic reviews and randomised trials.

- Probable evidence: evidence based on epidemiological studies showing fairly consistent associations between exposure and disease, although there are inconsistencies as well. Shortcomings in the evidence may be any of the following: insufficient duration of trials (or studies); insufficient trials (or studies) available; inadequate sample sizes; and incomplete follow-up.

- Possible evidence: evidence based mainly on findings from case-control and crosssectional studies. Insufficiently randomised controlled trials, observational studies or nonrandomised controlled trials are available. More trials are required to support the tentative associations.

- Insufficient evidence: evidence based on findings of a few studies which are suggestive, but are insufficient to establish an association between exposure and disease. Better designed research is required to support the tentative associations. 
Table 1.1 presents a summary of the health effects for children who are breastfed, as compared to those who received formula. Some publications are added to update the references.

Table 1.1 Overview of the health effects of BF compared to formula in mother and child

\begin{tabular}{|c|c|c|}
\hline Strength of evidence & Health effect child & Health effect mother \\
\hline Convincing & $\begin{array}{l}\text { Gastrointestinal infections including } \\
\text { diarrhoea*e.g.12 } \\
\text { Otitis media*e.g.13-14 } \\
\text { Obesity*e.g.15-16 }\end{array}$ & Rheumatoid arthritis*e.g.33 \\
\hline Probable & $\begin{array}{l}\text { Asthma } * \text { e.g. } 17-19 \\
\text { Wheezing* e.g. } 20 \\
\text { Eczema } * \text { e.g. } 21-22 \\
\text { Cognitive and motor development }{ }^{\wedge \text { e.g. } 23}\end{array}$ & \\
\hline Possible & $\begin{array}{l}\text { Crohn's disease* e.g.24 } \\
\text { Atopy*e.g. } 25-26 \\
\text { Diabetes type I*e.g. } 27 \\
\text { Leukaemia*e.g.28 }\end{array}$ & $\begin{array}{l}\text { Pre-menopausal breast cancer*.g. } 34 \\
\text { Ovarian cancer*e.g. } 35\end{array}$ \\
\hline Insufficient & $\begin{array}{l}\text { Urinary tract infections*e.g. } 29 \\
\text { Ulcerative colitis*e.g.24 } \\
\text { Lymphomas } * \text { e.g. } 30 \\
\text { All childhood cancers } * \text { e.g. } 31 \\
\text { Sudden infant death syndrome*.e.32 }\end{array}$ & $\begin{array}{l}\text { Hip fracture* e.g. } 36 \\
\text { Weight gain* e.g. } 37 \\
\text { Post-menopausal breast cancer } * \text { e.g. } 38\end{array}$ \\
\hline
\end{tabular}

In summary, according to the systematic review ${ }^{10} \mathrm{BF}$ has many positive health effects for mother and child. Regarding asthma, it is probable that BF protects children from developing asthma. This is defined as "probable" and not "convincing" since few studies found no, weak or even opposite associations between BF and prevention of asthma traits. $^{39-41}$

One of the major reasons that studies which investigate the effect of breastfeeding with regard to the development of allergies remain inconclusive may be the complexity of the interaction between breast milk and an infant's intestinal milieu and immune system. Some elements in breast milk are thought to act to protect the infant from developing allergies, whereas others might act in the opposite fashion (see Table 1.2). ${ }^{42-43}$ 
Table 1.2 Factors in breast milk that are currently being evaluated as either protecting or inducing against (food)allergies ${ }^{43}$

\begin{tabular}{lll}
\hline & Protective & Inducing \\
\hline Antigens & Tolerizing allergens & Sensitizing allergens \\
Cytokines & TGF- $\beta$ & IL-4 \\
& Soluble CD14 & IL-5 \\
& & IL-13 \\
Immunoglobulins & s-IgA to ovalbumin & \\
$\begin{array}{l}\text { Polyunsaturated fatty } \\
\text { acids }\end{array}$ & Eicosapentaenoic acid & Arachidonic acid \\
& Docosapentaenoic acid & C22:4n-6 \\
& Docosatetraenoic acid & C22:5n-6 \\
& $\alpha$-Linoleic acid & \\
Chemokines & n-3 Polyunsaturated fatty acids & \\
& & RANTES \\
Eosinophil-derived & & IL-8 \\
granular proteins & & Eosinophil cationic protein \\
Polyamines & & \\
& & \\
\hline
\end{tabular}

In the next section a more detailed overview will be given of recent studies on the relationship between exclusive $\mathrm{BF}$ and the development of asthma. It should be noted that differences in methodology and inevitable flaws in design make these studies difficult to compare, and that no single definite study has yet been published. ${ }^{43}$ Differences include whether a study is prospective or retrospective, interventional versus observational or selfselective versus randomised. Design flaws included, for example, small sample size, lack of randomisation, confounding by heredity and lifestyle factors, and brief duration of BF. Furthermore, a detailed description of the specific outcome disorder (such as asthma) needs to be defined precisely and the extent of BF exposure (never vs. always, partial vs. exclusive) needs to be known. However, despite these obstacles, many trends can be observed and conclusions can be drawn from recent literature.

\section{Exclusive breastfeeding and childhood asthma}

\section{Cohort studies}

Two recent, large prospective studies, one Swedish ${ }^{44}$ and one Australian, ${ }^{45}$ demonstrated a lower risk of asthma at four and six years of age respectively in infants who were breastfed exclusively for at least four months. In the Australian cohort study of 2,600 children ${ }^{45}$ it appeared that the positive association did not differ between children with or without a family history of asthma. At the same time, the authors of the Swedish birth cohort ${ }^{44}$ concluded that at the age of four the preventive effect of exclusive BF tends to be stronger 
in the children without a predisposition for allergy. The authors did not explicitly explain this positive, but smaller effect size in high-risk children, but one explanation could be that the high-risk children who already showed allergic symptoms were breastfed for a longer period and, therefore, gave the impression that exposure to BF in high-risk children was less protective as compared to low-risk children.

On the other hand, few studies reported even a negative relationship between exposure to $\mathrm{BF}$ and the development of asthma. For example, the retrospective study of Sears et al. ${ }^{41}$ revealed that exclusive $\mathrm{BF}$ for four weeks or longer was associated with a significantly increased risk for asthma at ages 9 to 26 (OR 1.8; 95\% CI 1.4-2.5, $p<0.001$ ). Unfortunately, the original cohort lost nearly $40 \%$ of its participants $(n=1037)$ in follow-up due to relocation to areas outside of the study's recruitment region by the time the study started. Furthermore, evaluations of this cohort were not performed before the age of 9 years, and they depended on retrospective recall of BF histories at the age of 3. Another explanation for these unexpected results is that the criterion for exclusive BF was set at a minimum of four weeks. This is a relatively short period, since a protective effect is expected at a minimum of four months of exclusive $\mathrm{BF}^{46}$

In addition, a new concern has been raised recently regarding BF by asthmatic mothers. Wright et al. ${ }^{42}$ showed in their prospective longitudinal study of 1,246 newborns that exclusive BF for more than four months by mothers suffering from asthma was associated with a significantly increased odds ratio for developing asthma in the child at the age of 6 , as compared to asthmatic mothers who breastfed their children for less than four months (OR 8.7, 95\% CI 3.4-22.2).

On the other hand, an Australian study ${ }^{44}$ found no statistically significant correlation between maternal asthma and the development of asthma children breastfed for more than four months (OR 1.46, 95\% CI 0.90 to 2.36 ).

One possible explanation for the tendency for studies to find that BF by asthmatic mothers is related to asthma outcome in their children has been proposed by van Schayck \& Knottnerus. ${ }^{47}$ In general, they stated that a serious validity problem in cohort studies was that the exposure was not determined by the play of chance (by means of randomisation) and so could be influenced by behaviour. Behaviour might, therefore, be a confounder because it can be associated with both exposure and outcome. For instance, it could be that asthmatic mothers are more likely to decide to breastfeed than are non-asthmatic mothers, since these mothers were informed that this would be better for their children. This might have resulted in an increased prevalence of asthma in breastfed high-risk children, given the established predisposition to asthma. Thus, an observed negative relationship between $\mathrm{BF}$ exposure and the occurrence of asthma could be an effect of susceptibility eventually influencing exposure, instead of exposure increasing asthma occurrence. 


\section{Review studies}

One well-designed meta-analysis included twelve prospective studies of more than 8,000 children with a mean follow-up of 4.1 years (1-8.4 years) showed that exclusive BF during at least three months after birth was associated with a decreased risk in the development of childhood asthma (OR 0.70; 95\% CI 0.60-0.81). This effect was particularly present in predisposed atopic children (OR 0.52, 95\% CI 0.35-0.79). ${ }^{45}$ In 2003 Van Odijk et al. ${ }^{49}$ published a large, critical multidisciplinary review of the literature from 1966 to 2001. A total of 4,323 articles were reviewed, but only 56 were considered conclusive and were then analysed. The studies included prospective and retrospective studies, but health effects had to be recorded, cohort selection had to be satisfactory and the statistics had to be adequate. The studies were not reviewed by meta-analyses, but by a committee. The committee found that exclusive BF reduced the risk of asthma, and the protection increased in all children with the continuation of exclusive BF for up to at least four months. Furthermore, the beneficial effects of BF seen in all children are particularly strong in infants with atopic heredity.

\section{Multifaceted intervention programmes}

Several prenatally started multifaceted intervention programmes are ongoing to evaluate the effect of a combined allergen avoidance regimen. ${ }^{1,50-51}$

The preventative strategies include avoidance of cow's milk protein with exclusive BF or hydrolyzed formula, house dust mite (HDM) allergens and pet allergens, and avoidance of environmental tobacco smoke (ETS). Recently, van Schayck et al. ${ }^{52}$ compared ten highquality studies in which a total of 3,473 participants were included, of which 1,124 participants received a multifaceted intervention and 2,349 received a mono intervention. The results showed that the multifaceted intervention studies had an OR of 0.73 (95\% CI $0.55-0.97)$, versus $\mathrm{OR}=1.22$ (95\% CI 0.83-1.78) for patients younger than five year and an OR of 0.52 (95\% CI $0.32-0.84$ ), versus 0.93 (95\% CI $0.66-1.31$ ) in patients older than five year. These results suggest that a multifaceted approach will have a greater chance of success in preventing or delaying asthma than studies using a monofaceted approach.

\section{Conclusion}

In conclusion, exclusive $\mathrm{BF}$ in the first six months is important preventive health behaviour, despite the controversy about the outcomes of studies investigating the association between asthma and exclusive BF. From a public health point of view even a small protective effect would be important, since asthma is a highly prevalent chronic disease in children. The evidence in favour of health benefits is overwhelming, and 
consequently the international recommendation by the World Health Organisation (WHO) is to stimulate mothers to breastfeed exclusively for the first six months. ${ }^{53-54}$

\section{Breastfeeding prevalence}

$\mathrm{BF}$ rates vary greatly in Europe, and data collection on BF rates is generally inconsistent and incomplete. Definitions and methods are different in many countries. Despite these difficulties in interpreting the available data, it is clear that BF rates fall short of WHO recommendations. In most countries the initiation rates are approximately 80 to $90 \%$. But there is a marked decline in exclusive BF rates in the first six months. ${ }^{55}$ In Europe, the exclusive BF rates at six months are low, as displayed in Figure 1.1. This figure includes the European countries which reported exclusive BF data or mainly BF data (breast milk and possible solids) at six months for the 1997-2005 period. ${ }^{55}$

The latest BF rates (2005) in the Netherlands show that $79 \%$ of the women initiate BF, which declines to around $35 \%$ at three months and to about $25 \%$ after six months. In the Netherlands BF figures are on the rise. Since the first registered rating in 1996-1997, the percentage of women who mainly breastfeed after six months has increased from $6 \%$ in 1996/1997 to $25 \%$ in 2005 (see Figure 1.2) ${ }^{56}$ Mainly breastfed infants receive human milk as their sole milk feeding; intake of solids and an occasional drink of water, for infants aged four months or older, cannot be excluded. How can this positive trend be explained? An explanation could be the increasing public concern regarding BF the past few years. In 2000, the Ministry of Health, Welfare and sport requested the Dutch Nutrition Center to promote BF in the Netherlands. In response, a "Masterplan" regarding BF has been developed and in 2002 the national BF campaign "BF deserves time" was launched. The certification of maternity and child health care institutions, better known as the Baby Friendly Hospital Initiative (BFHI) was also part of the campaign. Internationally, the BFHI has been shown to be effective to promote the initiation and duration of $\mathrm{BF} .{ }^{57}$ More about the BFHI and the effect on initiation and duration of BF in the Netherlands will be discussed further on this chapter.

Interestingly to know, Dutch women give birth to their children at a relatively high age. Currently, the mean age of Dutch women when giving birth to their first child is 29.4 years and the mean age overall is 31.1 years. ${ }^{58}$ It seems that Dutch women focus on their working career, before they start a career as a mother. 


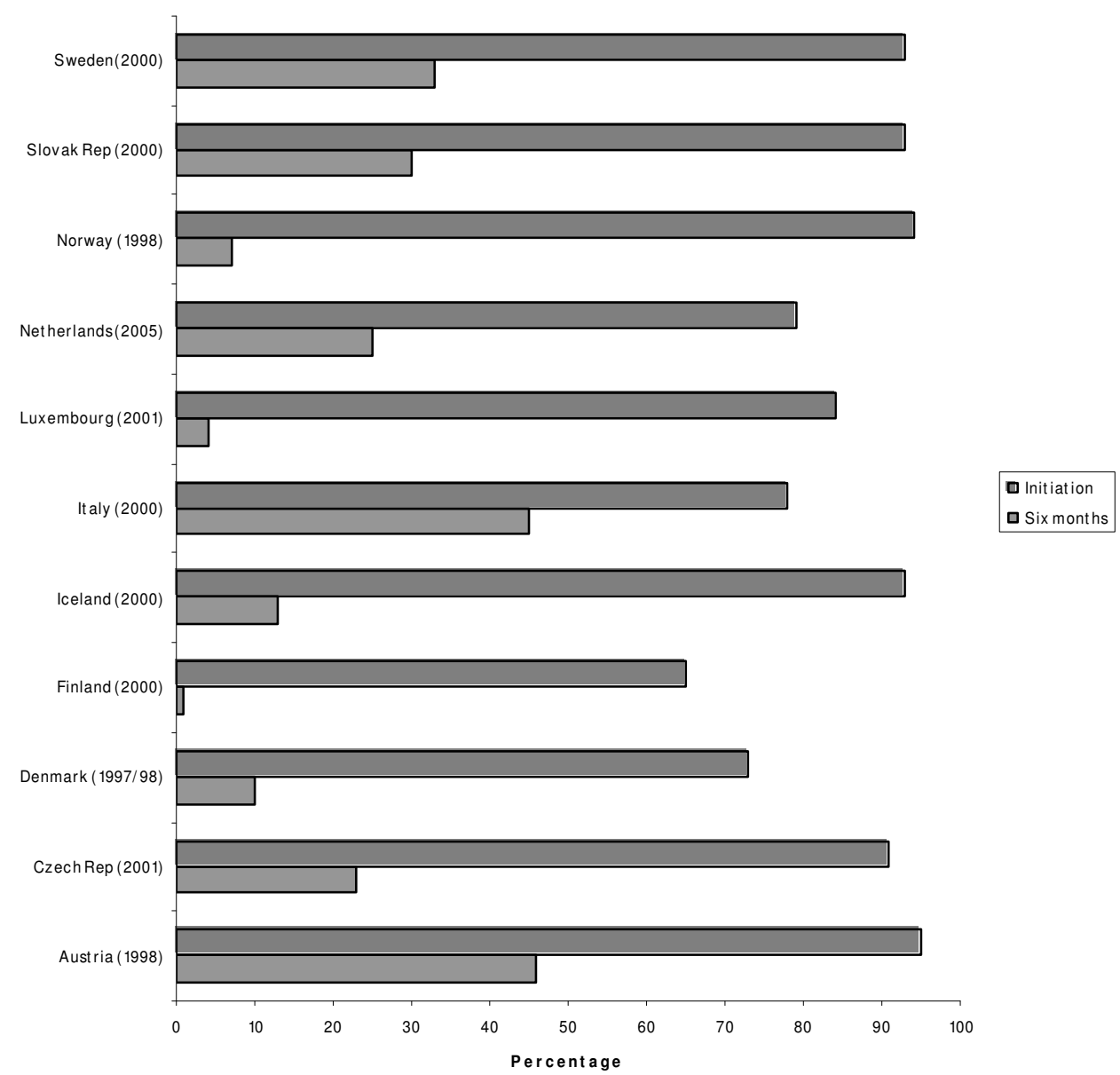

Figure 1.1 Exclusive breastfeeding rates in Europe ${ }^{55}$ 


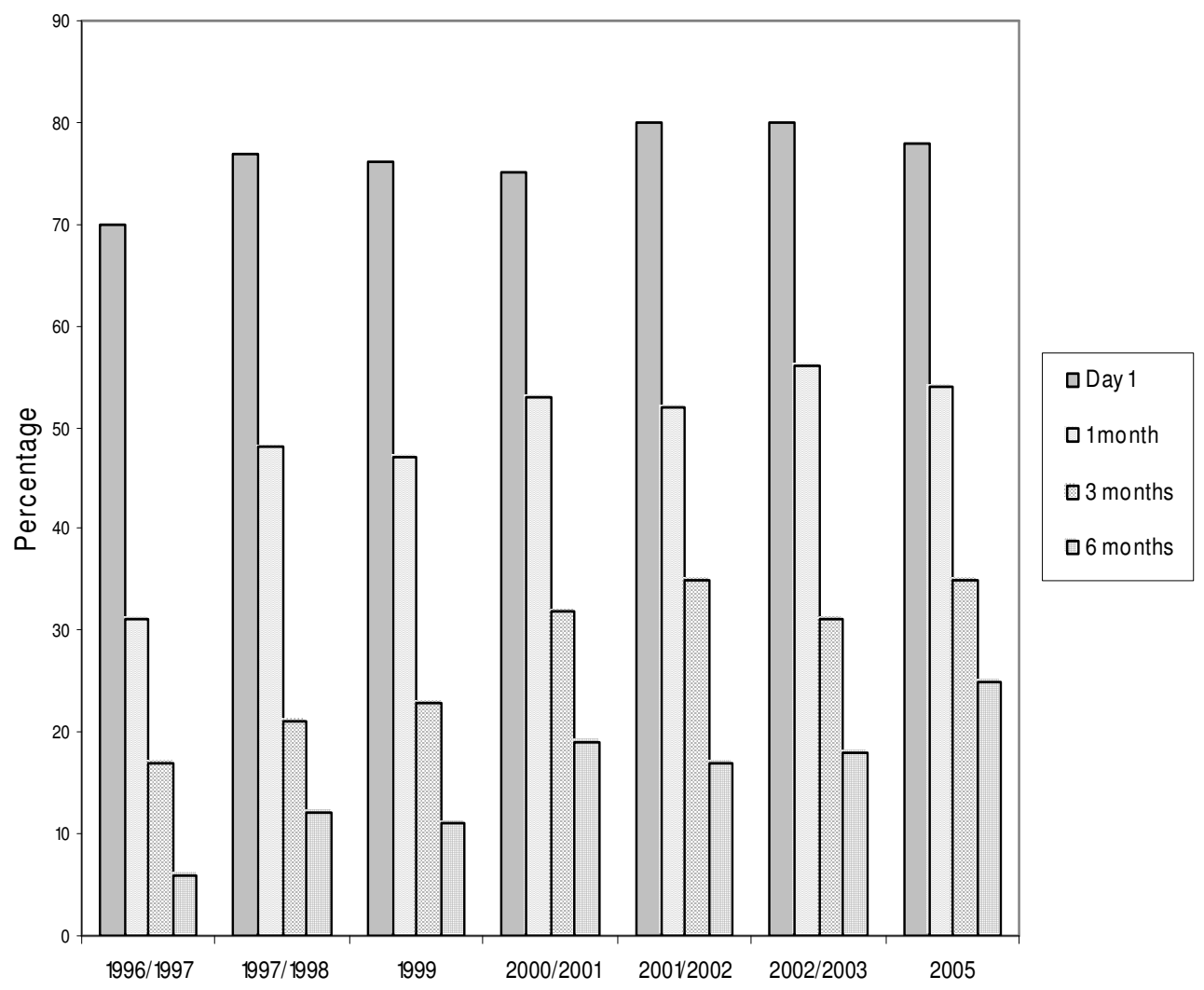

Figure 1.2 Exclusive breastfeeding rates in the Netherlands ${ }^{56}$

When looking at the BF behaviour in the Netherlands in detail, it appears that the lowest BF rates appear in the southern regions of the Netherlands (see Figure 1.3). Unfortunately, no recent data are available, but the trend as presented in Figure 1.3 seemed not to be changed in recent years. ${ }^{56}$ The study described in this thesis was performed in these southern regions. 


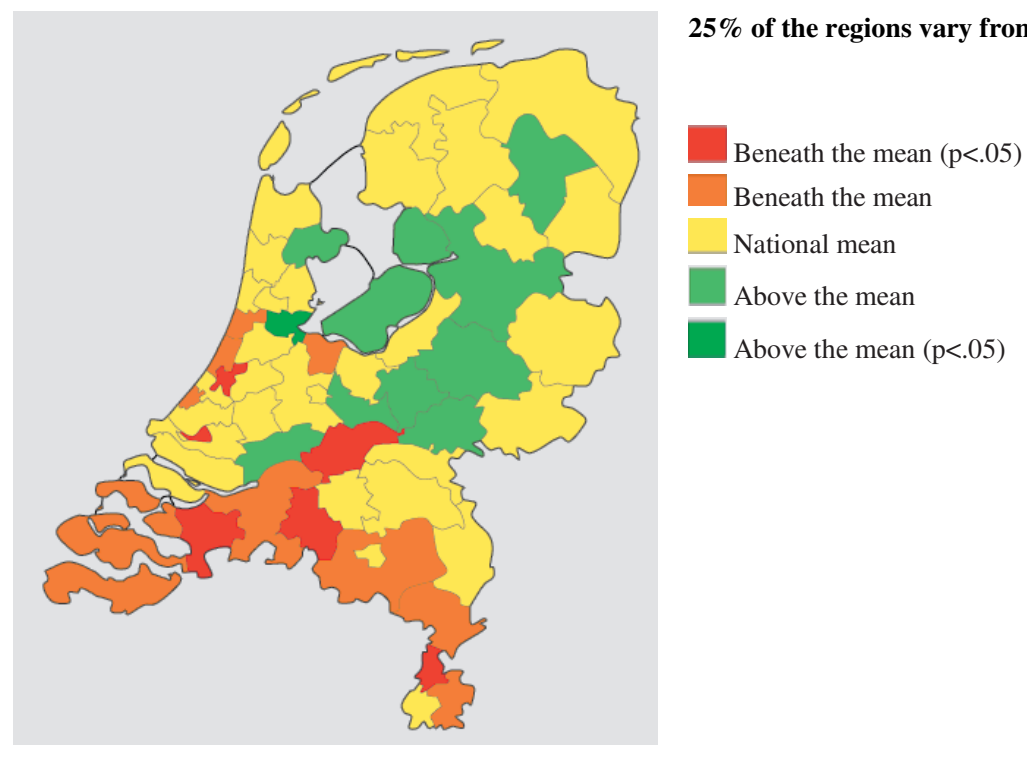

Figure 1.3 Breastfeeding rates at the age of six months per region in the period 1995-1999 ${ }^{59}$

\section{Breastfeeding promotion interventions}

In recent years, many different national and international intervention programmes were developed, and these have been evaluated with mixed results. ${ }^{60-63}$ International interventions aimed at promoting the initiation and duration of BF can be classified into five categories, which are listed in Table 1.3.

Table 1.3 Categories of interventions aimed at promoting the initiation and continuation of BF

\begin{tabular}{|c|c|}
\hline Category of intervention & Description \\
\hline $\begin{array}{l}\text { Health educational } \\
\text { interventions }\end{array}$ & $\begin{array}{l}\text { Factual information about BF often delivered via leaflets or educational } \\
\text { sessions, usually grounded in professional expertise }\end{array}$ \\
\hline Health sector initiatives & $\begin{array}{l}\text { Interventions that aim to change the organisational nature of health services in } \\
\text { favour of promotion } \mathrm{BF} \text {, including health professional training, social support } \\
\text { from health professionals, the Baby Friendly Hospital Initiative }\end{array}$ \\
\hline Peer support programmes & Interventions delivered by knowledgeable peers \\
\hline Media campaigns & Interventions that use a public medium such as TV and press \\
\hline Combined interventions & Interventions that have more than one component \\
\hline
\end{tabular}


It should be noted that a wide variety of BF interventions have been implemented and reported, but only a few have been designed and conducted in a manner allowing a qualitative evaluation of their effectiveness. ${ }^{64}$ Over the past few years, four systematic reviews have assessed the effectiveness of well-designed and conducted $\mathrm{BF}$ interventions. ${ }^{60-63} \mathrm{~A}$ short illustration of the first three intervention categories will be presented in the following sections. In addition, the current situation in the Netherlands regarding BF policy will be discussed.

\section{Health educational interventions}

According to the systematic reviews, the provision of only factual or technical information about $\mathrm{BF}$ has been of limited value. ${ }^{62}$ However, when the written information was combined with small, informal group health-education classes in the antenatal period, it was in some cases effective in increasing the duration of BF among women from different income or ethnic groups. ${ }^{61}$ These interventions consisted of individual or group instruction about BF knowledge, practical skills and problem-solving techniques.

\section{Health sector initiatives: The Baby-Friendly Hospital Initiative (BHHI)}

Many interventions evaluated in the literature are health sector initiatives, such as the Baby Friendly Hospital Initiative (BFHI). The BFHI is a joint initiative of UNICEF and WHO, aimed at improving BF rates world-wide. The requirements for achieving baby-friendly status by maternity services are listed in Figure 1.4, while the seven steps for the child health care settings are listed in Figure 1.5. In the Netherlands about $16 \%$ of the hospitals and $84 \%$ of the maternity care institutions have received the BFHI certificate, and the trend is that practices of midwives and child health care institutions will also receive the certificate. In the Netherlands this certification has had a positive effect on the initiation and duration of $\mathrm{BF}$ in the beginning, ${ }^{65}$ but the latest results show no differences in $\mathrm{BF}$ duration compared to institutions with no certification. ${ }^{56}$

On the other hand, according to a randomised controlled trial in the Republic of Belarus, BFHI certification was associated with a significantly increased duration of BF. ${ }^{66}$ Another study, in Scotland, showed that babies born in BFHI-accredited hospitals were more likely to be breastfed exclusively than were infants born in other maternity units. ${ }^{67}$

\section{Health sector initiatives: training of health professionals}

Britton et al. ${ }^{68}$ conducted an update of a review on the effectiveness of professional BF support. They have included 34 trials (29,385 mother-infant pairs) from 14 countries. The main purpose of this review was to analyse the impact of the intervention, along with extra BF support for the purpose of facilitating continued BF. They included studies on whether 
the intervention occurred in the postnatal period alone, or also included an antenatal component. Interventions taking place in the antenatal period alone, as well as interventions described as solely educational in nature, were excluded.

BF was significantly prolonged with the use of WHO/UNICEF training (RR 0.69, 95\% CI 0.52 to 0.91 ). The WHO/UNICEF training is an 8- or 40-hour BF training course to train professionals and appears to be an effective model for professional training. Spiby ${ }^{69}$ has also suggested that the WHO/UNICIF training for professionals might have the potential to influence BF duration.

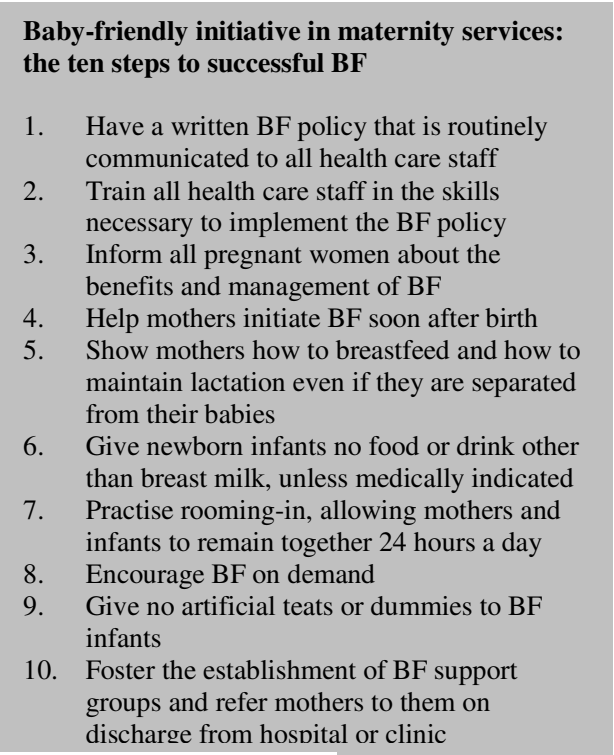

Figure 1.4 ten steps BFHI

\section{Seven-Point Plan for the protection, promotion and support of BF in child health care settings}

1. Have a written BF policy that is routinely communicated to all health care staff

2. Train all health care staff in the skills necessary to implement the BF policy

3. Inform all pregnant women about the benefits and management of $\mathrm{BF}$

4. Support mothers in initiating and maintaining BF

5. Encourage exclusive and continued BF, with appropriately-timed introduction of complementary foods

6. Provide a welcoming atmosphere for BF families

7. Promote co-operation between health care staff, BF support groups and the local community

Figure 1.5 seven steps child health care

In the Netherlands only one study is known that has conducted a randomised trial to evaluate a BF promotion programme initiated by the Home Health Care. ${ }^{70}$ The caregivers were trained in health counselling principles. Due to study restrictions, not all the caregivers received training. Only maternity nurses and the child health care nurses, as well as physicians of the Home Health Care Organisations, were trained. Midwives, an important group of professionals, did not participate in the study. The intervention appeared not to be effective; at three months $27 \%$ of the intervention group, compared to $32 \%$ of the control group, continued to breastfeed exclusively. ${ }^{78}$ 
Also popular are the peer support programmes, in which volunteers, often connected to a $\mathrm{BF}$ organisation such as the La Leche League, visit the women during their pregnancy. Still, there continues to be considerable debate over their effectiveness. ${ }^{59}$ Nevertheless, several reviews of controlled trials have provided further evidence of the effectiveness of peer support programmes. Moreover, these programmes represent a cost-effective alternative to professionally delivered services. ${ }^{71-72}$

\section{Breastfeeding promotion in the Netherlands}

In the Netherlands, BF research and activities are divided among several institutions. The Netherlands Nutrition Center ("Voedingscentrum") coordinates the national promotion campaigns, such as "BF deserves time". The National Institute for Public Health and the Environment ("RIVM") bundles the knowledge of the benefits of BF in the Public Health Future Exploration, ${ }^{73}$ and the Netherlands Organisation for Applied Scientific Research (TNO) investigates the BF determinants and performs a national inquiry into milk feeding practices every two years.

Furthermore, different groups of health professionals (GPs, maternity assistants, midwives, paediatricians, child health care workers) support the national guideline for infant feeding, in which BF exclusively for six months is recommended as the optimal feeding for an infant, especially in high-risk families. ${ }^{74}$ This recently updated report, a co-production of the Dutch Health Care Inspectorate and the Netherlands Nutrition Center, consists of 42 assumptions on feeding recommendations in children between the ages of 0 and 4 . Finally, the foundation "Zorg voor Borstvoeding" ("SZB") runs the WHO/UNICEF certification of hospitals, midwife practices and child health care settings.

\section{Breastfeeding definition}

In 1990 the WHO and UNICEF adopted "The Innocenti Declaration on the protection, promotion and support of $B F "{ }^{75}$ This declaration stated their vision of an environment that would enable mothers, families and other caregivers to make informed decisions about optimal feeding. Optimal feeding was defined in this declaration as exclusive BF for six months followed by the introduction of appropriate complementary feeding and continuation of BF up to the age of two or beyond. Exclusive BF implies that no other drink or food is given to the infant during the first six months; the infant should feed frequently and for unrestricted periods. ${ }^{53-54}$ In the present study we use the definition of exclusive $\mathrm{BF}$ as defined by the WHO/UNICEF. 


\section{Factors associated with breastfeeding initiation and duration}

In general, women from developed countries who start and continue to breastfeed tend to share a number of the characteristics. Table 1.4 gives a short literature overview of the socio-demographic, biomedical and psychosocial factors associated with BF initiation and duration.

Table 1.4 Factors associated with initiation or duration of BF

\begin{tabular}{|c|c|}
\hline Factors & Initiation and duration \\
\hline \multirow[t]{3}{*}{ Socio-demographic } & Older $^{76-77}$ \\
\hline & Higher educational level / social class ${ }^{78-79}$ \\
\hline & $\begin{array}{l}\text { Positive intention to work full-time after } \\
\text { maternity leave (inconsistent results) }\end{array}$ \\
\hline \multirow[t]{4}{*}{ Biomedical } & Increase in parity (inconsistent results) ${ }^{76,81}$ \\
\hline & Vaginal delivery (inconsistent results) ${ }^{76}$ \\
\hline & No health problems of infant ${ }^{82-83}$ \\
\hline & Non-smoking ${ }^{80,84}$ \\
\hline \multirow[t]{6}{*}{ Psychosocial } & Prenatal BF intentions $s^{78,85-87}$ \\
\hline & Positive attitudinal beliefs ${ }^{80,82,88}$ \\
\hline & Higher maternal confidence/self-efficacy ${ }^{* 82,89}$ \\
\hline & Stronger social support ${ }^{81,90}$ \\
\hline & More BF knowledge ${ }^{91-93^{*}}$ \\
\hline & Prior BF experience ${ }^{94-95}$ \\
\hline
\end{tabular}

The literature showed that BF initiation and duration were related to a number of factors. Women who started and continued to breastfeed appeared to be older and have higher educational levels and socio-economical status. There were conflicting results about the association between return to work and BF initiation and duration. This could also be affected by different definitions of BF or working status after maternity leave. Some studies measured the intended working hours after maternity leave, while other studies described the actual working hours.

Smoking and delivery of a child with health problems were negatively associated with the initiation and continuation of BF. The method of delivery and the number of previous children appeared not to be a consistent predictor for BF behaviour.

Women who have the intention to breastfeed have positive attitudinal beliefs, experience social support, have previous BF experience, have confidence in their ability and have a high level of $\mathrm{BF}$ knowledge, and these were likely both to initiate and continue to breastfeed. 


\section{Theory-based programme development: The Attitude-Social influence-self-Efficacy model (ASE model)}

The ASE model (see Figure 1.6) has been influenced by several social cognition models and concepts such as the Theory of Reasoned Action ${ }^{96}$ and Theory of Planned Behavior, ${ }^{97}$ concepts of social pressure, ${ }^{98}$ and Bandura's Social Learning theory (SLT) and his constructs of modelling and self-efficacy. ${ }^{99}$ The ASE model states, just as does the TRA ${ }^{96}$ and its successor the TPB, ${ }^{97}$ that behaviour is a function of a person's intention. In the ASE model it is assumed that three types of proximal cognitive variables primarily determine behavioural intention: attitudinal beliefs (and emotions), social influences (social norms, social support and social pressure, and modelling) and self-efficacy expectations. The model also postulates that intention predicts subsequent behaviour. Furthermore, the distal or external variables, such as behavioural factors (e.g., previous experience and knowledge) and socio-demographic variables (e.g., age and educational level) are assumed to be moderated by the three proximal factors (attitudinal beliefs, social influences and selfefficacy).

The ASE model has been successfully applied in several studies to explain various aspects of preventive health behaviour, such as fruit and vegetable consumption, ${ }^{100}$ breast cancer screening, ${ }^{101}$ and smoking cessation, ${ }^{102}$ and recently also in predicting BF initiation and duration. $^{103}$

Recently, the ASE model was extended and is now called the Integrated Change Model (Ichange model). ${ }^{104}$ The I-change model builds on the ASE model and assumes that motivational factors are determined by various distal factors, such as awareness factors, ${ }^{105}$ and includes predisposing factors such as behavioural factors (e.g., personality); psychological factors; biological, social and cultural factors; and information factors.

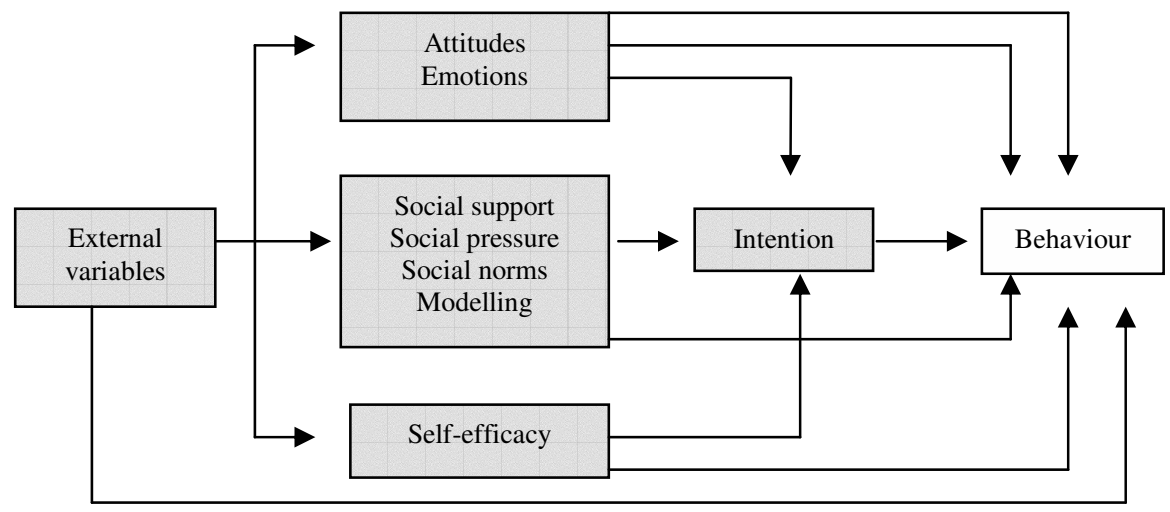

Figure 1.6 The ASE model ${ }^{106}$ 


\section{Outline of the thesis}

As mentioned at the beginning of this chapter, this research project originated in the PREVASC programme (PREVention of ASthma in Children), a research programme that addresses the primary prevention of asthma in children. The PREVASC programme focuses on four major research questions. First of all, it examines the predictive value of a positive family history of asthma, assessed in the prenatal period by the general practitioner, for the development of respiratory tract and asthma related morbidity $(\mathrm{PhD}$ thesis, Sandra Kuiper, 2007). Secondly, it investigates whether a multifaceted prenatally started intervention strategy, based on reducing the exposure to indoor and food allergens and tobacco smoke in high-risk infants, leads to a decrease in the occurrence of asthma (PhD theses, Huub Schönberger 2005 and Tanja Maas 2007). Furthermore, it evaluates whether a systematically theory-based developed educational programme leads to an increase in the adherence to one preventive measure, namely avoiding food allergens (this thesis). Finally, the programme studies the health-economic benefits of primary prevention of asthma (PhD thesis, Sandra Kuiper, 2007). An overview of the various studies carried out as part of the PREVASC programme has been published elsewhere. ${ }^{3}$

Chapter 2 focuses on the pilot study. Focus-group interviews were conducted to explore the behavioural and psychosocial determinants of adherence regarding exclusive BF and postponement of solid food for at least six months. The participants were parents with a history of asthma, who were randomly selected from the PREVASC study.

Chapter 3 describes the effect of the intervention on the proportion of women who exclusively breastfed for the first six months.

Chapter 4 shows the elements of the educational programme and the methods used to systematically develop a health education programme to promote exclusive BF for the first six months. Furthermore, it explores why the programme was effective.

Chapter 5 investigates the association between both the variables of the ASE model and the intended duration and the actual initiation of BF. The results show which factors are predictors for intending to breastfeed and then actually initiating breastfeeding in this specific target group, and go on to show the usefulness of the ASE model to predict BF behaviour.

Chapter 6 explores the predictors for long-term exclusive BF duration, since the main recommendation was to breastfeed exclusively for six months, and will answer the question of which behavioural or social psychological factors influence the target behaviour.

Chapter 7 provides a general discussion in which the findings will be discussed, and suggestions for implications and recommendations for future research will be offered. Finally a summary, also in Dutch, of the various studies and findings is given. 


\section{References}

1. Schönberger HJ, Dompeling E, Knottnerus JA, Maas T, Muris JW, et al. The PREVASC study: the clinical effect of a multifaceted educational intervention to prevent childhood asthma. Eur Resp J 2005;25:660-670.

2. Warner JA, Jones AC, Miles EA, Colwell BM, Warner JO. Materno-fetal interaction and allergy. Allergy 1996;51:447-451.

3. Kuiper S, Maas T, van Schayck CP, Muris JWM, Schönberger JAM, Dompeling E, Gijsbers B, van Weel C, Knottnerus JA. The primary prevention of asthma in children (PREVASC) study: design of a multifaceted prevention program. Pediatr Allergy Immunol 2005;16:321-333.

4. Warner JA, Jones CA, Jones AC, Warner JO. Prenatal origins of allergic disease. J Allergy Clin Immunol 2000;105:S493-498.

5. Mommers M, Gielkens-Sijstermans C, Swaen GMH, van Schayck CP. Trends in prevalence of respiratory symptoms and treatment in Dutch children over a 12 year period: results of the fourth consecutive survey. Thorax 2005;60:97-99.

6. Van Schayck CP, Smit HA. The prevalence of asthma in children: a reversing trend. Eur Respir J 2005;26:647-650.

7. Brunekreef B, Smit J, De Jongste J, Nijens H, Gerritsen J, Postma D. The prevention and incidence of asthma and mite allergy (PIAMA) birth cohort study: design and first results. Pediatr Allergy Immunol 2002;13:55-60.

8. Von Mutius. Towards prevention. Lancet 1997;350:SII 14-17.

9. Maas T, Dompeling E, van Schayck CP, Muris JWM, Schönberger HJAM, Wesseling G, Platts-Mills TAE, Knottnerus JA. Birth cohort studies on asthma development. Pediatr Asthma Allergy Immunol 2005;18:201215.

10. Van Rossum CTM, Buchner FL, Hoekstra J. Quantification of health effects of BF - Review of the literature and model simulation. [ Kwantificering van de gezondheidseffecten van borstvoeding - Literatuuroverzicht en modelsimulatie ]. RIVM rapport nr. 350040001. Bilthoven 2005.

11. WHO/FAO expert consultation. Diet, Nutrition and the prevention of chronic diseases. 2003; WHO technical report series; 916.

12. Achmed T, Fuchs GJ. Gastrointestinal allergy to food: review. J Diarrhoeal Dis Res 1997;15:211-223.

13. Duffy LC, Faden H, Wasielewski R, Wolf J, Krystofik D. Exclusive breastfeeding protects against bacterial colonization and day care exposure to otitis media. Pediatrics 1997;100:E7.

14. Uhari M, Mantysaari K, Niemala M. A meta-analytic review of the risk factors for acute otitis media. Clin Infect Diseases 1996;22:1079-1083.

15. Toschke AM, Martin RM, von Kries R, Wells J, Smith GD, Ness AR. Infant feeding method and obesity: body mass index and dual-energy X-ray absorptiometry measurements at 9-10 y of age from the Avon Longitudinal Study of Parents and Children (ALSPAC). Am J Clin Nutr 2007;85:1578-1585.

16. Scholtens S, Gehring U, Brunekreef B, Smit HA, de Jongste J, Kerkhof M, Gerritsen J, Wijga AH. Breastfeeding, weight gain in infancy, and overweight at seven years of age, the prevention and incidence of asthma and mite allergy birth cohort study. Am J Epidemiol 2007;165:919-926.

17. Oddy WH, de Klerk NH, Sly PD, et al. The effects of respiratory infections, atopy, and breastfeeding on childhood asthma. Eur Respir J 2002;19: 899-905.

18. Oddy WH, Holt PG, Sly PD, et al. Association between BF and asthma in 6 year old children: findings of a prospective birth cohort study. BMJ 1999; 319:815-819.

19. Kull I, Almquist C, Lilja G, et al. Breast-feeding reduces the risk of asthma during the first 4 years of life. $J$ Allergy Clin Immunol 2004;114: 755-760.

20. Oddy WH, Sly PD, de Klerk NH, et al. Breastfeeding and respiratory morbidity in infancy: a birth cohort study. Arch Dis Child 2003;88:224-228. 
21. Stabell Benn C, Wohlfahrt J, Aaby P, et al. Breastfeeding and Risk of atopic dermatitis, by parental history of allergy, during the first 18 months of Life. Am J Epidemiol 2004;160:217-223.

22. Tariq SM, Matthews SM, Hakim EA, Stevens M, Arshad SH, Hide DW. The prevalence of and risk factors for atopy in early childhood: a whole population birth cohort study. J Allergy Clin Immunol 1998;101:587593.

23. Anderson JW, Johnstone BM, Remley DT. Breastfeeding and cognitive development: a meta-analysis. Am J Clin Nutr 1999;70:5225-5255.

24. Klement E, Cohen RV, Boxman J, Joseph A, Reif S. Breastfeeding and risk of inflammatory bowel disease: a systematic review with meta-analysis. Am J Clin Nutr 2004;80:1342-1352.

25. Chandra RK, Hamed A. Cumulative incidence of atopic disorders in high risk infants fed whey hydrolysate, soy, and conventional cow milk formulas. Ann Allergy 1991;67:129-132.

26. Kramer MS, Kakuma R. Optimal duration of exclusive BF. Cochrane Database Syst Rev 2002;(1):CD003517.

27. Norris JM, Scott FW. A meta-analysis of infant diet and insulin-dependent diabetes mellitus: do biases play a role? Epidemiology 1996;7:87-92.

28. Hardell L, Dreifaldt AC. Breast-feeding duration and the risk of malignant diseases in childhood in Sweden. Eur J Clin Nutr 2001;55:179-185.

29. Marild S, Hansson S, Jodal U, Oden A, Svedberg K. Protective effect of breastfeeding against urinary tract infection. Acta Paediatr 2004;93:164-168.

30. UK Childhood Cancer Study Investigators. Breastfeeding and childhood cancer. Br J Cancer 2001;85:16851694.

31. Davis MK. Review of the evidence for an association between infant feeding and childhood cancer. Int $J$ Cancer Suppl 1998;33:1129-1133.

32. McVea KL, Turner PD, Peppler DK, Cunningham DS. The role of breastfeeding in sudden infant death syndrome. More on crib death and BF. J Hum Lact 2000;16:13-20.

33. Brun JG, Nilssen S, Kvale G. Breastfeeding, other reproductive factors and rheumatoid arthritis. A prospective study. Br J Rheumatol 1995;34:542-546.

34. Bernier MO, Plu-Bureau G, Bossard N, Ayzac L, Thalabard JC. Breastfeeding and risk of breast cancer: a meta-analysis of published studies. Hum Reprod Update 2000;6:374-386.

35. Siskind V, Green A, Bain C, Purdie D. Breastfeeding, menopause, and epithelial ovarian cancer. Epidemiology 1997;8:188-191.

36. Cumming RG, Klineberg RJ. Breastfeeding and other reproductive factors and the risk of hip fractures in elderly women. Int J Epidemiol 1993;22:684-691.

37. Rogers IS, Golding J, Emmett PM. The effects of lactation on the mother. Early Hum Dev 1997;49 Suppl:S191-203.

38. Furberg H, Newman B, Moorman P, Millikan R. Lactation and breast cancer risk. Int J Epidemiol 1999;28:396-402.

39. Chulada PC, Arbes SJ Jr, Dunson D, Zeldin DC. Breast-feeding and the prevalence of asthma and wheeze in children: analyses from the Third National Health and Nutrition Examination Survey, 1988-1994. J Allergy Clin Immunol 2003;111:328-336.

40. Wright AL, Holberg CJ, Taussig LM, Martinez FD. Factors influencing the relation of infant feeding to asthma and recurrent wheeze in childhood. Thorax 2001;56:192-197.

41. Sears MR, Greene JM, Willan AR, Taylor DR, et al. Long-term relation between breastfeeding and development of atopy and asthma in children and young adults: A longitudinal study. Lancet 2002;360:901907.

42. Friedman NJ, Zeiger RS. The role of breast-feeding in the development of allergies and asthma. J Allergy Clin Immunol 2005;115:1238-1248.

43. Friedman NJ, Zeiger RZ. Prevention and natural history of food allergy. In: Leung DYM, Sampson HA, Geha RS, Szefler SJ, editors. Pediatric allergy, principles and practice. St. Louis: Mosby, Inc; 2003. p. 496. 
44. Oddy WH, Peat JK, de Klerk NH. Maternal asthma, infant feeding, and the risk of asthma in childhood. $J$ Allergy Clin Immunol 2002;11:65-67.

45. Kull I, Almquist C, Lilja G, Pershagen G, Wickman M. Breast-feeding reduces the risk of asthma during the first 4 years of life. J Allergy Clin Immunol 2004;114:755-760.

46. Oddy WH, Klerk de NH, Sly PD, Holt PG. The effects of respiratory infections, atopy, and breastfeeding on childhood asthma. Eur Respir J 2002;19:899-905.

47. Van Schayck CP, Knottnerus JA. Can the 'hygiene hypothesis' be explained by confounding behavior. $J$ Clin Epid 2004;57:435-437.

48. Gdalevich M, Mimouni D, Mimouni M. Breast-feeding and the risk of bronchial asthma in childhood: A systematic review with meta-analysis of prospective studies. J of Pediatr 2001;139:261-266.

49. Van Odijk J , Kull I, Borres MP, et al. Breastfeeding and allergic disease: a multidisciplinary review of the literature (1966-2001) on the mode of early feeding in infancy and its impact on later atopic manifestations. Allergy 2003;58:833-843.

50. Arshad SH, Stevens M, Hide DW. The effect of genetic and environmental and factors on prevalence of allergic disorders at the age of two years. Clin Exp Allergy 1993;23:504-511.

51. Chan-Yeung M, Fergusson A, Watson W, Dimich-Ward H, Rousseau R, et al. The Canadian childhood asthma primary prevention study: Outcomes at 7 years of age. J Allergy Clin Immunol 2005;116:49-55.

52. Van Schayck CP, Maas T, Kaper J, Knottnerus JA, Sheikh A. Is there any role for allergen avoidance in the primary prevention of childhood asthma? J Allergy Clin Immunol 2007;119;1323-1328.

53. World Health Organization (2002). Infant and Young Child Nutrition; Global strategy for Infant and Young Child Feeding. Executive Board Paper EB 109/12. WHO, Geneva.

54. WHO, 2001. The optimal duration of exclusive breastfeeding. Results of a WHO systematic review. www.who.int/inf-pr-2001/en/note2001-07.html. World Health Organization.

55. Promotion of breastfeeding in Europe. Eu project Contract N. SPC 2002359. Protection, promotion and support of breastfeeding in Europe : current situation. Instituto per l'infanzia, 2003, Trieste Italy.

56. Lanting CI, van Wouwe JP. Peiling melkvoeding van zuigelingen 2005: Borstvoeding in Nederland en relatie met certificering door stichting Zorg voor Borstvoeding.Rapport KvL/JPB/2006.017. Leiden: TNO, 2006.

57. Naylor AJ. Baby-friendly Hospital Initiative. Protecting, promoting, and supporting breastfeeding in the twenty-first century. Pediatr Cln North Am. 2001;48:475-483.

58. Central Bureau of Statistics, StatLine. URL: http://statline.cbs.nl (2007-9-9).

59. Giesbers H, Frenken F. Achtergrondinformatie bij de brongegevens. In: Volksgezondheid Toekomst Verkenning, Nationale Atlas Volksgezondheid. Bilthoven: RIVM, URL: http://www.zorgatlas.nl. (2007-99).

60. De Oliveira M, Bastos Camacho L, Tedstone A. Extending breastfeeding duration through primary care: A systematic review of prenatal and postnatal interventions. J Hum Lact 2001;17:326-343.

61. Fairbank L, O'Meara S, Renfrew M, Woolridge M, Sowden A, Lister-Sharpe D. A systematic review to evaluate the effectiveness of interventions to promote the initiation of breastfeeding. Health Technol Assess 2000;4:1-171.

62. Guise J, Palda V, Westhoff C, Chan B, Helfand M, Lieu T. The effectiveness of primary carebased interventions to promote breastfeeding: systematic evidence review and meta-analysis for the US Preventive Services Task Force. Ann Fam Med 2003;1:70-78.

63. Sikorski J, Renfrew M, Pindoria S, Wade A. Support for breastfeeding mothers: A systematic review. Paed Peri Epid 2003:17;407-417.

64. Scott JA. What works in breastfeeding promotion. J Roy Soc Prom Health 2005:25;203.

65. Lanting CI, Herschderfer K, van Wouwe JP, Reijneveld SA. Effect van invoering van het ' Baby Friendly Hospital Initiative' op het geven van borstvoeding in Nederland. TNO-rapportPG/jeugd, 2003.212, Leiden, 2003. 
66. Kramer M, Chalmers B, Hodnett E, Sevkovskaya Z, Dzikovich I, Shapiro S, et al. Promotion of Breastfeeding Intervention Trial (PROBIT): a randomised trial in the Republic of Belarus. JAMA 2001;285:413-420.

67. Broadfoot M, Britten J, Tappin D, MacKenzie J. The Baby-Friendly Hospital Initiative and breastfeeding rates in Scotland. Arch Dis Child Fetal Neonatal Ed 2005;90:114-116.

69. Britton C, McCormick FM, Renfrew MJ, Wade A, King SE. Support for breastfeeding mothers. Cochrane Database of Systematic Reviews 2007, Issue 1. Art. No.: CD001141. DOI: 10.1002/14651858.CD001141.pub3.

70. Spiby H, McCormick F, Wallace L, Renfrew MJ, D’Souza L, Duson L. A systematic review on education and evidence-based practice interventions with health professionals and breast feeding counsellors on duration of breastfeeding. Midwifery 2007, doi:10.1016/j/midw.2007.01.006.

71. Kools EJ, Thijs C, Kester ADM, van den Brandt PA, de Vries H. A breast-feeding promotion and support program a randomised trial in the Netherlands. Prev Med 2005;40:60-70.

72. Dennis CL, Hodnett E, Gallop R, Chalmers B. The effect of peer support on breast-feeding duration among primiparous women: a randomized controlled trial. CMAJ 2002;166:21-28.

73. McInnes R, Love J, Stone D. Evaluation of a community-based intervention to increase breastfeeding prevalence. J Public Health Med 2000;22;138-145.

74. Overberg R, van Drongelen K, Herschderfer K. Volksgezondheid Toekomst Verkenning. In: Nationaal Kompas Volksgezondheid. Bilthoven: RIVM, http://www.nationaalkompas.nl, (2003-9-9).

75. National guidelines report 2007. Voeding van zuigelingen en peuters. Uitgangspunten voor de voedingsadvisering voor kinderen van 0-4 jaar. Het Voedingscentrum 2007.

76. WHO/UNICEF, The Innocenti declaration on the protection, promotion and support of breastfeeding. In breastfeeding in the 1990's: A global initiative meeting in Florence Italy and New York. Geneva, Switzerland. 1990, WHO/UNICEF: Geneva.

77. Ford R, Mitchell E, Scragg R, Stewart A, Taylor B, Allen E. Factors adversely associated with breastfeeding in New Zealand. J Ped Child Health 1994;30:483-489.

78. Scott JA, Aitkin I, Binns CW, Aroni RA. Factors associated with the duration of breastfeeding amongst women in Perth, Australia. Acta Paediatr 1999;88:416-421.

79. Kools EJ, Thijs C, Kester ADM, de Vries H. The motivational determinants of breast-feeding: Predictors for the continuation of breastfeeding. Prev Med 2006;43:394-401.

80. Riva E, Banderali G, Agostoni C, Silano M, Radaelli G, Giovannini M. Factors associated with initiation and duration of breastfeeding in Italy. Acta Paediatr 1999; 88:411-415.

81. Scott JA, Binns CW, Oddy WH, Graham KI. Predictors of breastfeeding duration: Evidence from a cohort study. Pediatrics 2006;117:646-655.

82. Clements MS, Mitchell EA, Whright SP, Esmail A, Jones FR, Ford RPK. Influences on breastfeeding in southeast England. Acta Paediatr 1997;86:51-56.

83. Ford K, Labbok M. Who is breastfeeding? Implications of associated social and biomedical variables for research on the consequences of method of infant feeding. Am J Clin Nutr 1990;52:451-456.

84. Lawson K, Tulloch MI. BF duration: prenatal intentions and postnatal practices. J Advanced Nurs 1995;22:841-849.

85. Donath SM, Amir LH. The relationship between maternal smoking and breastfeeding duration after adjustment for maternal infant feeding intention. Acta Paediatr 2004;93:1514-1518.

86. Manstead ASR, Plevin CE, Smart JL. Predicting mothers' choice of infant feeding method. Br J Soc Psychol 1984;23:223-231.

87. Janke JR. Development of a breastfeeding attrition prediction tool. Nurs Res 1994;43:100-104.

88. Rempel LA. Factors influencing the breastfeeding decisions of long-term breastfeeders. J Hum Lact 2004;20:306-318.

89. Duckett L, Henley S, Avery M, et al. A theory of planned behaviour-based structural model for breastfeeding. Nur Res 1998;47:325-336. 
90. Blyth R, Creedy DK, Dennis CL, Moyle W, Pratt J, de Vries SH. Effect of maternal confidence on breastfeeding duration: an application of breastfeeding self-efficacy theory. Birth 2002;29:278-284.

91. Swanson V, Power KG. Initiation and continuation of breastfeeding: theory of planned behavior. J Adv Nurs 2005;50:272-282.

92. Chezem J, Friesen C, Boettcher J. Breastfeeding knowledge, breastfeeding confidence, and infant feeding plans: effect on actual feeding practices. J Obstet Gynecol Nenonatal Nurs 2003;32:40-47.

93. Avery M, Duckett L, Dodgson J, Savik K, Henly SJ. Factors associated with very early weaning among primiparas intending to breastfeed. Mat Child Health J 1998;2:167-179.

94. Kronborg H, Vaeth M. The influence of psychosocial factors on the duration of breastfeeding. Scand $J$ Public Health 2004;32:210-216.

95. Nagy E, Orvos H, Pal A, Kovacs L, Loveland K. Breastfeeding duration and previous breastfeeding experience. Acta Paediatr 2001;90:51-56.

96. Barber CM, Abernathy T, Steinmetz B, Charlebois J. Using a breastfeeding prevalence survey to identify a population for targeted programs. Can J Public Health 1997;88:242-245.

97. Ajzen I, Fishbein M. Understanding attitudes and predicting social behavior. Englewood Cliffs: Prentice Hall 1980.

98. Ajzen I. The theory of planned behavior. Organizational Behavior and Human Decision Processes 1991;50;179-211.

99. Bandura A. Social foundations of thought and action: a social cognitive theory. Englewood Cliffs: Prentice Hall 1986.

100. Triandis HC. Interpersonal behavior. Montery, CA: Brooks/Cole, 1977.

101. Brug J, Lechner L, de Vries H. Psychological determinants of fruit and vegetable consumption. Appetite 1995;25:285-296.

102. Lechner L, de Vries H, Offermans H. Participation in a breast cancer screening program: influence of past behavior and determinants on future screening participation. Prev Med 1997;26:473-482.

103. De Vries H, Backbier E, Kok G, et al. The impact of social influences in the context of attitude, selfefficacy, intentions and previous behavior as predictors of smoking onset. J Appl Soc Psychol 1995;25:237257.

104. Kools EJ, Thijs C, de Vries H. The behavioral determinants of breastfeeding in the Netherlands predictors for the initiation of breastfeeding. Health Educ Behav 2005;6:809-824.

105. De Vries H, Mesters I, van de Steeg H, Honing C. The general public's information needs and perceptions regarding hereditary cancer: an application of the Integrated Change Model. Patient Educ Couns 2005; 56:154-165.

106. Janz NK, Becker MH. The health belief model: a decade later. Health Educ Q 1984;11:1-47.

107. De Vries H, Mudde AN. Predicting stage transitions for smoking cessation applying the Attitude-Social influence-self-Efficacy model. Psychol Health 1998;13:369-385. 



\section{2}

\section{Factors influencing breastfeeding practices in asthmatic families: results from an explorative study}

Barbara Gijsbers, Ilse Mesters, André J. Knottnerus, Anita H. Legtenberg, Constant P. van Schayck

Published as: Factors influencing breastfeeding practices and postponement of solid food to prevent allergic disease in high-risk children: results from an explorative study 


\begin{abstract}
This paper presents results of seven focus group interviews conducted to gain insight into the feelings, opinions and perceived barriers of parents with a history of asthma who have recently delivered a child. The parents $(n=43)$ participated in an educational programme regarding breastfeeding and postponement of solid food to prevent their child from developing allergic symptoms. Breastfeeding exclusively for six months seemed an advice difficult to follow. The most important influencing factors regarding initiation and continuation of breastfeeding were health advantages for the baby, social support, modeling, knowledge about all the aspects of breastfeeding and breastfeeding confidence. In general, parents adhered to the advice to postpone solid food until the child had reached the age of six months. The few obstacles revealed were social pressure, hungry babies and eagerness of parents to give solid food.
\end{abstract}




\section{Introduction}

World-wide, the prevalence of asthma and allergies in children is high and seems to be increasing. ${ }^{1}$ To reduce (chronic) morbidity of asthma and allergy and concomitant expenses for supply of care, it is essential that effective methods to prevent clinical manifestations of allergic symptoms be put into practice by parents of children with a high risk of developing such symptoms. Breastfeeding exclusively ${ }^{* 2-4}$ and postponement of solid food $^{5-7}$ for six months are two promising measures to reduce the risk of developing asthma and allergies in children with a family history of asthma. The impact of both measures, though, is highly dependent on adherence of parents to these preventive behaviours. About $80 \%$ of Dutch mothers initiate breastfeeding. However, this number drops to $52 \%$ within a month and decreases to $35 \%$ when the child is three months old. Only $15 \%$ of the mothers succeed in breastfeeding their child exclusively for the recommended period to reduce the chance of allergies in 2002/2003. ${ }^{8}$ Regarding the introduction of solid food, a large number (90\%) of babies receive, solid food before the age of four months. ${ }^{2}$ Participants in this study followed an educational prevention programme (PREVention of ASthma in Children, PREVASC), ${ }^{9}$ which included advice to breastfeed exclusively for at least six months and postpone solid food until the child is six months of age. PREVASC data revealed that the compliance with the preventive advice mentioned was not optimal. Especially the advice of breastfeeding exclusively for six months was difficult to perform. This study addresses the question how to encourage parents to initiate and continue breastfeeding and postpone solid food for at least six months. The purpose is to elucidate relevant behavioural and psychosocial determinants of adherence regarding breastfeeding exclusively and postponement of solid food for at least six months among parents with a family history of asthma. To gain insight into the feelings, ideas and experienced barriers of this specific target group, seven focus group interviews were conducted. Eventually, the educational programme will be improved to increase the adherence to the preventive advice.

\footnotetext{
* Breastfeeding exclusively: the infant receives only breast milk from his/her mother, or expressed breast milk, and no other liquids or solids with the exception of drops or syrups consisting of vitamins, mineral supplements or medicines. $^{10}$
} 


\section{Method}

\section{Focus Group Interviews}

Focus group discussions were conducted in seven cities in the south of the Netherlands under the guidance of two moderators. This method was used for exploring parents' knowledge of and experiences with the preventive actions and for examining not only what they think, but also how they think and why they think that way. Focus groups are particularly effective in a group process as they stimulate participants to explore and clarify their attitudes, beliefs and behaviour by interacting with similar others. ${ }^{11}$ The role of the first moderator within the group was to facilitate the discussion in a non-directive and unbiased way, using predetermined questions to increase validity. ${ }^{12}$ The role of the second moderator was to take notes, to supervise the tape recording of the interview and to keep record that every item was discussed. Group sizes were limited to a maximum of six to ten persons. ${ }^{13}$ Prior to the focus group interviews, the researchers devised a list of questions and relevant probes related to the advised preventive measures, which were piloted by a social scientist, general practitioner and a focus group discussion expert.

\section{Participants}

Parents were randomly selected from a Dutch birth cohort study called PREVASC. ${ }^{9}$ The eligibility criteria were that one or either both of the parents or one of the children had doctor-diagnosed asthma. 89 households received an invitation letter and a total of 43 households (59 participants) were scheduled to meet at times and locations thought to be convenient for the participants. There were six mixed groups and one group that contained only fathers, since fathers may have different opinions and thoughts about breastfeeding and postponement of solid food, which might be missed in the presence of women.

\section{Data analysis}

The group discussions were tape-recorded and transcribed. Two researchers independently analysed the content of the verbatim transcripts of each focus group. ${ }^{12-13}$ The content was analysed line-by-line to look for trends and patterns that reappeared within either a single or multiple focus groups. Content analysis was supported by the qualitative computer programme QSR NUD*IST®4.0 (N4). ${ }^{14}$ 


\section{Ethical issues}

The Ethical Review Board of the Academic Hospital and University of Maastricht approved the study protocol and all participants provided written informed consent. Prior to the interviews, participants were told that the discussion would be recorded and the procedures used to maintain confidentiality were explained.

\section{Results}

\section{Characteristics of participants}

43 households (59 persons) participated in this study. The reasons for the 39 nonrespondent households were: interested, but date not convenient $(n=14)$, no time $(n=7)$, location of interview not convenient $(n=3)$, on holiday $(n=2)$, unknown $(n=13)$. To assess possible bias chi-square tests were conducted, revealing no significant difference between the participation and no-participation group with respect to the variables level of education, feeding behaviour and asthma in family. The education level of the 59 participants was rather high. More than half of the fathers (52\%) and $44 \%$ of the mothers had a high level of education (at least finished higher vocational education). Almost $42 \%$ of the women and $39 \%$ of the men have been diagnosed with asthma. Only $4(10 \%)$ mothers had breastfed their child exclusively for at least six months. Approximately $72 \%$ adhered to the advice of postponement of solid food for six months (see Table 2.1).

Table 2.1. Characteristics of participants

\begin{tabular}{llll}
\hline & Mothers $(\mathrm{n}=36)$ & Fathers $(\mathrm{n}=23)$ & Households $(\mathrm{n}=43)$ \\
\hline Education level $^{\mathrm{a}}$ & & & \\
Low $^{\mathrm{a}}$ & $4(11.1)$ & $4(17.4)$ & \\
Middle $^{\mathrm{b}}$ & $16(44.4)$ & $7(30.4)$ & \\
High $^{\mathrm{c}}$ & $16(44.4)$ & $12(52.2)$ & $4(10.3)$ \\
Asthma & $15(41.7)$ & $9(39.1)$ & $31(72.2)$ \\
Breastfeeding for & & & \\
six months & & & \\
Postponement solid & & & \\
food for six months & & & \\
\hline
\end{tabular}

${ }^{\mathrm{a}}$ Low education level: completed primary school and vocational school.

${ }^{\mathrm{b}}$ Middle educational level: completed secondary (vocational) school.

${ }^{c}$ High education level: completed the highest level of secondary (vocational) school or university. 


\section{Focus group results}

During the interviews, the necessity to divide the subject of breastfeeding into two different behavioral stages became clear. Therefore, the initiation of breastfeeding is described separately from issues about the maintenance of breastfeeding. Furthermore, findings concerning expressing milk and postponement of solid food are presented together.

\section{Initiation of breastfeeding}

\section{Intrapersonal factors}

Regarding initiation of breastfeeding, several intrapersonal factors were identified. The majority of parents were familiar with the hypothesis that breastfeeding could prevent allergic symptoms. The awareness of an increased risk of asthma appeared to be a strong motivator to start breastfeeding. Moreover, the idea that breastfeeding supplies the baby with antibodies appeared to be a reason for initiation. However, one mother was not convinced that breastfeeding could prevent allergic symptoms so she decided to give her child formula instead of breast milk.

The practicability of breastfeeding was mentioned a few times, as one mother declared: "No fuss with bottles and pacifiers you must boil. Especially the feeding at night is ideal. You just pick up your child. No need to go downstairs and make a bottle". Nevertheless, some dual income families mentioned the loss of freedom. They assumed that breastfeeding would cause a lot of unnecessary fuss and would be incompatible with their busy life style. Having to be at home all the time and scheduling their lives in accordance with feeding times did not appeal to them. Socio-emotional aspects seemed essential for the decision to start breastfeeding. Some mothers even felt morally obliged to breastfeed their child: "I already assumed that breastfeeding for longer periods would be helpful in case of asthma vulnerability in the family". Many women stressed the expected impact that breastfeeding has on the bond between mother and child. A mother stated: "I think that giving your child breast milk is so special and beautiful; that is beyond dispute”. However, a few mothers just did not like the idea of breastfeeding their child. They were not comfortable (referring to the sexual function of their breast) or simply disliked the idea of breastfeeding. As one mother stated: "I am not a cow !" It appeared that mothers who already had positive breastfeeding experiences made the decision to breastfeed again more easily: "I know from experience that it is wonderful to breastfeed your child. The bond between mother and child is very special. So, I think it is normal to give your child breast milk". On the other hand, a prior negative breastfeeding experience (crying baby, sore nipple, etc) made some mothers decide not to try breastfeeding again with their second child. 
Interpersonal factors

During the interviews, two different types of social influence were referred to: modeling and social support. Female best friends who had successfully breastfed their children stimulated mothers to start breastfeeding: "I thought if she can breastfeed her child for over seven months, so can I". Furthermore, a lot of mothers mentioned that their partners also played a crucial role in their decision to initiate breastfeeding. Nevertheless, some mothers were confronted with conflicting feelings of their partners, as fathers expressed that they looked forward to giving their child the bottle and that breastfeeding made feel them left out: "My wife was convinced that she would start breastfeeding, no discussion possible. She decided, and I thought, okay, fine, but I felt left out a bit". In general, most women experienced the decision to breastfeed as their own choice, but considered their partners' opinion to be important as well.

\section{Maintenance of breastfeeding}

\section{Intrapersonal factors}

During the interviews, mothers emphasized their intention to breastfeed for at least six months in order to prevent the development of allergic symptoms in their children. However, even with the motivation to breastfeed being present, most mothers stopped before the recommended sixth month, for different reasons. The misconception regarding antibodies that it is only necessary to breastfeed your child in the first few weeks was one reason. Another important issue was that many mothers had not prepared themselves properly. Their expectation was that breastfeeding happens automatically because it is natural; many mothers assumed that their baby would know how to drink. When common problems (e.g. sore nipples, thrush or a yeast infection) arose, some mothers became uncertain and appeared unprepared and unable to solve these problems: "Actually, I was not properly prepared for breastfeeding my baby. I think this was the main reason why it went wrong. I thought, well, I just give it a try. I found it awful and it hurt tremendously. One night, I decided to stop breastfeeding, even though I thought myself to be a bad mother, because that was the way it felt". Another problem was that several children showed symptoms of cow milk allergy despite the fact they were being breastfed. Some professionals (general practitioners or other health workers) recommended the mother(s) a diet that excluded dairy-products. The PREVASC education did not mention this recommendation; therefore, several mothers switched to formula. Afterwards, a lot of mothers were very disappointed that they had stopped breastfeeding due to this lack of knowledge: "Unfortunately, I have not heared of the possibility to try a diet without dairyproducts earlier. I would have liked to try it". 
Some mothers mentioned that they felt uncertain about the amount of milk their child was getting. They found it reassuring that when giving the bottle they could see how much the child had drunk. Most of these insecure parents were not aware that the child can be weighed before and after breastfeeding in order to monitor the amount of milk the child has drunk: "I felt very unsure whether I was able to produce an adequate supply of nutritious breast milk and my child did not gain enough weight".

A few mothers did not feel comfortable breastfeeding their child, especially when they had to feed in public or in company of family and friends. They felt "uncivilized" and/or found the sucking of their child unpleasant: "Being a bit prudish, I became very tense every time I latched on my child. Especially when there were visitors in the house, it was very hard to breastfeed in front of them and I did not want to go upstairs while they were still there". Other mothers with very sensitive breasts and nipples already felt pain just thinking about breastfeeding. "When the maternity assistant latched my baby on I found the feeling so horrible that I could not stand it any longer. I knew this was nothing for me; even my stomach hurt when I thought about giving her the breast. So I thought, why am I tormenting myself, I stop”.

\section{Interpersonal factors}

The support that women received from the newborn's father and from close friends was often crucial for the decision to continue breastfeeding. As one father mentioned: "I must say that I don't know whether my wife continued to breastfeed if I had not stimulated her to go on. I am proud that she kept on right to the end".

There were some fathers who felt somewhat left out, because they were not able to feed their child. On the other hand, several fathers were very proud of their wives and took it for granted that they could not give a bottle and found it more important that their child received the best possible nutrition.

Many parents were told by family or friends that breastfed babies' crying must be caused by hunger, whereas bottle-fed babies' crying could be the result of different factors: "People started to say: 'Why don't you stop breastfeeding? Your child does not drink enough and needs more nutrition'. This made me very uncertain, also because my child did not gain weight for some weeks. I was disappointed that people who I had expected to be supportive only made me feel more insecure".

It appeared that many parents had to explain frequently to people why they intended to breastfeed their child for at least six months. Sometimes social pressure was enormous and some mothers even started having doubts about the given recommendations to prevent asthma complaints: "Mainly, when things don't go smoothly, family and friends make comments, such as: 'Why all the effort trying to give the breast? Just give your child the bottle. It is far more convenient and you don't have to stay at home all the time”. Although 
breastfeeding is generally accepted in the Dutch society, it is not considered normal to breastfeed after the age of four or five months. As one father pointed out: "Nowadays, it is not entirely common practice to breastfeed your child for six months. As a woman you must almost defend yourself against people if you intend to breastfeed for six months". The maternity assistant turned out to have a great influence on the new mother. "During the first couple of days after the delivery, your maternity assistant is essential in providing information and coaching. This will make or break the success of breastfeeding. If the first few days go well, then you pass the critical period and the chance is high that you continue to give your child the breast. But if something goes wrong that first week, you become unsure and the result is that everything makes you insecure and you are more likely to switch to a bottle, even if you were very motivated to breastfeed your child". Some mothers who delivered their child in hospital and had to stay for a few days were not positive about the nurses' support concerning breastfeeding. Some hospital nurses did not make any effort to help mothers to breastfeed; other nurses, however, supported and helped the mother immediately after the child was born. As one mother stated: "The nurse assumed that I did not need any help because I gave birth to my second child. She did not check if I latched my child properly to my breast, and I felt very alone and insecure those first few days". Fortunately, not all mothers with initial problems quit immediately. Some mothers asked someone from the breastfeeding organisation (La Leche League) for assistance because they experienced some problems to latch on their child in the right way.

\section{Expressing milk and postponement of solid food}

Only some mothers tried to express milk, and the experiences were diverse. A few mothers found expressing milk easy to do and experienced it as a form of freedom: The partner could give the expressed milk to their child when the mother was not there to feed the child: "It was very easy to do. You can adjust the machine as you like. It did not hurt at all, and sometimes I even felt asleep".

The greater part of the mothers found expressing milk an unpleasant experience, emotionally and physically. "I felt like a cow every time I went on the machine; I was fed up with it". Many mothers did not even try to express milk and switched to formula the moment they returned to work or when they had an obligation outside the house. Another mother told: "Expressing milk appeared to be a painful experience for me. The main reason for me to quit was the pain, but I disliked the whole idea of expressing milk as well".

Many parents had consciously made the decision to postpone solid food, and some parents experienced postponement of solid food as an advantage. Their children could not make a mess and the grandparents could not give their children sweets until they reached the age of six months. Parents found it often necessary to explain to family and friends why they 
waited with solid food until their child was at least six months of age. The other people often found this hard to understand, especially when the baby was crying: "Are you sure you have enough milk to breastfeed your child for so long " or "I think there is not enough milk in those breasts of yours" and "Your child needs some real food". Most parents did not receive much support, even after they explained that they wanted to prevent their child from developing an allergy. A few parents found it hard themselves not to give some fruit or vegetables during the first six months, because they thought that their child was still hungry. "I breastfed my first child for eight months and my second child for even ten months. Although I had made a positive experience concerning breastfeeding, I had not waited for six months with giving some solid food. This time I am planning to wait until Peter is six months old". Some parents found that their baby needed solid food before the age of six months. "My child was hungry; he needed something else besides breastfeeding". Or, as another parent declared: "The whole time she stared at the food I ate, so I assumed my child wanted something else". Some parents found it very hard to wait with giving their child solid food because they were looking forward to giving the first bite of food.

\section{Discussion and conclusion}

Much research has identified factors that influence breastfeeding initiation and duration. ${ }^{15}$ Non-modifiable high-risk factors are demographic variables, such as ethnic background, maternal age, education, socioeconomic status, and biomedical variables, such as parity, infant health and maternal health. ${ }^{16}$ However, the more complex psychosocial variables regarding maternal infant feeding methods may be of greater interest than demographic and biomedical characteristics as the psychosocial factors are often modifiable. ${ }^{17}$ Therefore, this study focused on intra- and interpersonal factors influencing breastfeeding initiation and maintenance.

\section{Intrapersonal factors}

Regarding our study, the most salient reason to start breastfeeding was that it is better for the baby. Because our participants were aware that they were genetically predisposed, they perceived their child to be highly susceptible to allergic symptoms and subsequently were motivated to initiate breastfeeding. Other studies confirmed that parents' understanding and beliefs in relation to breastfeeding and health of the baby play a crucial role in the decision to breastfeed. ${ }^{18-19}$ Therefore, it is important to emphasize the preventive health behaviors that can be performed by parents to reduce the risk that their child becomes ill. If parents feel they are capable of diminishing the chance that their child becomes ill, they are more motivated to perform the protective behavior. ${ }^{20}$ 
In our study, breastfeeding knowledge appeared to be an important factor in breastfeeding maintenance. Knowledge includes skills required to breastfeed, e.g. the practical skills regarding positioning, supply and demand, onset of lactation etc. Our participants seemed to have insufficient knowledge and skills to continue to breastfeed for six months. Lawson and Tulloch ${ }^{21}$ found a lack of lactation knowledge to be very common among pregnant women. Other studies describe similar results, namely that women's inadequate knowledge of the mechanisms of breastfeeding may lead to less successful feeding attempts. ${ }^{22-23}$ These findings suggest that breastfeeding education can be a powerful tool to promote sustained breastfeeding. According to the stories that were told during the interviews it appeared that different skills are needed at different moments. During pregnancy, mothers need different information from when the baby is newborn or a few months old. Different skills are needed at different times, and parents must be prepared for specific problems that can occur at certain moments. As a consequence, a lack of knowledge and skills often leads to a lack of confidence. According to different studies, it appeared that maternal confidence is a significant predictor of breastfeeding duration. ${ }^{24-26}$ Breastfeeding confidence is a woman's belief or expectation that she possesses the knowledge and skills to successfully breastfeed her infant. ${ }^{27} \mathrm{~A}$ lack of confidence is often expressed as doubts about the ability to produce an adequate supply of nutritious breast milk as well as doubts about being able to acquire the necessary skills to breastfeed successfully. ${ }^{28}$ A major reason why mothers give up breastfeeding early is their concern that their baby does not gain enough weight. ${ }^{29}$ Low levels of maternal confidence often are the basis of this concern. ${ }^{20}$ During the interviews, it became clear that lack of self-confidence, especially in the mothers, resulted in giving formula instead of breastfeeding because mothers were reassured when they saw how much the child had drunk. The failure of women to initiate or to persist in breastfeeding has been attributed to lack of self-confidence due to lack of knowledge. ${ }^{20}$ Finally, the intrapersonal factor bonding and especially the desire to form an exclusive, lasting relationship with the child is mentioned in several studies. According to the literature, the importance of bonding between mother and child cannot be overemphasized in educational material. ${ }^{30}$

\section{Interpersonal factors}

Our results indicate that fathers, according to the female study population, influence the initiation and maintenance of breastfeeding by acting as key supports or deterrents. Support from the partner, family and friends, known as emotional support, has been shown to be an important factor that influences the choice and duration of breastfeeding. ${ }^{31-32}$ Ideally, fathers should have knowledge about breastfeeding in order to help mothers make decisions about how to feed their babies and provide better support for breastfeeding mothers. Giugliaini et al confirmed that improving fathers' knowledge helped to promote breastfeeding by their partners. ${ }^{32}$ It is also essential for the parents to receive formal 
support from health professionals, such as physical assistance, sharing knowledge of the benefits of breastfeeding, and learning the skills. Especially the support from maternity assistants is crucial for both parents when it comes to initiating and continuing breastfeeding. The assistant, who helps the mothers during the first days after delivery, must have full knowledge of breastfeeding and must be willing to help the mothers to learn the skills of breastfeeding. The modeling principle, in other words, having friends who master the skills and knowledge required to breastfeeding, seems to be an important factor for the new mother. ${ }^{33-34}$ Therefore, it is also important to expose young mothers to other mothers while they are breastfeeding. It is important that women can identify with the role models, so it seems to be relevant that in education material different characteristics are presented to enlarge the chance that a woman can identify with one of the models.

\section{Expressing milk and postponement of solid food}

Less research has been done towards expressing milk and the difficulties that mothers can experience while expressing milk, for example, no suitable location at work, etc. It turned out that only a few mothers used the option of expressing milk. But if a mother wants to breastfeed her child for at least six months it is usually required to express milk, especially if the mother returns to work. Therefore, it is essential that more detailed information about expressing milk and specific information about breast pumps be provided in the educational material. Furthermore, mothers who worry that their child will develop allergies often abstain from early introduction of solid food if they know about the protective effects of breastfeeding exclusively. ${ }^{34}$ The focus interviews confirmed that parents were aware of the benefits of postponing solid food until their children had reached the age of six months, and only sometimes was this advice neglected. Babies' hunger was mentioned as a major reason for parents to give their children fruit or vegetables before the age of six months.

\section{Limitations of study}

A limitation of this study is the restricted external validity due to the specific target group, namely families with a history of asthma who participated in an educational programme. Furthermore, adding a group containing only mothers could have been informative regarding possible sexe-influences during the mixed group interviews. 


\section{Implications for practice}

In conclusion, breastfeeding exclusively for six months does not seem to be easy to do. A woman and her partner must learn how to correctly breastfeed their child and need a proper preparation period during pregnancy. As various risk situations turn up in different phases, it is important to divide the educational material in phases accordingly. The first phase, the preparatory stage, starts at the beginning of the pregnancy. In this phase, future parents must read about and visualize the different aspects of breastfeeding including expressing milk. They must become "experts" in the field of breastfeeding in order to solve problems that may arise during the first six months after birth. It is also important that they become more self-confident to stand up to the "wise advice" from family and friends. Parents must obtain the fighting spirit to maintain breastfeeding for six months. Moreover, the educational programme must also pay attention to the role the future father plays. It seems that fathers play a crucial role in successful breastfeeding. Furthermore, health professionals, such as maternity assistants, must be up-to-date regarding breastfeeding and expressing milk. It is especially important that they give unambiguous advice about breastfeeding. The next phase starts after delivery. Certain problems, such as wrong latching and sore nipples, may occur, and the mother must prepare herself for this. If people have already been mentally confronted with possible risk situations, they are better prepared when those situations actually arise. ${ }^{35}$ The last phase includes information about combining breastfeeding and returning to work. For example, the mother should ask her work boss to arrange a room for her to express milk. Lack of information on the availability of breast pumps and expressing milk was often the reason why the mothers quit prematurely. Presenting realistic outcome-expectations is also of great importance for avoiding disappointment and, therefore, the risk of prematurely stopping breastfeeding. Finally, the educational material should not make mothers feel guilty if they are not capable of breastfeeding exclusively for six months. It is important to recommend alternative options, for example hypoallergenic formula.

\section{Acknowledgements}

We would like to thank the NAF, the focus group participants, drs. A.J.E. Manders and dr. L. McCormick. 


\section{References}

1. Jarvis D, Burney P. ABC of allergies. The epidemiology of allergic disease. BMJ 1998;316:607-610.

2. Wilson AC, Forsyth JS, Greene SA, Irvine L, Hau C, Howie PW. Relation of infant diet to childhood health: seven year follow up of cohort of children in Dundee infant feeding study. BMJ 1998;316:21-25.

3. Saarinen UM, Kajosaari M. Breastfeeding as prophylaxis against atopic disease: prospective follow-up study until 17 years old. Lancet 1995;346:1065-1069.

4. Gdalevich M, Mimouni D, Mimouni M. Breast-feeding and the risk of bronchial asthma in childhood: A systematic review with meta-analysis of prospective studies. J Pediatr 2001;139:261-266.

5. Kajosaari M, Saarinen UM. Prophylaxis of atopic disease by six months' total solid food elimination. Evaluation of 135 exclusively breast-fed infants of atopic families. Acta Paediatr Scand 1983;72:411-414.

6. Oldaeus G, Anjou K, Bjorksten B, Moran JR, Kjellman NIM. Extensively and partially hydrolysed infant formulas for allergy prophylaxis. Arch Dis Child 1997;77:4-10.

7. Lucas A, Brooke OG, Morley R, Cole TJ, Bamford MF. Early diet of preterm infants and development of allergic or atopic disease: randomised prospective study. BMJ 1990;300:837-840.

8. Lanting CI, van Wouwe JP, Reijneveld SA. Infant milk feeding practices in the Netherlands and associated factors. Acta Pead 2005;94:935-942.

9. Schönberger HJAM, van Schayck CP. Prevention of asthma in genetically predisposed children in primary care - from clinical efficacy to a feasible intervention programme. Clin Exp Allergy 1998;1325-1331.

10. WHO/UNICEF. The Innocenti declaration on the protection, promotion and support of breastfeeding. In Breastfeeding in the 1990's: A global initiative meeting in Florence, Italy and New York. Geneva, Switserland. 1990 WHO/UNICEF: Geneva.

11. Kitzinger J. Qualitative research. Introducing focus groups. BMJ 1995;311:299-302.

12. Van Assema P, Mesters I, Kok G. Het focusgroep-interview: een stappenplan [The focus groupinterview: stepwise guidelines]. T Soc Gezondheidsz, 1992;70:431-437.

13. Krueger RA. Analyzing \& Reporting Focus Group Results. Focus Group Kit. Vol. 6. London: Sage, 1998.

14. Strauss A, Corbin J. Grounded Theory In Practice. London: Sage, 1997.Dennis CL. Breastfeeding initiation and duration: a 1990-2000 literature review. J Obstet Gynecol Neonatal Nurs 2002;31:12-32.

15. Janke JR. The incidence, benefits and variables associated with breastfeeding: implications for practice. Nurse Pract 1993;18:22-32.

16. Losch M, Dungy CI, Russel D, Dusdieker LB. Impact of attitudes on maternal decisions regarding infant feeding. J Pediatr 1995;126:507-514.

17. Libbus MK, Kolostov LS. Perceptions of breastfeeding and infant feeding choice in a group of low-income mid-Missouri women. J Hum Lact 1994;10:17-23.

18. Jaeger MC, Lawson M, Filteau S. The impact of prematurity and neonatal illness on the decision to breastfeed. J Adv Nurs 1997;25:729-737.

19. Rogers, RW. Cognitive and physiological processes in fear appeals and attitude change: A revised theory of protection motivation. In Cacioppo J, Petty R (eds) Social Psychophysiology. 1983, New York: Guilford. 153-176.

20. Chapman DJ, Perez Escamilla R. Does delayed perception of the onset of lactation shorten breastfeeding duration? J Hum Lact 1999;15:107-111.

21. Lawson K, Tulloch MI. Breastfeeding duration: prenatal intentions and postnatal practices. $J$ Adv Nurs 1995;22:841-849.

22. Susin LR, Giugliani ER, Kummer SC, Maciel M, Simon C, da Silveira LC. Does parental breastfeeding knowledge increase breastfeeding rates? Birth 1999;26:149-156.

23. Kruger R, Gericke GJ. A qualitative exploration of rural feeding and weaning practices, knowledge and attitudes on nutrition. Public Health Nutr 2003;6;217-223. 
24. Blyth R, Creedy DK, Dennis CL, Moyle W, Pratt J, de Vries SH. Effect of maternal confidence on breastfeeding duration: an application of breastfeeding self-efficacy theory. Birth 2002;29:278-284.

25. O'Campo P, Faden R, Gielen A, Wang M. Prenatal factors associated with breastfeeding duration: Recommendations for prenatal interventions. Birth 1992;19;195-201.

26. Creedy DK, Dennis C-L, Blyth R, Moyle W, Pratt J, de Vries SH. Psychometric characteristics of the breastfeeding self-efficacy scale: data form an Australian sample. Res Nurs Health 2003;26;143-152.

27. Chezem, J, Friesen C, Boettcher J. Breastfeeding knowledge, breastfeeding confidence, and infant feeding plans: effects on actual feeding practices. J Obstet Gynecol Neonatal Nurs 2003;32:40-47.

28. Bryant CA, Coreil J, D'Angelo SL, Bailey DF, Lazarov M. A strategy for promoting breastfeeding among economically disadvantaged women and adolescents. NAACOGS Clin Issu Perinat Womens Health Nurs 1992;3:723-730.

29. Zetterstrom R. Breastfeeding and infant-mother interaction. Acta Paediatr Suppl 1999;88:1-6.

30. Graffy JP. Mothers' attitudes to and experience of breast feeding: a primary care study. Brit J Gen Pract 1992;42:61-64.

31. Freed GL, Kennard Fraley J, Schanler RJ. Attitudes of expectant fathers regarding breast-feeding. J Pediatr 1992;90:224-227.

32. Giugliani ER, Bronner Y, Caiaffa WT, Vogelhut J, Witter FR, Perman JA. Are fathers prepared to encourage their partners to breast feed? A study about fathers' knowledge of breast feeding. Acta Paediatr 1994;83:1127-1131.

33. Maehr JC, Lizarraga JL, Wingard DL, Felice ME. A comparative study of adolescent and adult mothers who intend to breastfeed. J Adolesc Health 1993;14:453-457.

34. Wiemann CM, DuBois JC, Berenson AB. Strategies to promote breast-feeding among adolescent mothers. Arch Pediatr Adolesc Med 1998;152:862-869.

35. Bandura A. Social foundations of thought and action: a social cognitive theory. Englewood Cliffs, N.J.: Prentice-Hall, 1986. 



\section{3}

\section{The success of an educational programme to promote exclusive breastfeeding for six months in families with a history of asthma -a randomised controlled trial-}

Barbara Gijsbers, Ilse Mesters, J. André Knottnerus, Arnold D.M. Kester, Constant P. van Schayck 


\begin{abstract}
The objective was to investigate the effect of a theory-based educational programme in promoting exclusive breastfeeding for at least six months in asthmatic families. Eighty-nine families, in which the woman was less than 7 months pregnant and at least one first-degree relative (mother, biological father, or sibling) had asthma that had been diagnosed by a doctor, were recruited by means of posters in the practices of midwives and participated in a randomised controlled trial. When the families in the intervention group were visited (twice before the births of their babies and once after) they received written and oral advice about all aspects of breastfeeding and storing and expressing milk. The proportion of women breastfeeding exclusively at 6 months was significantly higher in the intervention group than among the control group (21/44 [48\%] versus 12/45 [27\%]; odds ratio 2.91; 95\% Confidence Interval [1.10-7.71] ( $p=0.03)$, controlled for maternal age, education level and breastfeeding experience. This study provides evidence that the new programme (written and oral advice about breastfeeding) is effective in improving the exclusive breastfeeding rates at six months in asthmatic families. A next step would be to make this programme available for health professionals who support pregnant women who have a familial history of asthma.
\end{abstract}




\section{Introduction}

Considerable research over the past few years has suggested that breastfeeding provides the best possible nutrition a child can be given during the first six months of its life, partly because of the protective effect against a variety of infections during infancy and early childhood. ${ }^{1-3}$ Because the etiology of asthma is multifactorial, with immunologic profile genetic predisposition, and allergic sensitization playing major roles, ${ }^{4}$ it is biologically plausible that breastfeeding exclusively may offer some protection against the occurrence of asthma by decreasing allergic sensitization and/or modulating the infant's immune system. ${ }^{5}$ Moreover, several review and birth cohort studies have shown that exclusive breastfeeding during the first 6 months after birth is associated with lower asthma rates during childhood, particularly if a family history of allergic disease is present. ${ }^{6-9}$ Nevertheless, some controversy about the protective effect of breastfeeding against asthma remains, since a few studies found no association or even suggest that breastfeeding is associated with an increased risk for childhood asthma in the presence of maternal asthma. ${ }^{10-11}$ Despite the recommendation of the World Health Organisation (WHO) to breastfeed exclusively for up to six months, ${ }^{12-13}$ a recent study found that, although $80 \%$ of Dutch mothers did start exclusive breastfeeding, only $25 \%$ continued this for the full six months. ${ }^{14}$

Several studies have been conducted to determine whether programmes to help support breastfeeding can promote the initiation and duration of breastfeeding. ${ }^{15-17}$ The PREVASC study (PREVention of ASthma in Children) strongly advised to give only breast milk for up to six months in their study to investigate whether a simultaneous reduction of important exposures before and after birth might prevent allergy and asthma in predisposed children. ${ }^{18-19}$ According to this study, which focused on families with a history of asthma, only $10 \%$ of the women in the experimental group, did continue to breastfeed exclusively for six months. ${ }^{20}$

A recent study by Kools et al. ${ }^{21}$ has shown that their care provider breastfeeding support protocol, which includes a combination of health counseling, early spotting of breastfeeding problems, lactation consultancy and a prenatal distributed booklet for women, appears not to be effective either. In contrast to these findings, Sikorsky et al. ${ }^{22}$ concluded that there is evidence for the effectiveness of extra support, either professional or from peers, in improving the prevalence of exclusive breastfeeding.

Above findings show there appears to be considerable room for improvement regarding the reduction of exposure to food allergens during the first six months after birth.

The aim of the present study was to explore whether a newly developed educational programme, based on a social psychological model and the experiences of the target group, could have a positive effect on the duration of exclusive breastfeeding in families who have a history of asthma. 


\section{Material and Methods}

One hundred thirteen families were recruited in the south-eastern part of the Netherlands between March 2002 and March 2003 using posters in the practices of participating midwives and by advertisements in local papers. Families were eligible when (1) the mothers were less than 7 months pregnant and (2) at least one first-degree relative (mother, biological father, or sibling) had asthma that had been diagnosed by a doctor. A family was excluded in case of intra-uterine or neonatal death, serious birth defects (illness or malformation), breast surgery of mother, major language problems, or if it moved outside the Netherlands. The study was approved by the medical ethics committee of Maastricht University Medical Center. Written informed consent was obtained from all participants.

\section{Randomisation and statistical power}

Cluster randomisation at family practice level was carried out since the intervention could not be performed blindly and to avoid communication between the two study groups. A family practice was assigned to the control or intervention group using a randomisation list prepared by the statistical adviser when the first potential participant of a particular practice received information about the study. It was not possible to randomise after consent of the participant since the study information differed for both groups. Once the family practice had been allocated randomly as either a control or intervention practice, every family recruited afterwards that also attended that particular practice was automatically assigned to the same group. This cluster-randomised design resulted in 89 participating families who attended 84 different practices. The analyses were based at individual level rather than at cluster level since this is an almost one-to-one match.

Statistical significance was defined at the two sided $p=0.05$ level. The final data set generated $84 \%$ power to detect an expected absolute increase of exclusive breastfeeding at 6 months from $10 \%$ (results of the experimental group of the PREVASC study) ${ }^{18}$ to $35 \%$.

\section{Intervention}

The renewed educational programme was based on the principles of the Attitude-Social influence-self-Efficacy-model (ASE model) ${ }^{23}$ and on the results of previously held focus group interviews among participants of the PREVASC study. ${ }^{24}$

The barriers and problems that the mothers experienced concerning breastfeeding behaviour were discussed during the focus group interviews. Important topics arising from the focus groups were integrated in a booklet. The booklet was divided into three parts pregnancy, the period just after birth and the months after birth - in which practical information regarding breastfeeding and expressing milk alternated with the personal 
experiences of three mothers and one father, that were used as models. The models differed in age, ethnic group and socioeconomic status, in order to increase the chance that families could identify with a model.

A trained research assistant visited the families twice before the birth of the baby and once after. During the home visits the assistant motivated the women to breastfeed for six months and to postpone solids for six months, and questions about breastfeeding were answered. All aspects of breastfeeding, illustrated in the booklet were reviewed. We consider the supportive role of the assistant is important in making the women more confident of success. The families in the control group received the usual care according to the guidelines of the Dutch College of General Practitioners ${ }^{25}$ in which breastfeeding is recommended for all babies in the Netherlands (see Figure 3.1 for more detailed information about the contents of the booklet).

\section{Content of intervention \\ Home visits}

The trained assistants visited the participants of the intervention group twice during pregnancy and once postnatal to provide basic information about all aspects of breastfeeding and expressing milk. The main goal was to prepare the women for future problems that might occur during breastfeeding for at least six months. During the first visit the women received a booklet about breastfeeding. The contents of the booklet reinforced the information given orally.

Main points discussed in the booklet:

- Why "breast is best" for the mother and the infant

- $\quad$ Specific health benefits for families predisposed to asthma

- Breastfeeding and the use of asthma medication

- The special role of the father as a coach for the mother

- What to do when no breastfeeding support is available in hospital

- How breastfeeding works: good breastfeeding positioning, infant latching, frequency of feeding

- Breastfeeding myths

- How to check if the child receives enough breast milk. How to check urine output and weight gain before and after feeding to see whether the child receives enough breast milk

- How to manage sore and inverted nipples, breast engorgement and mastitis

- Cow milk allergy and diet of the mother

- What to expect from health professionals regarding advice on breastfeeding

- How to express milk because of return to work and how to store it

- Phone numbers of lactation organisations/consultants and useful web sites

\section{Usual care}

The guidelines of the Dutch College of General Practitioners recommend breastfeeding for six months for all babies in the Netherlands

Figure 3.1 Details of the educational breastfeeding programme including home visits, booklet, and usual care 


\section{Outcome measures}

The main outcome was the prevalence of exclusive breastfeeding at six months. Exclusive breastfeeding was defined according to the guidelines of the WHO as a situation in which no other types of milk or solids were given except vitamins and minerals. ${ }^{12-13}$ The parents registered their child's feeding history on a diary card during the first six months postpartum.

The self-report diary method to measure the exposure to breast milk has been used in earlier studies. ${ }^{20,27}$ The duration of breastfeeding was counted in weeks for the analysis. A breastfeeding questionnaire also had to be filled in twice during pregnancy (between 3 and 6 months of the pregnancy and around the eighth month of pregnancy) and twice after the child was born (3 and 6 months post-partum). The breastfeeding questionnaire, based on the Attitude-Social influences-self-Efficacy model, ${ }^{23}$ was designed to assess the intention of the pregnant mothers to breastfeed for six months, their attitudes towards breastfeeding, social influences (expected social norm, support and pressure), self-efficacy, and several external variables. The post-partum version of the breastfeeding questionnaire, which was given around three months and six months post-partum, also included questions on the actual breastfeeding behaviour, the introduction of solids and possible problems experienced. Only the external variables, such as the demographic and biomedical information, from the questionnaires were used in this study. Both the intervention and control groups received the same questionnaires.

\section{Statistical analysis}

The proportion of mothers who exclusively breastfed their child at six months was analysed using multiple logistic regression with correction for maternal age, education level, and breastfeeding experience. Exclusive breastfeeding duration was analysed for all women participating using Kaplan-Meier survival functions. The duration for those mothers who continued breastfeeding exclusively when their child was 26 weeks old was censored in the survival analysis at 26 weeks post-partum. The duration of the non-starting mothers was set at 0.1 weeks. Separate curves were estimated for the experimental and control groups. The Cox regression model was used to assess the association between group allocation and exclusive breastfeeding duration, correcting for maternal age, education level, and breastfeeding experience. The proportional hazards assumption of the Cox regression model was tested using interactions with a time variable $(\mathrm{t}>13$ weeks). None of these interactions was statistically significant, confirming the validity of the model. It was not possible to use a mixed model where a random intercept per practice is assumed because of the almost one-to-one match between patients and general practices. The variance of such a 
random intercept cannot be separated from the per-subject error variance. Statistical significance was assumed for p-values $<0.05$. SPSS (version 11.0) was used for analysis.

\section{Results}

\section{Characteristics}

A total of 113 families was assigned randomly to receive study information (intervention: $n=58$; control: $n=55$ ) as shown in Figure 3.2. Of these, 24 families were excluded before the first house visit took place. Exclusions were families with no family history of asthma according to their general practitioner $(n=2)$, women who had had breast surgery and were unable to breastfeed $(n=3)$, women who had suffered miscarriages in the first or second trimester of pregnancy $(n=2)$ and participants who did not give their consent for a variety of reasons $(n=17)$.

Maternal age in both groups was around 31 years, and the educational level was rather high in both groups (around 54\% could be regarded as having a high level of education). Only a few mothers smoked during pregnancy and most women delivered their baby in hospital (see Table 3.1). 


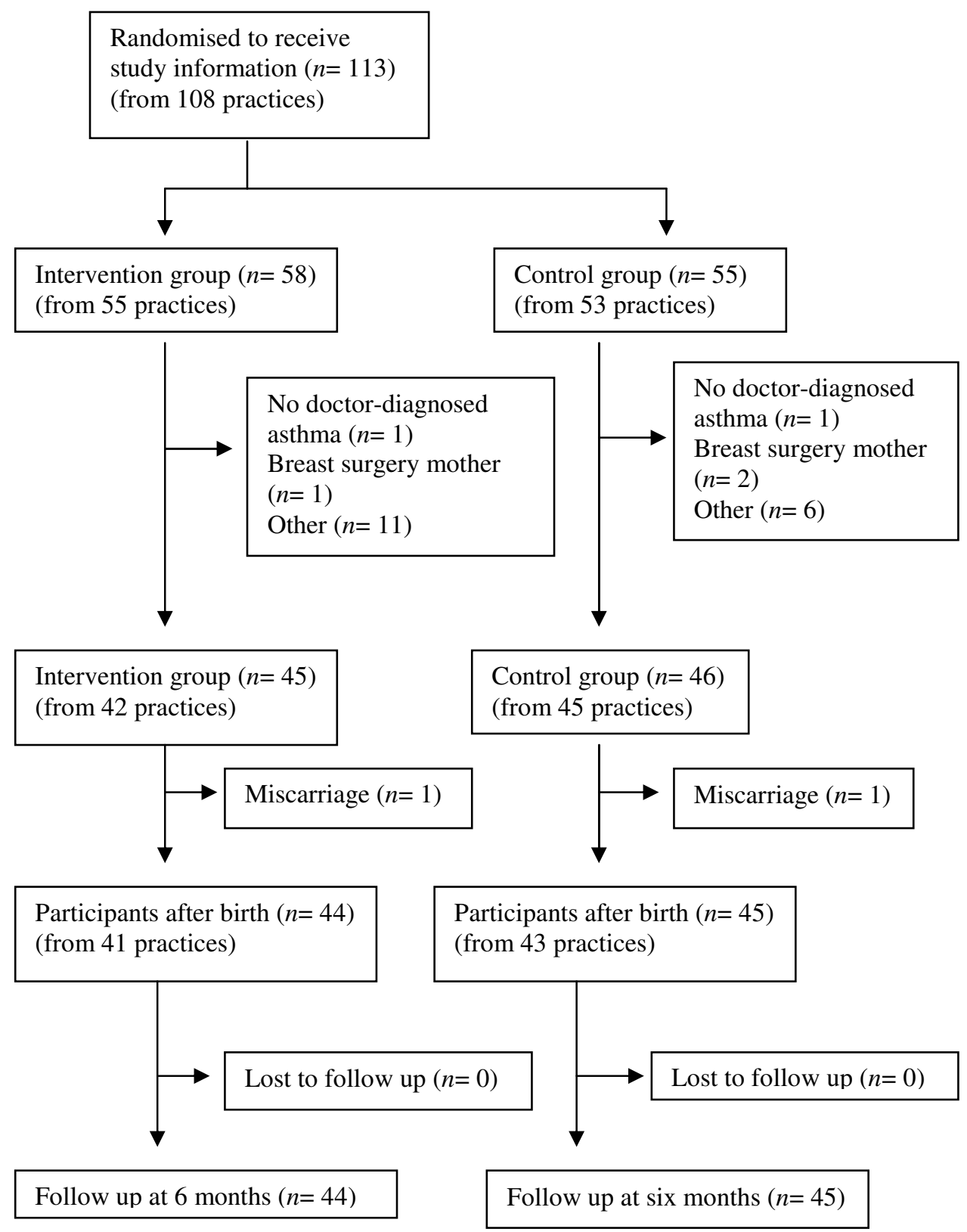

Figure 3.2 Trial profile 
Table 3.1 Characteristics of intervention and control group

\begin{tabular}{|c|c|c|}
\hline & $\begin{array}{l}\text { Intervention group } \\
(n=44)\end{array}$ & $\begin{array}{l}\text { Control group } \\
(\mathrm{n}=45)\end{array}$ \\
\hline Maternal age at birth of child & $31.0(4.1)$ & $31.9(3.6)$ \\
\hline \multicolumn{3}{|l|}{ Maternal education level ${ }^{\text {(a) }}$} \\
\hline Low & $1(2.3)$ & $4(8.9)$ \\
\hline Intermediate & $19(43.2)$ & $17(37.8)$ \\
\hline High & $24(54.4)$ & $24(53.3)$ \\
\hline \multicolumn{3}{|l|}{ Asthma level } \\
\hline Single (moth.or fath. and/or sibling) & $43(97.7)$ & $44(97.8)$ \\
\hline Double (moth.+ fath. and/or sibling) & $1(2.3)$ & $1(2.2)$ \\
\hline Smoking during pregnancy (yes) & $2(4.5)$ & $2(4.4)$ \\
\hline \multicolumn{3}{|l|}{ Medical setting of birth ${ }^{(\mathrm{b})}$} \\
\hline Home & $14(31.8)$ & $18(40.9)$ \\
\hline Hospital & $30(68.2)$ & $26(59.1)$ \\
\hline Breastfeeding experience (yes) & $19(43.2)$ & $29(64.4)$ \\
\hline \multicolumn{3}{|l|}{ Delivery $^{(b)}$} \\
\hline Vaginal & $34(77.3)$ & $41(93.2)$ \\
\hline Caesarean section & $10(22.7)$ & $3(6.8)$ \\
\hline \multicolumn{3}{|l|}{ Parity } \\
\hline First child & $23(52.3)$ & $14(31.1)$ \\
\hline Second child & $14(31.8)$ & $23(51.1)$ \\
\hline Third or later child & $7(15.9)$ & $8(17.8)$ \\
\hline \multicolumn{3}{|l|}{ Gender of infant ${ }^{(\mathrm{c})}$} \\
\hline Boy & $20(43.5)$ & $24(53.3)$ \\
\hline Girl & $26(56.5)$ & $22(46.7)$ \\
\hline Birth weight in grams & $3388(590)$ & $3470(484)$ \\
\hline
\end{tabular}

Figures are numbers with percentages in brackets, unless otherwise listed.

a) low: completed primary school and vocational school; intermediate: completed intermediate secondary or vocational school; high: completed the highest level of secondary or vocational school or university

b) one missing value

c) total of 92 children due to three set of twins

\section{Effect of intervention (duration of exclusive breastfeeding)}

At six months, $48 \%$ of the mothers who received the educational programme breastfed exclusively compared with $27 \%$ of the mothers in the control group ( $p=0.03$ ), Odds Ratio $(\mathrm{OR})=2.91$, 95\% Confidence Interval (CI) [1.10-7.71] corrected for maternal age, educational level and breastfeeding experience. The Cox regression analysis (see Figure 3.3) also showed a significant difference in the duration of exclusive breastfeeding between the control and experimental groups (for discontinuation of breastfeeding, $\mathrm{HR}=0.58$ [0.330.99], $p=0.05$ ) corrected for maternal age, education level and breastfeeding experience. 


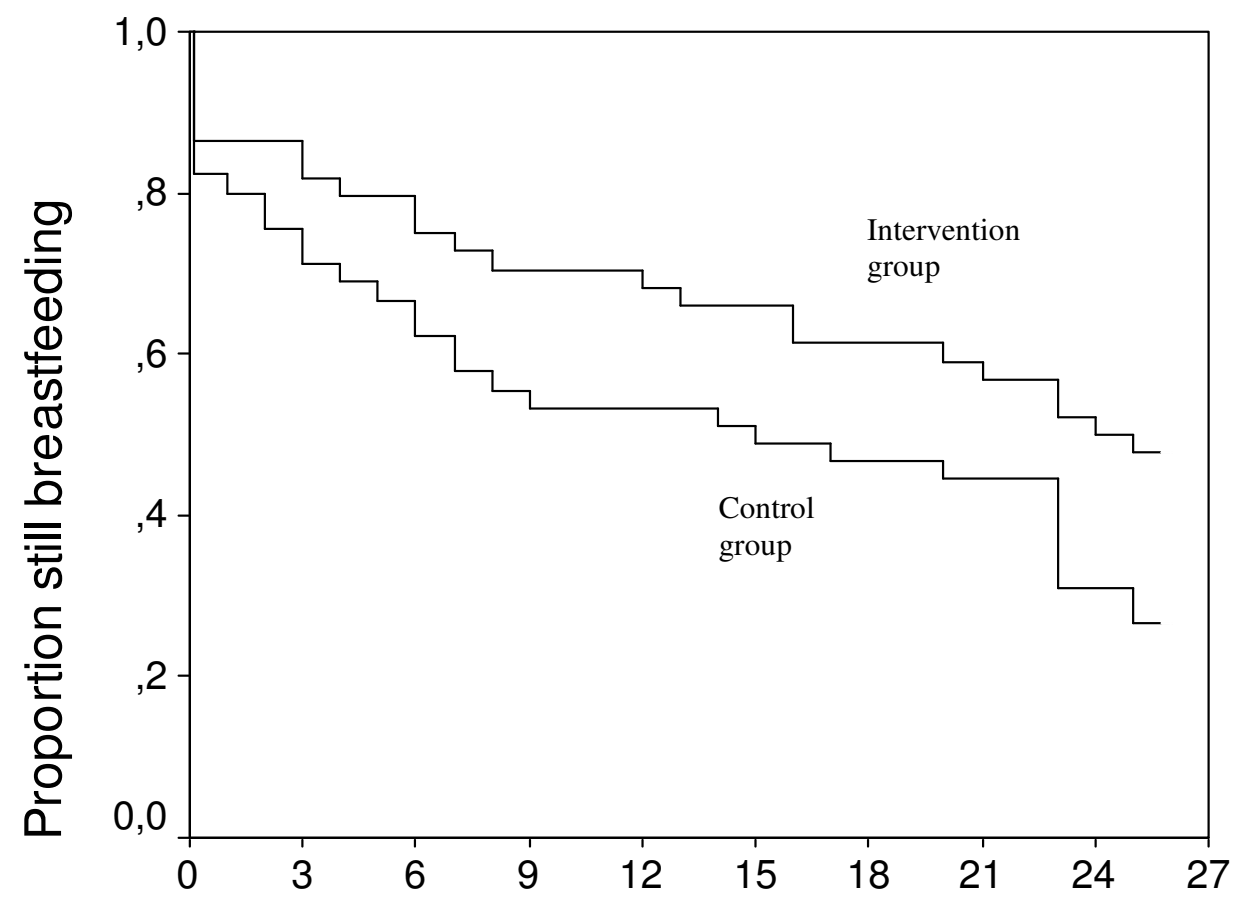

\section{Weeks}

Figure 3.3 The survival curve of the continuation of exclusive breastfeeding adjusted for possible confounders (maternal age, education level and breastfeeding experience). Intervention group $\mathrm{N}=44$, control group $\mathrm{N}=45$. All participants were analysed. A value of 0.1 weeks was appointed for non-starters; mothers who still breastfed exclusively at 26 weeks, were censored at 26 weeks. 


\section{Discussion}

The intervention with a newly developed educational breastfeeding programme based on both a social psychological theoretical model and experiences of a target group was shown to be effective in promoting exclusive breastfeeding for six months among women who were pregnant with a child who had a predisposition for asthma (21/44 [48\%] versus 12/45 [27\%], $(p=0.03)$.

The accent on preparation behavior in the newly developed educational programme and especially in the antenatal (2) and post-natal (1) contacts, in which its advantages as well as the common problems of breastfeeding were discussed, may have contributed to the high success of the intervention group in this study. It is not significant to compare our results with national figures for breastfeeding since the history of asthma in the participating families probably motivated them to breastfeed exclusively for a longer period of time than would families without a history of asthma. The authors do not believe that this is a limitation of this study as this high-risk group is more likely to benefit from breastfeeding. ${ }^{9}$ In recent years several randomised trials have been carried out to examine whether breastfeeding programmes are effective in promoting the initiation and duration of breastfeeding, ${ }^{15-17,26-29}$ but only a few of these studies promoted breastfeeding among highrisk groups, such as those with a predisposition to asthma. This is remarkable since exclusive feeding with breast milk may prevent the development of asthmatic symptoms. ${ }^{3,6}$ Some studies that focused on the primary prevention of asthma have included advice on the avoidance of food allergens. ${ }^{30}$ These studies often have a multifaceted approach and education on breastfeeding is minimal. In many studies the definition of breastfeeding is not clear. Moreover, studies often use the less strict definition of "any breastfeeding" or "complementary breastfeeding", despite the advice of the WHO to breastfeed exclusively for at least six months. ${ }^{12-13}$ This makes a comparison of effectiveness between the studies difficult. The present study involved the investigation of the duration of exclusive breastfeeding and it is hoped that future studies will also use this definition.

The open character of recruitment in this study, on a volunteer basis, may have contributed to the relatively high level of education of the mothers (54\% had a high level of education) and the low number of mothers who smoked during pregnancy (around 5\%). This may have had a positive influence on the initiation and duration of breastfeeding and may have restricted the external validity of this study. Instrument reactivity, i.e. the direct effect of our questionnaires have been responsible for the high percentage of women breastfeeding at six months $(27 \%)$ in our control group. Completing these questionnaires, the so-called Hawthorne effects, might have triggered and influenced the feeding choice and breastfeeding duration of the women in the control group, but this would have also have influenced the intervention group. Our breastfeeding educational programme has the potential to increase the duration of exclusive breastfeeding in families with a 
predisposition to asthma, as shown by the high success rate at six months. As the majority of pregnant women in the Netherlands visit a midwife on a regular basis, a next step would be to investigate the possibilities for implementing the newly developed booklet in the daily routine of midwives or other health professionals providing support for pregnant women.

\section{Acknowledgements}

The authors would like to express their thanks to the research assistant A.H.G. Legtenberg, who visited the participating families and contributed to the conception and design of the study. They also wish to thank dr. S. Kuiper for her comments on the manuscript, and all the participating families for their time and effort.

This work was supported by a grant from the Dutch Asthma Foundation (3.2.99.39) and the Netherlands Organisation for Health research and Development (ZonMw) (No 2300.0009). 


\section{References}

1. Kramer MS, Kakuma R. The optimal duration of exclusive breastfeeding: a systematic review. Adv Exp Med Biol 2004;554:63-77.

2. Fairbank L, O'Meara S, Renfrew MJ, Woolridge M, Sowden AJ, Lister Sharp D. A systematic review to evaluate the effectiveness of interventions to promote the initiation of breastfeeding. Health Technol Assess 2000;4:1-171.

3. Wilson S, Forsyth JW, Greene SA, et al. Relation of infant diet to childhood health: seven year follow up of cohort of children in Dundee infant feeding study. BMJ 1998;316:21-25.

4. Sears M. Epidemiology of childhood asthma. Lancet 1997;250:1015-1020.

5. Wold AE, Adlerberth I. Does breastfeeding affect the infant's immune responsiveness? Acta Paediatr 1998;87:19-22.

6. Gdalevich M, Mimouni D, Mimouni M. Breast-feeding and the risk of bronchial asthma in childhood: A systematic review with meta-analysis of prospective studies. J Pediatr 2001;139:261-266.

7. Odijk van J, Kull I, Borres MP, et al. Breastfeeding and allergic disease: a multidisciplinary review of the literature (1966-2001) on the mode of early feeding in infancy and its impact on later atopic manifestations. Allergy 2003;58:833-843.

8. Halken S. Prevention of allergic disease in childhood: clinical and epidemiological aspects of primary and secondary allergy prevention. Pediatr Allergy Immunol 2004; 15/16:4-5, 9-32.

9. Oddy WH, Holt PG, Sly PD, et al. Association between breast feeding and asthma in 6 year old children: findings of a prospective birth cohort study. BMJ 1999;319:815-819.

10. Sears MR, Greene. JM, Willan AR, et al. Long-term relation between breastfeeding and development of atopy and asthma in children and young adults: a longitudinal study. Lancet 2002;360:901-907.

11. Wright AL, Holberg CJ, Taussig LM, et al. Factors influencing the relation of infant feeding to asthma and recurrent wheeze in childhood. Thorax 2001; 56:192-197.

12. WHO/UNICEF, The Innocenti declaration on the protection, promotion and support of breastfeeding. In Breastfeeding in the 1990's: A global initiative meeting in Florence Italy and New York. Geneva, Switzerland. 1990, WHO/UNICEF: Geneva.

13. World Health Organization (2002). Infant and Young Child Nutrition; Global strategy for Infant and Young Child Feeding. Executive Board Paper EB 109/12. WHO, Geneva.

14. Lanting CI, van Wouwe JP. Breastfeeding in the Netherlands 2005: a provisional report. TNO-report; KVL JPB2005.212.

15. Di Napoli A, Di Lallo D, Fortes C, Franceschelli C, Armeni E, Guasticchi G. Home breastfeeding support by health professionals: findings of a randomised controlled trial in a population of Italian women. Acta Paediatr 2004;93:1108-1114.

16. Chapman DJ, Damio G, Young S, Perez Escamilla R. Effectiveness of breastfeeding peer counseling in a low-income, predominantly latina population: a randomised controlled trial. Arch Pediatr Adolesc Med 2004; 158:897-902.

17. Forster D, McLachlan H, Lumley J, Beanland C, Waldenstrom U, Amir L. Two mid-pregnancy interventions to increase the initiation and duration of breastfeeding: a randomised controlled trial. Birth 2004;31:176-182.

18. Schönberger HJ, Dompeling E, Knottnerus JA, Maas T, Muris JW, et al. The PREVASC study: the clinical effect of a multifaceted educational intervention to prevent childhood asthma. Eur Resp J 2005;25:660-670.

19. Kuiper S, Maas T, van Schayck CP, Muris JWM, Schönberger HJ, Dompeling E, et al. The primary prevention of asthma in children study: Design of a multifaceted prevention program. Pediatr Allergy Immunol 2005; 16:321-331. 
20. Schönberger HJ, Maas T, Dompeling E, Knottnerus JA, van Weel C, van Schayck CP. Compliance of asthmatic families with a primary prevention program of asthma and effectiveness of measures to reduce inhalant allergens - a randomised trial. Clin Exp Allergy 2004;34:1024-1031.

21. Kools EJ, Thijs C, Kester ADM, van den Brandt P, de Vries H. A breastfeeding promotion and support program in the Netherlands: The randomised trial. Prev Med 2005;40:60-70.

22. Sikorski J, Renfrew MJ, Pindoria S, Wade A. Support for breastfeeding mothers. Cochrane Database Syst Rev 2002;1;Cd001141.

23. De Vries H, Mudde, AN. Predicting stage transitions for smoking cessation applying the Attitude-Social influence-Efficacy model. Psychol Health 1998;13:369-385.

24. Gijsbers B, Mesters I, Legtenberg AHG, Knottnerus AJ, van Schayck CP. Factors influencing breastfeeding practices and postponement of solid food to prevent allergic disease in high-risk children: results from an explorative study. Patient Educ Couns 2005;57:15-21.

25. Dirksen WJ, Geijer GMM, de Haan M, de Koning G, Flikweert S, Kolnaar BGM. [NHG-standard Asthma in children (first revision)]. Huisarts en wetenschap 1998;41;130-143.

26. Boulvain M, Perneger TV, Othenin Girard V, et al. Home-based versus hospital-based, postnatal care: a randomised trial. BJOG 2004;111:807-813.

27. Graffy J, Taylor J, Williams A, Eldridge S. Randomised controlled trial of support from volunteer counsellors for mothers considering breast feeding. BMJ 2004;328:26.

28. Chapman DJ, Perez Escamilla R. Does delayed perception of the onset of lactation shorten breastfeeding duration? J Hum Lact 1999;15:107-111.

29. Curro V, Lanni R, Scipione F, Grimaldi V, Mastroiacovo P. Randomised controlled trial assessing the effectiveness of a booklet on the duration of breast feeding. Arch Dis Child 1997;76:500-503.

30. Simpson BM, Custovic A, Simpson A, et al. NAC Manchester Asthma and Allergy Study (NACMAAS): risk factors for asthma and allergic disorders in adults. Clin Exp Allergy 2001;31:391-399. 


\section{4}

The effective breastfeeding educational programme: its content and why it may work -a RCT based analysis- 


\begin{abstract}
Exclusive breastfeeding for the first six months is promoted as the preferred method of feeding infants. In particular, infants of parents with a history of asthma could benefit from a longer period (at least six months) of breastfeeding, since this may reduce the chance of developing childhood asthma. Since continuing to breastfeed for six months appeared difficult to perform for many women, an educational programme was developed and implemented that improved breastfeeding rates at six months post partum. Intervention elements included a theory-based booklet and pre- and postnatal home visits by trained assistants employing a supportive attitude. The key message was that breastfeeding for six months is a challenge and therefore a good preparation is indispensable. Repeated measurements analyses showed increases in knowledge, $\mathrm{F}(1.8,157.7)=7.95, p<0.00$, and more positive attitudinal beliefs regarding breastfeeding for six months $F(2.16,185.7)=$ 3.66, $p=0.03$, after exposure to the programme compared to the controls. Implications for practice are discussed.
\end{abstract}




\section{Introduction}

Exclusive breastfeeding during the first six months after birth is associated with a decreased risk to develop asthma in childhood. ${ }^{1-2}$ This effect is particularly present in children who have a familial predisposition to asthma. ${ }^{3-4}$ Unfortunately, breastfeeding for some women appears to be a difficult behaviour to perform and to continue for a period of 6 months. Only $25 \%$ of Dutch women accomplish to breastfeed exclusively for the recommended six months. ${ }^{5}$ In recent years, many programmes to improve breastfeeding initiation and duration, based on different methods and theories have been implemented with mixed results. ${ }^{6-8}$ Our systematically developed and theory- and evidence- based educational breastfeeding programme, which combined various theoretical methods delivered in pre- and postnatal home visits and a booklet, was demonstrated to be effective in promoting exclusive breastfeeding for at least six months in asthmatic families. ${ }^{9}$ Fortyeight percent of the women who were exposed to the educational programme breastfed their child exclusively the first six months compared to $27 \%$ of the women in the control group $(p<0.03){ }^{9}$

The development of this breastfeeding programme was guided by the Intervention Mapping (IM) protocol $^{10}$ and was based on the Attitude-Social Influence-self-Efficacy model (ASE model). IM was previously used to develop effective health promotion programme for smoking prevention ${ }^{11-12}$ asthma management, ${ }^{13-14}$ leg ulcer management ${ }^{15}$ and urinary incontinence management. ${ }^{16}$ For more detailed information about IM see Bartholomew et al. $^{10}$

The purpose of this paper is to describe the evidence and theory basis of the programme and to clarify why it was effective in promoting exclusive breastfeeding in asthmatic families.

\section{Methods}

\section{The breastfeeding promotion intervention}

The educational breastfeeding programme was designed for mothers who are pregnant of a child at high-risk to develop asthma. This predisposition to asthma of the newborn is caused by a first-degree relative history of asthma. To reduce the chance that a predisposed newborn develops asthma, the child should receive exclusively breast milk the first six months instead of formula feeding. In addition, solids must be avoided the first six months of the infants' life. During the intervention period, pregnant women were visited at home by trained assistants for the first time between the $3^{\text {rd }}$ and $6^{\text {th }}$ month of their pregnancy. A second home visit took place around the $8^{\text {th }}$ month of pregnancy and a postnatal visit was planned within 4 weeks after delivery. The visits lasted approximately one hour each. At 
the beginning of the first home visit, the women received our booklet about breastfeeding for families with a history of asthma (see Table 4.1). During the three visits, the trained assistant reviewed all aspects of breastfeeding, expressing milk and postponing solids as displayed in the booklet. Obviously, the home visitor had a supportive and understanding attitude to encourage the women to continue to breastfeed the full six months. At the end of the first and second home visit, the women were encouraged to read the booklet themselves and with their partner before the next home visit by the assistant.

In the following paragraphs, we illustrate how we designed the educational breastfeeding programme. First, we present a summary of the results of a thorough problem analysis, conducted to elucidate the most important barriers in performing breastfeeding for six months by the target group. Next, the main objectives of the programme were formulated, and based on both empirical and theoretical data; intervention methods for influencing determinants of adherence to exclusive breastfeeding for six months were chosen and translated into practical strategies. Furthermore, we clarify how the programme was pretested and finally the impact of exposure to the breastfeeding programme on the psychosocial factors will be described.

\section{Problem analysis}

A review of the literature and qualitative and quantitative methods were used to increase our understanding of the relevant determinants of early quitting with breastfeeding among mothers with newborn children. From seven focus groups interviews and electronic literature searches, (using Psychlit and Medline), the following relevant (behavioural, psychosocial and external) determinants of initiation and continuation of breastfeeding were revealed: health advantages for the baby, social support, modeling, knowledge about all the aspects of breastfeeding and breastfeeding confidence. ${ }^{17}$ Our programme focused on changeable determinants of breastfeeding, which are under personal control. Other, external determinants such as social norms or social support may directly influence the desired health behaviour as well, but they are often very difficult to change. Only one external factor was approached directly, namely the father as a provider for social support. An alternative for other remaining factors is to deal with them indirectly through personal determinants. ${ }^{10}$ Thus, the social influence by grandmothers for example, was rephrased into the personal determinant perceived social influence. 
Table 4.1 Content of breastfeeding booklet

\begin{tabular}{|c|c|}
\hline \multicolumn{2}{|c|}{ Main topics per period discussed in the booklet } \\
\hline Introduction & $\begin{array}{l}\text { Introducing four target group representatives (three } \\
\text { women and one man) who share their personal } \\
\text { experiences in the booklet. Central theme: Breast } \\
\text { feeding is a challenge; be prepared! }\end{array}$ \\
\hline During pregnancy & $\begin{array}{l}\text { - Why "breast is best" for the mother and the infant } \\
\text { - Specific health benefits for families predisposed to } \\
\text { asthma } \\
\text { - } \quad \text { Breastfeeding duration? } \\
\text { - } \quad \text { The special role of the father as a coach for the mother } \\
\text { - What to do when no breastfeeding support is available } \\
\text { - } \quad \text { in hospital }\end{array}$ \\
\hline The first few weeks after delivery & 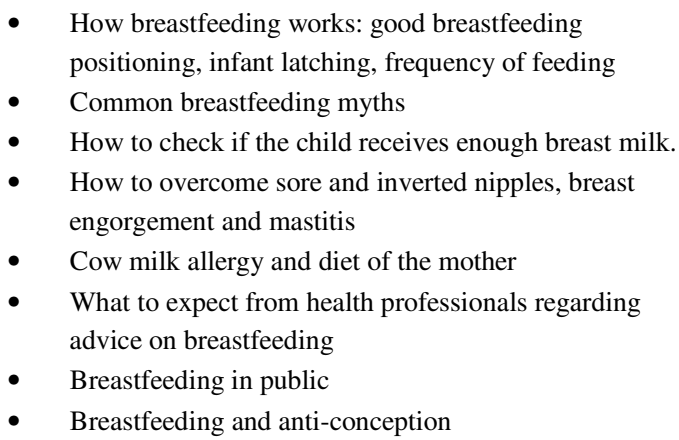 \\
\hline A few months after delivery & $\begin{array}{l}\text { - When try the bottle with breast milk? } \\
\text { - What if your child refuses the bottle? } \\
\text { - } \quad \text { Expressing milk, how does it work? } \\
\text { - } \quad \text { Brew to restore expressed milk } \\
\text { the law } \\
\text { - } \quad \text { Itternatives for breastfeeding } \\
\text { Introducing solids after six months }\end{array}$ \\
\hline Additional & $\begin{array}{l}\text { Phone numbers of lactation organisations/consultants, } \\
\text { useful web sites and further reading options }\end{array}$ \\
\hline
\end{tabular}




\section{Methods and strategies}

The conclusion of the problem analysis was that breastfeeding exclusively for six months appeared difficult to perform. A woman and her partner must learn how to correctly breastfeed their child and need a proper preparation period during pregnancy. As various risk situations turned up in different time periods, it seemed important to fine-tune the educational material to these periods accordingly. The first period, called the preparatory stage, starts at the beginning of the pregnancy. In this period, future parents must read about and visualize the different aspects of breastfeeding including expressing breast milk. They should become "experts" in the field of breastfeeding in order to solve problems that may arise during the first six months after birth. Practice shows that looking for solutions only when problems raise guarantees failure since child feeding can not be postponed. It is also important that parents become more self-confident to stand up to "discouraging advice" from family and friends. Parents must obtain the fighting spirit to maintain breastfeeding for six months. Moreover, the educational programme must also pay attention to the role the future father plays. It seems that fathers play a crucial role in successful breastfeeding, thus they should be prepared as well. The next critical period starts after delivery. Certain problems, such as wrong latching and sore nipples, may occur, and the mother must prepare herself for this. If people have already been mentally confronted with possible risk situations, they are better prepared to cope with such situations when those circumstances actually arise. In addition, there appeared to be a strong social pressure against breastfeeding. This is a risk situation one really needs to be prepared for since this social pressure appeared rather unexpected. Also, a simple lack of knowledge for instance on how to tell whether the baby drinks enough milk seemed essential. Not knowing made parents feel uncertain since for them this feedback was lacking. The last precarious period includes essential information about combining breastfeeding and returning to work. For example, the mother should ask her work boss to arrange a room for her to express milk and be aware of the law regarding expressing milk during working time. Lack of information on the availability of breast pumps and expressing milk was often the reason why the mothers quitted prematurely. Presenting realistic outcome-expectations in each stage is also of great importance for avoiding disappointment and, therefore, the risk of prematurely stopping breastfeeding.

In order to overcome the barriers mentioned during the focus group interviews our breastfeeding programme used methods derived from different theories (see Table 4.2). The strategies mentioned in the table are meant for the home visitors. We used for example, the method "active learning", which is derived from Mcguire's Persuasion Communication Model. ${ }^{18}$ To receive attention from the target group the health message of the programme was formulated in an unexpected way. The key message was that breastfeeding is the optimal nutrition for newborns, but that it is hard work, and several barriers can make you (involuntarily) quit before the advised six months. Presenting messages like this should 
increase the likelihood that readers process the content actively and stimulates an increase in their knowledge about the subject. ${ }^{19}$ Since knowledge alone is no guarantee for behaviour change, it is important to provide the reader with the required skills to perform the behaviour. ${ }^{20}$ Therefore, the booklet contained skill-based practical pictures alternated with the information on breastfeeding. Furthermore, we have chosen to combine written information with interpersonal communication. The written information was read together with the home visitor during the first home visit. Between the first and second visit the women and their partner had the opportunity to read the brochure themselves and questions that came up could be asked during the second visit. Moreover, the conditions for being more equal partners in the conversation about breastfeeding (empowerment) could be increased by this strategy. The interpersonal contact between the home visitor and women was also aimed to review the information that had been read by the women and to check understanding, clarify, repeat and reinforce key points. ${ }^{21}$

Furthermore, fear appeal messages (your child might be predisposed to asthma) underlined the child's vulnerability to the threat (e.g. Risk awareness), ${ }^{22}$ but at the same time we presented an effective solution that women were able to perform (increase self-efficacy); breastfeeding exclusively for six months. This combination of threat messages and efficacy information is more likely to stimulate people to uptake the desired health behaviour. ${ }^{23}$ In our attitude strategy we explicitly paid attention to existing beliefs for women with previous (probably short lasting) breastfeeding experience, since these women are at risk not to continue for longer periods. For this group we acknowledged that it was difficult to breastfeed, but being better prepared this time, they can do it. Naturally, we tried by persuasive messages to accomplish positive breastfeeding attitudinal beliefs in first-time mothers. The models in the booklet were chosen for several reasons, but mainly to enlarge the identification process. The four role models illustrated the information and provided real-life experiences with adherence to breastfeeding, which were inspired by focus group stories. The models may stimulate positive attitudinal beliefs, increase feelings of selfefficacy, but also provided warning stories to prepare families for the social pressure they can expect and examples of coping responses were presented. ${ }^{20}$ 
Table 4.2 Examples of determinants, methods and strategies

\begin{tabular}{|c|c|c|c|}
\hline Determinant & Method & Strategy & Material/tools \\
\hline \multirow[t]{3}{*}{ Knowledge } & Active learning & $\begin{array}{l}\text { Encourage the mother to ask } \\
\text { questions and check } \\
\text { understanding }\end{array}$ & $\begin{array}{l}\text { Specific } \\
\text { breastfeeding } \\
\text { brochure and }\end{array}$ \\
\hline & Rehearsal & $\begin{array}{l}\text { Several home-visits to repeat key } \\
\text { messages }\end{array}$ & $\begin{array}{l}\text { several personal } \\
\text { home-visits }\end{array}$ \\
\hline & Individual education & $\begin{array}{l}\text { Provide one-to-one written and } \\
\text { verbal information }\end{array}$ & \\
\hline Risk perception & Fear arousal & $\begin{array}{l}\text { Underline vulnerability of } \\
\text { expecting child to develop } \\
\text { asthma, but give immediately a } \\
\text { solution to enhance self-efficacy }\end{array}$ & $\begin{array}{l}\text { Specific } \\
\text { breastfeeding } \\
\text { brochure and } \\
\text { personal } \\
\text { communication }\end{array}$ \\
\hline \multirow[t]{4}{*}{ Attitudinal beliefs } & $\begin{array}{l}\text { Persuasive } \\
\text { communication }\end{array}$ & $\begin{array}{l}\text { Encourage women to breastfeed } \\
\text { for six months }\end{array}$ & $\begin{array}{l}\text { Specific } \\
\text { breastfeeding } \\
\text { brochure and }\end{array}$ \\
\hline & Active learning & $\begin{array}{l}\text { Present the health messages in an } \\
\text { unexpected/novel way }\end{array}$ & $\begin{array}{l}\text { personal } \\
\text { communication }\end{array}$ \\
\hline & Anticipated regret & $\begin{array}{l}\text { Asking people to imagine how } \\
\text { they would feel after not trying to } \\
\text { breastfeed (regret question } \\
\text { should stimulate imagery) }\end{array}$ & \\
\hline & Modelling & $\begin{array}{l}\text { Provide role-model expressing } \\
\text { adherence }\end{array}$ & \\
\hline \multirow[t]{2}{*}{$\begin{array}{l}\text { Social support/ } \\
\text { pressure }\end{array}$} & $\begin{array}{l}\text { Modelling/building } \\
\text { skills to resist social } \\
\text { pressure }\end{array}$ & $\begin{array}{l}\text { Provide role-model expressing } \\
\text { possible barriers and ways to } \\
\text { overcome }\end{array}$ & $\begin{array}{l}\text { Four role-models } \\
\text { used in brochure }\end{array}$ \\
\hline & Involvement of partner & $\begin{array}{l}\text { Discuss what social support is } \\
\text { meaningful }\end{array}$ & $\begin{array}{l}\text { Partner explicitly } \\
\text { mentioned in } \\
\text { brochure }\end{array}$ \\
\hline \multirow[t]{2}{*}{ Self-efficacy/Skills } & Modelling & $\begin{array}{l}\text { Provide role model expressing } \\
\text { confidence in accomplishing } \\
\text { breastfeeding }\end{array}$ & $\begin{array}{l}\text { Pictures and } \\
\text { messages in } \\
\text { breastfeeding } \\
\text { brochure }\end{array}$ \\
\hline & $\begin{array}{l}\text { Planning coping } \\
\text { responses }\end{array}$ & $\begin{array}{l}\text { Describe high risk situations and } \\
\text { give solution }\end{array}$ & \\
\hline
\end{tabular}




\section{Pretest}

Another important step was to pretest the programme in members of the target population before actual implementation of the intervention. The booklet was tested by means of the plus minus method. ${ }^{24}$ The plus-minus method involved asking participants to read the booklet from start to finish and to mark their positive and negative experiences with pluses and minus, respectively, in the margin. Pluses and minus may be assigned to all sorts of text elements (from chapters to words) and for various reasons (e.g. comprehensibility, appreciation, relevance of the information). After that, individual interviews were held, focusing on the reasons for every plus and minus. The interviews resulted in a list of reading problems, actual or potential, which then formed the input for a revision. After the plus-minus method a short semi-structured questionnaire focusing on the macrostructure and a general evaluation of the text in the brochure was followed. ${ }^{24}$

The eight women who pre-tested the booklet were multiparous. Two of them had no experience with breastfeeding, three women breastfed an earlier child for 2 to 3 months and three women breastfed an earlier child for more than six months. The results of the plusminus method showed that the overall opinion about the booklet was very positive. The women commented that the brochure was interesting to read, useful and contained not too much or too little information. The language in the brochure appeared to be clear, and examples and pictures were appreciated. Despite the overall positive evaluations, the women had several suggestions to improve the brochure. For example, one woman liked to have more information about expressing milk and more focus on how to handle the social pressure of the environment in the brochure. Other suggestions were a different title of the brochure and more pictures.

\section{Effect on the psychosocial factors}

\section{Study population and design}

The study population participated in a cluster randomised controlled trial, which was started in 2002 in the south-eastern part of the Netherlands. Families were eligible when (1) the mothers were less than 7 months pregnant, and (2) at least one first-degree relative (mother, biological father, or sibling) had asthma that had been diagnosed by a doctor. Families were recruited from March 2002 till March 2003 using posters and flyers put up at the practices of participating midwives and advertisements in local papers. A family was excluded in case of intra-uterine or neonatal death, serious birth defects (illness or malformation), breast surgery of mother, major language problems, or moving outside the Netherlands. The participants were randomised at the family practice level in order to reduce the possibility of contamination. A total of 113 families indicated interest in the 
study and received project information. The following participants were excluded: families with no family history of asthma according to their general practitioner $(n=2)$, women who had experienced a miscarriage $(n=2)$, and women who had had breast surgery and were unable to breastfeed $(n=3)$. Seventeen families did not return the informed consent form so that cluster randomised design resulted in 89 participating families who attended 84 different practices. The analyses were based at individual level rather than at cluster level since this is an almost one-to-one match. All participants provided written informed consent .The Medical Ethical Committee of Maastricht University and the Maastricht University Hospital approved the study.

\section{Psychosocial factors}

The complete definitions and the used scales of all the ASE-model components are described in detail elsewhere. ${ }^{27}$ In short, the main factors will be discussed hereafter.

\section{ASE Attitudinal beliefs}

A bipolar five-point scale was used to assess the positive and negative attitudinal beliefs (29 items) about breastfeeding behaviour with end points of totally agree $(+2)$ and totally disagree (-2). The positive attitudinal beliefs referred to what women might expect to gain by breastfeeding exclusively for six months, such as "Breastfeeding for six months will protect my child from developing eczema". The negative beliefs contained statements about negative consequences of breastfeeding for six months. An example is "Breastfeeding my child for six months requires a lot of effort".

Positive and negative emotions (10 items) were measured on five-point scales and contained the end points never (1) and very often (5). Women reported to what extent they anticipated positive or negative emotions regarding succeeding or failing to breastfeed exclusively for six months, for example "If I succeeded in breastfeeding for six months I would feel very proud". $(\alpha=0.91)$. A mean score was calculated for the attitudinal beliefs and emotions.

\section{ASE Social support}

The extent of social support that women expected if they intended to breastfeed was measured on bipolar five-point scales (5 questions), with end points of totally agree $(+2)$ and totally disagree (-2). An example is "If I breastfeed my child, I can expect to receive enough practical help". 
ASE Self-efficacy expectations

Self-efficacy expectations were assessed by means of sixteen items in which respondents were asked to evaluate how certain they were to breastfeed for six months during different situations (e.g. when their child is sick, during holidays, when the mother is not feeling well), on bipolar five-point likelihood scales with end points of very certain $(+2)$ and very uncertain (-2). A mean score was calculated for the sixteen items.

\section{Breastfeeding knowledge}

Breastfeeding knowledge was measured by twenty multiple-choice questions (right/wrong/ don't know). Item content included techniques for nursing a newborn, nutrition during lactation, milk supply, sore nipples, the law concerning breastfeeding during work time, and safe milk storage. Possible scores on the test ranged from 0 to 20, with a higher score reflecting greater knowledge about breastfeeding.

\section{Statistical analyses}

Group (experimental vs. control) by time (pretest vs. posttests) repeated measures analysis of variance (RM ANOVA) was performed to examine (1) group/intervention main effect, (2) time main effect, and (3) group/intervention by time interaction effect on each of the social cognitive outcome measures. If Mauchley's test indicated that the assumption of sphericity had been violated for the main effects of a variable, the degrees of freedom were corrected using Greenhouse-Geisser estimates of spherecity. ${ }^{25-26}$

If the interaction was statistically significant, analysis of simple effects was performed for the purpose of post hoc analysis. The four measurement moments were 3-6 months pregnant, 8 months pregnant, 3 months postpartum and 6 months postpartum.

Statistical significance was assumed for $p$-values $\leq 0.05$. SPSS (version 11.0) was used for analysis.

\section{Results}

\section{Characteristics}

The characteristics of the 89 participating randomised women are presented in Table 4.3. Almost $87 \%$ of the women in both groups had a positive intention to start breastfeeding and the average intended duration to breastfeed was around 13 weeks for the women in the intervention group and almost 18 weeks for the women in the control group. Furthermore, the majority of women $(67 \%)$ made their choice for breastfeeding or formula before 
pregnancy. Most of the women intended to return to work after their maternity leave $(87 \%)$ for an average of 19 hours per week, after a mean of 14 weeks of maternity leave.

Table 4.3 Sociodemographic, biomedical and psychosocial characteristics of the participating mother-infant pairs.

\begin{tabular}{|c|c|c|}
\hline & $\begin{array}{l}\text { Intervention } \\
(\mathrm{n}=44)\end{array}$ & $\begin{array}{l}\text { Control } \\
(\mathrm{n}=45)\end{array}$ \\
\hline \multicolumn{3}{|l|}{ Sociodemographic factors } \\
\hline Maternal age (years) at birth of child (sd) & $31.0(4.1)$ & $31.9(3.6)$ \\
\hline \multicolumn{3}{|l|}{ Maternal education level ${ }^{(\mathrm{a})}$} \\
\hline Low $(\%)$ & $1(2.3)$ & $4(8.9)$ \\
\hline Intermediate (\%) & $19(43.3)$ & $17(37.8)$ \\
\hline High (\%) & $24(54.4)$ & $24(53.3)$ \\
\hline Return to work after maternity leave (yes, \%) & $39(88.6)$ & $39(86.7)$ \\
\hline Duration of leave after birth in weeks (sd) & $13.9(4.9)$ & $14.7(11.3)$ \\
\hline Hours work after leave per week (sd) & $19.4(10.1)$ & $18.1(10.1)$ \\
\hline \multicolumn{3}{|l|}{ Asthma level } \\
\hline Single (moth. or fath. or sibling) (\%) & $43(97.7)$ & $44(97.8)$ \\
\hline Double (moth.+ fath. and/or sibling) (\%) & $1(2.3)$ & $1(2.2)$ \\
\hline \multicolumn{3}{|l|}{ Breastfeeding experience } \\
\hline Primiparous (\%) & $23(52.3)$ & $14(31.1)$ \\
\hline $0-5$ weeks experience $(\%)$ & $5(11.4)$ & $10(22.2)$ \\
\hline$\geq 6$ weeks experience $(\%)$ & $16(36.4)$ & $21(46.7)$ \\
\hline \multicolumn{3}{|l|}{ Biomedical factors } \\
\hline Smoking during pregnancy (yes) (\%) & $2(4.5)$ & $2(4.4)$ \\
\hline \multicolumn{3}{|l|}{ Medical setting of birth ${ }^{(b)}$} \\
\hline Home $(\%)$ & $14(31.8)$ & $18(40.9)$ \\
\hline Hospital (\%) & $30(68.2)$ & $26(59.1)$ \\
\hline \multicolumn{3}{|l|}{ Delivery $^{(\mathrm{b})}$} \\
\hline Vaginal (\%) & $34(77.3)$ & $41(93.2)$ \\
\hline Caesarean $(\%)$ & $10(22.7)$ & $3(6.8)$ \\
\hline Birth weight in grams (sd) & $3388(590)$ & $3470(484)$ \\
\hline \multicolumn{3}{|l|}{ Gender of infant ${ }^{(\mathrm{c})}$} \\
\hline Boy $(\%)$ & $20(43.5)$ & $24(52.2)$ \\
\hline $\operatorname{Girl}(\%)$ & $26(56.5)$ & $22(47.8)$ \\
\hline \multicolumn{3}{|l|}{ Psychosocial factors } \\
\hline Feeding decision made before pregnancy $(\%)$ & $31(70.5)$ & $29(64.4)$ \\
\hline Intention to initiate breastfeeding (\%) & $37(84.1)$ & $40(88.9)$ \\
\hline Intended duration to breastfeed in weeks (\%) & $13.2(15.5)$ & $17.7(22.9)$ \\
\hline
\end{tabular}

a) low: completed primary school and vocational school, intermediate: completed intermediate secondary or vocational school, and high: completed the highest level of secondary or vocational school or university

b) One missing value

c) Total of 92 children due to three sets of twins 


\section{The ASE factors}

Regarding the attitudinal beliefs, the RM ANOVA showed a statistically significant time effect, $\mathrm{F}(2.16,185.7)=24.02, p<0.00$ and a significant group by time interaction effect, $\mathrm{F}(2.16,185.7)=3.66, p=0.03$. The main group effect was not statistically significant $\mathrm{F}(1,86)=0.17, p=0.68$. Contrasts revealed that attitudes increased positively over time in both groups, but the effect was significantly larger in the experimental group, especially between the two measurements in the preparatory period during pregnancy $\mathrm{F}(1,86)=5.78$, $p<0.02$.

The RM ANOVA showed a statistically significant time effect concerning the factor breastfeeding knowledge, $\mathrm{F}(1.8,157.7)=56.5, p<0.00$ and a significant group by time interaction effect, $\mathrm{F}(1.8,157.7)=7.95, p<0.00$. The main group effect was also statistically significant $\mathrm{F}(1,86)=6.72, p<0.01$. Contrasts revealed that knowledge increased over time in both groups, but the effect was significantly larger in the experimental group, especially the comparison between the measurement at 7 months pregnancy and 6 months post partum $\mathrm{F}(1,86)=10.84, p<0.00$.

Regarding the factor social support only the main time effect was statistically significant, $\mathrm{F}(3,258)=8.63, p<0.00$. Contrasts revealed that between the third month postpartum and sixth month postpartum the extent of perceived social support decreased significantly in both groups; $\mathrm{F}(1,86)=7.7, p<0.01$.

The RM MANOVA showed only a statistically significant time effect concerning the factor emotions, $\mathrm{F}(2.23,192.4)=1.54, p<0.00$. Contrasts revealed significant increases in positive emotions between the third month pregnancy and seventh month pregnancy, $F(1,86)=6.1$, $p<0.02$ and between the seventh months pregnancy and three months postpartum, $\mathrm{F}(1,86)=9.68, p<0.00$.

Regarding the self-efficacy expectations the RM ANOVA showed only a significant time effect, $\mathrm{F}(1.83,157.7)=13.96, p<0.00$. Contrasts revealed a statistically difference between the seventh month pregnancy and three months postpartum in which self-efficacy expectation increased, $\mathrm{F}(1,86)=20.68, p<0.00$. The significant outcome variables are presented in Figure 4.1, the other outcome variables (social norm, social pressure, models, and intention) showed no statistically significant time, group or interaction effect. 


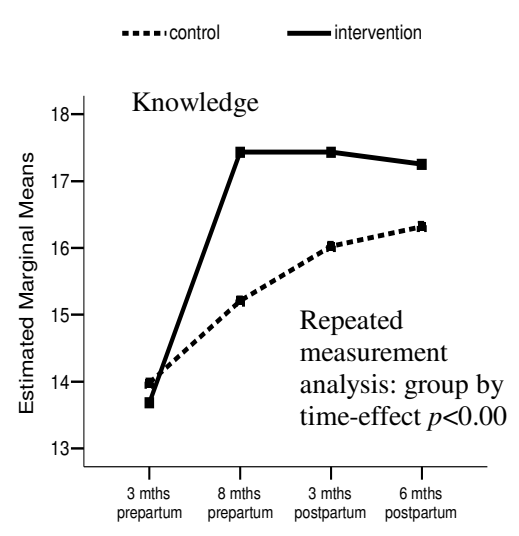

Follow-up
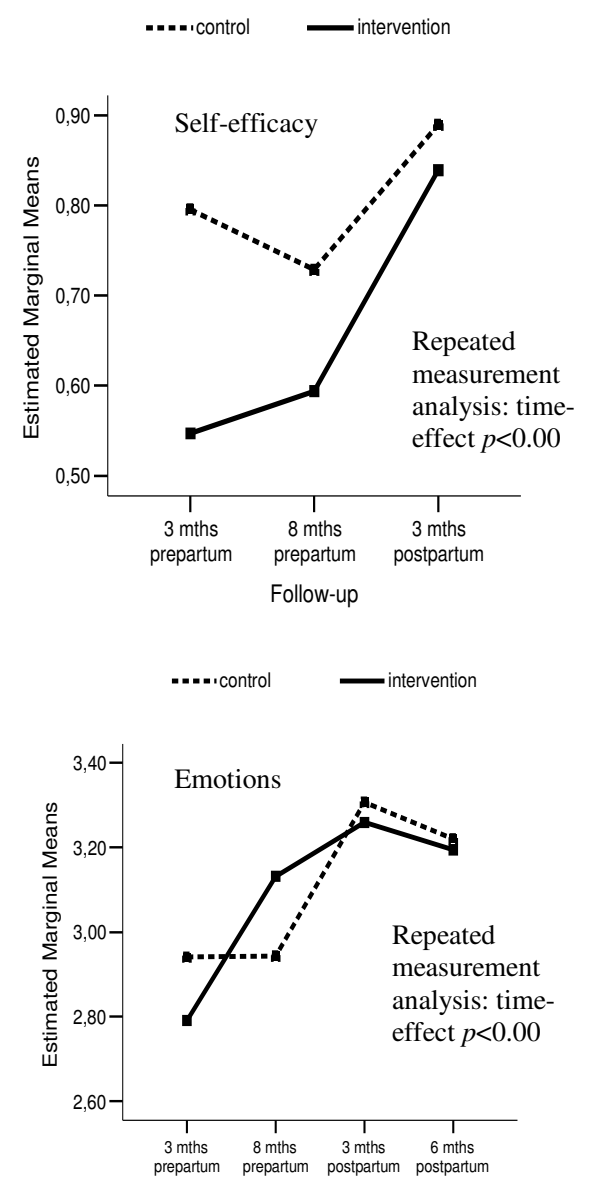

Follow-up

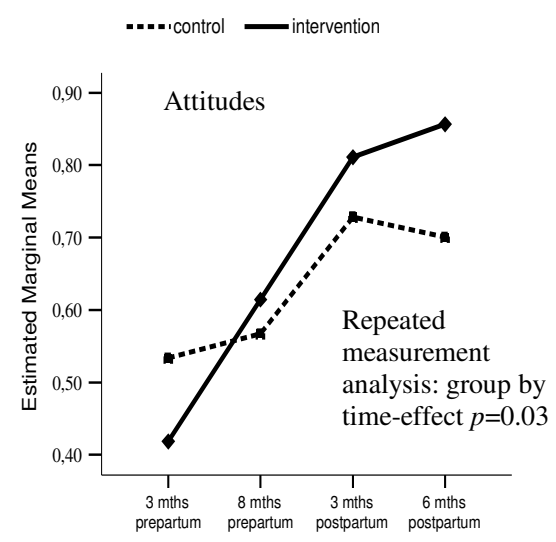

Follow-up

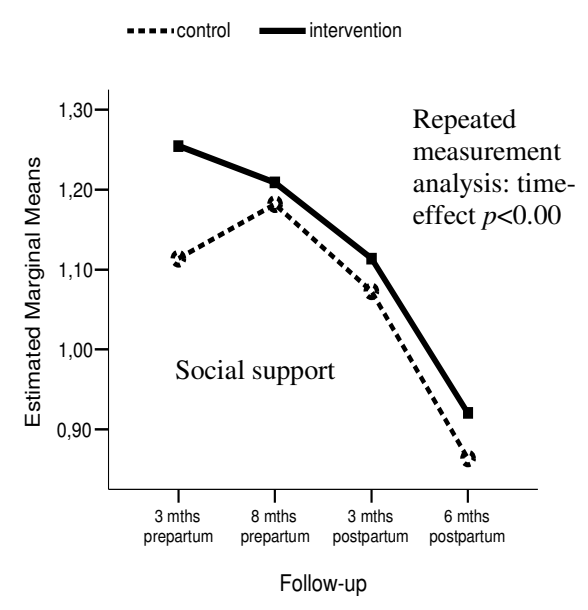

Figure. 4.1 Follow-up of ASE factors in intervention and control group. The graphs demonstrate pattern of estimated marginal means in controls, and the effect of intervention. P-values shown are group by time or timeeffects. 


\section{Evaluation users' booklet by its users}

In order to get insight in the usefulness of the breastfeeding booklet, parents in the intervention group completed a questionnaire to evaluate the educational programme and were asked to reward the whole programme between zero and ten. The overall appreciation of the programme on a ten-point scale was rewarded with an 8.1 (range 6-10). The main comments reflected a general positive view of the booklet. Almost all women $(98 \%)$ read the programme, in whole or parts of it. The programme was evaluated accessible, easy to read and attractive.

\section{Discussion}

In this paper we described the development and content of an effective breastfeeding educational programme, ${ }^{9}$ which consisted of a combination of pre- and postnatal home visits and a corresponding theory-based booklet and the impact of exposure to the programme on breastfeeding predisposing variables, was evaluated. The programme increased long-term duration of exclusive breastfeeding from $27 \%$ in the control group to $48 \%$ in the experimental group. ${ }^{9}$ An explanation for the success of our breastfeeding programme could be found in the significant increase of women's knowledge and their attitudinal beliefs regarding breastfeeding exclusively for six months.

The strengths of this study include the prospective randomised controlled design with up to six months post partum follow up of exclusive breastfeeding. The follow up period allowed us to perform repeated measurements, which gave insight into the process of change of factors which are responsible for performing the health behaviour. Furthermore, our educational programme was developed systematically using elements of the Intervention Mapping protocol, ${ }^{10}$ which has proven its value in developing earlier health promotion programmes. Despite, our intervention was developed for a specific population, women who are expecting a child at high risk to develop asthma, the authors do not believe that this is a limitation of this study as this high-risk group is especially likely to benefit from breastfeeding. The open character of recruitment in this study, on a volunteer basis, may have contributed to the relatively high level of education of the mothers (54\% had a high level of education) and the low number of mothers who smoked during pregnancy (around $5 \%$ ). This may have had a positive influence on the initiation and duration of breastfeeding and may have restricted the external validity of this study, but also on abilities to read and understand our material (health literacy). However, results between control and intervention group remain most important. Finally, in this study the definition of the outcome parameter, exclusive breastfeeding fir six months, corresponded with the recommend definition of the World Health Organisation. Moreover, parents kept a diary, which decreased the chance of recall bias. ${ }^{9}$ 
World-wide, many breastfeeding promotion programmes have been evaluated to extend the duration of breastfeeding but the majority of the studies are not comparable with each other due to several different basic assumptions. ${ }^{6-8}$ For example, most studies focus just on education or on support only or provide only written materials, the timing points of contact moments fluctuate (pre- or postnatal or both), contact formats vary (the usage of group sessions or individual contacts, face-to face or just telephone contacts) and frequency of contacts differ. ${ }^{8}$ Also, many studies were performed in disadvantaged low-income groups or developing countries. ${ }^{28-30}$ In addition, disappointing methodology of study designs are often the short follow up periods (less than six months), poor quality trials due to substantial base-line differences or lack of adjustment to confounders and the vague definition of the outcome measure. ${ }^{6}$

Two studies ${ }^{31-32}$ showed that offering women only written material was not successful, the difference between the success rate of the intervention and control group, appeared only 7 percent after six months in one study (59\% vs. 52\%), and $4 \%$ in the other study (48\% vs. $44 \%$ ). Sikorski et al, ${ }^{6}$ concluded in their systematic review that offering extra support leads to a higher proportion women accomplishing to breastfeed exclusively the first six months (RR, for giving up breastfeeding before six months, 0.96 [0.92-0.99], three trials 17,825 women). The studies that were compared used different supportive strategies and trained volunteers or professionals offered the breastfeeding support. A meta-analysis of four trials which made use of the WHO/UNICEF training (a training to educate health professionals) showed significant benefit in prolonging exclusive breastfeeding (RR 0.70 [0.53-0.93]) but was highly heterogeneous. Analysis of studies reporting a predominantly face-to-face intervention showed a statistically significant benefit (RR 0.86 [0.78-0.94]; eight trials, 2044 women) whereas those using mainly telephone contact had almost a similar RR that was not statistically significant (RR 0.92 [0.78-1.08]; five trials, 1168 women). Guise et al, ${ }^{7}$ performed a systematic review and included studies which originated in the primary care setting and contained a concurrent control group. They concluded that the effect on long term breastfeeding practices (4-6 months) was the largest when breastfeeding education was combined with support (difference I-C $=13 \%$, 95\% CI 1-25). In the Netherlands only one other study evaluated the effectiveness of a breastfeeding promotion programme. This programme aimed to increase the breastfeeding continuation until at least three months. ${ }^{33}$ The combination of a health counseling training for the caregivers in postpartum care, in order to enhance the cooperation between caregivers and continuity of care, early signaling of breastfeeding problems and free lactation consultancy appeared not to be successful (OR 0.82, [0.58-1.14]). Emphasize on educating the postpartum health professionals could be a wrong assumption, since women chose early in pregnancy if they will breastfeed their child and can already benefit from prenatal support and education. Putting effort in preparing and educating the women starting from the mid pregnancy seems more logical than to train health professionals which the women will see in a later stadium of their pregnancy or in some cases even post-partum. 
Another aim of this study was to evaluate the influence of the breastfeeding programme on the psychosocial variables. Interestingly, the self-efficacy expectations and positive emotions increased over time but the breastfeeding programme did not seem to influence these processes. This can be explained as a natural process, since a personal positive experience with breastfeeding enhances the confidence and positive emotions. As expected, but still remarkable is the decrease of perceived social support between the third and sixth month postpartum in both groups. This finding illustrates that it is still not common practice that women breastfeed more than three months confirmed our focus groups finding, stressing the need as we did in our programme to warn parents for such pressures so they are prepared and therefore can better resist such pressures. Few studies examined the influence of their intervention on the psychosocial influencing variables. Ryser, ${ }^{34}$ showed just as present study that as positive attitudes increase the breastfeeding rates go up.

In conclusion, strong points of our programme are the systematically development of the programme based on theoretical models, pre- and postnatal home visits, starting in midpregnancy and the supportive role of the home visitor, stressing partner support and resistance to social influence in combination with the written material.

\section{Implications for practice}

At a national level, important organisations such as the professional organisation for midwives and the health home care services adopted the national feeding guidelines for newborns to promote exclusive breastfeeding for the first six months. Also the Dutch government promotes breastfeeding for six months because of the many proven health benefits for mother and child. Our effective breastfeeding promotion programme was evaluated positively by participating families who graded the programme with an eight on a scale from zero to ten. We believe this programme holds a promise for future care to coach women, pregnant of a predisposed child, towards adherence with breastfeeding for six months and improve health in high-risk newborns. Therefore, an attempt must be made to implement the programme in daily practice of health professionals.

\section{Acknowledgements}

The authors would like to express their thanks to the research assistant, Anita Legtenberg, who contributed to the conception and design of the study. They are also grateful to Tessa Essing, Marieke Vriend and Maartje van der Rijt who assisted with data entry. This study was funded by a grant from the Dutch Asthma Foundation (3.2.99.39) and ZonMw (2300.0009). 


\section{References}

1. Kull I, Wickman M, Lilja G, et al. Breastfeeding and allergic diseases in infants- a prospective birth cohort study. Arch Dis Child 2002;87:478-481.

2. Oddy WH, Sly PD, de Klerk NH, et al. Breast feeding and respiratory morbidity in infancy: a birth cohort study. Arch Dis Child 2003;88:224-228.

3. Gdalevich M, Mimouni D, Mimouni M. Breast-feeding and the risk of bronchial asthma in childhood: A systematic review with meta-analysis of prospective studies. J of Pediatr 2001;139:261-266.

4. Odijk van J, Kull I, Borres MP, et al. Breastfeeding and allergic disease: a multidisciplinary review of the literature (1966-2001) on the mode of early feeding in infancy and its impact on later atopic manifestations. Allergy 2003;58:833-843.

5. Lanting CI, van Wouwe JP. Breastfeeding in the Netherlands 2005: a provisional report. TNO-report; KVL JPB2005.212.

6. Sikorski J, Renfrew MJ, Pindoria S, Wade A. Support for breastfeeding mothers: a systematic review. Paediatr Peri Epid 2003;17:407-417.

7. Guise JM, Palda V, Wesrhoff C, Chan BKS, Helfand M, Lieu TA. The effectiveness of primary care-based interventions to promote breastfeeding: systematic evidence revies and meta-analysis for the US preventive service task force. Ann Fam Med 2003;2:70-78.

8. Oliveira de MIC, Camacho LAB, Tedstone AE. Extending breastfeeding duration through primary care: a systematic review of prenatal and postnatal intervention. J Human Lact 2001;17:326-343.

9. Gijsbers B, Mesters I, Knottnerus JA, Kester ADM, van Schayck CP. The success of an educational programme to promote exclusive breastfeeding for 6 months in families with a history of asthma: A randomised controlled trial. Pediatr Asthma Allergy Immunol. 2006;19:214-222.

10. Bartholomew LK, Parcel GS, Kok G, Gottlieb NH. Planning health promotion programmes. An intervention mapping approach. John Wiley \& Sons, 2006.

11. De Vries H, Mudde AN. Predicting stage transitions for smoking cessation applying the Attitude-Social influence-Efficacy model. Psychol Health 1998;13:369-385.

12. Mullen PD, DiClemente CC, Bartholomew LK. Theory and context in project PANDA: a programme to help postpartum women stay off cigarettes. In: Bartholomew LK, Parcel GS, Kok G, Gottlieb NH, editors. Intervention mapping: designing theory and evidence-based health promotion programmes. Mountain View, CA: Mayfield Publishing Co., 2001.

13. Fernandez ME, Bartholomew LK, Lopez A, Tyrrell S, Czyzewski DR, Sockrider MM. Using intervention mapping in the development of a school-based asthma management intervention for Latino children and families: the FAMILIAS project. In: 128th annual meeting of the American Public Health Association; 2000.

14. Bartholomew LK, Gold RS, Parcel GS, Czyzewski DI, Sockrider MM, Fernandez ME, Shegog R, Swank PR.Watch. Discover, think, and act: evaluation of computer assisted instruction to improve asthma selfmanagement in inner-city children. Patient Educ Couns 2000;39:269-280.

15. Heinen MM, Bartholomew LK, Wensing M, van de Kerkhof P, van Achterberg T. Supporting adherence and healthy lifestyles in leg ulcer patients: Systematic development of the Lively Legs programme, for dermatology outpatient clinics. Patient Educ Couns 2006;61:279-291.

16. Alewijnse D, Mesters I, Metsemakers JFM, van den Borne B. Programme development for promoting adherence during and after exercise therapy for urine incontinence. Patient Educ Couns 2002;48:147-160.

17. Gijsbers B, Mesters I, Legtenberg AGH, Knottnerus JA, van Schayck CP. Factors influencing breastfeeding practices and postponement of solid food to prevent allergic disease in high-risk children: results from an explorative study. Patient Educ Couns 2005; 57:15-21.

18. McGuire WJ. Attitudes and attitude change. In G. Lindzey\& E. Aronson (eds.). The handbook of social psychology: Vol. 2 . Special fields and applications ( $3^{\text {rd }}$ ed., pp. 233-346). New York: Knopf. 
19. Maibach EW, Parrot RL. Designing health messages: Approaches from communication theory and public health practice. Thousand Oaks, CA: Sage. 1985.

20. Bandura A. Social foundations of thought and action: a social cognitive theory. Englewood Cliffs: Prentice Hall 1986.

21. Raynor DK. The influence of written information on patient knowledge and adherence to treatment in Adherence to treatment in medical conditions. Edited by Myers LB, Midence K 1998 Harwood publishers Amsterdam.

22. Witte K. The role of threat and efficacy in AIDS prevention. Intern Quar Com Health Educ 1992;59:329349.

23. Ruiter RA, Abraham C, Kok G. Scary warnings and reactional precautions: A review of the psychology of fear appeals. Psychology and Health 2001;16:613-630.

24. De Jong M. Reader feedback in text design; Validity of the plus-minus method for the pretesting of public information brochures. Editions Rodopi, Amsterdam. 1998.

25. Field A (2000). Discovering statistics using SPSS. Thousand Oaks, Sage Publication London.

26. Tabachnick, B. G., \& Fidell, L. S. (1996). Using multivariate statistics (3rd ed.). New York: Harper Collins.

27. Gijsbers B, Mesters I, Knottnerus JA, van Schayck CP. Factors associated with the initiation of breastfeeding in asthmatic families: The Attitude-Social Influence-Self-Efficacy Model. Breastfeed Med 2006;1:236-246.

28. Haider R, Ashworth A, Kabir I, Huttly S. Effect of community-based peer counsellors on exclusive breastfeeding practices in Dhaka, Bangladesh: a randomised controlled trial. Lancet 2000;356:1643-1647.

29. Froozani MD, Permehzadeh K, Motlagh ARD, Golestan B. Effect of breastfeeding education on the feeding pattern and health of infants in their first 4 months in the Islamic Republic of Iran. Bull WHO 1999;77:381385 .

30. Morrow AL, Lourdes Guerrero M, Shults J, Calva JJ, Lutter C, Ruiz-Palacios GM, et al. Efficacy of homebased peer counselling to promote exclusive breastfeeding: a randomised controlled trial. Lancet 1999;353:1226-1231.

31. Currò V, Lanni R, Scipione F, Grimaldi V, Mastroiacovo P. Randomised controlled trial assessing the effectiveness of a booklet on the duration of breast feeding. Arch Dis Child. 1997;76:500-504.

32. Hauck YL, Dimmock JE. Evaluation of an information booklet on breastfeeding duration: a clinical trial. $J$ Adv Nurs 1994;20:836-843.

33. Kools EJ, Thijs C, Kester ADM, van den Brandt PA, de Vries H. A breast-feeding promotion and support programme a randomised trial in the Netherlands. Prev Med 2005;40:60-70.

34. Ryser FG. Breastfeeding attitudes, intention, and initiation in low-income women: the effect on the best start programme. J Hum Lac 2004;20:300. 



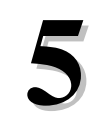

\section{Factors associated with the intended duration and initiation of breastfeeding in asthmatic families}

Barbara Gijsbers, Ilse Mesters, J. André Knottnerus, Constant P. van Schayck

Published as: Factors associated with the initiation of breastfeeding in asthmatic families:The Attitude-Social Influence-Self-Efficacy model Breastfeed Med 2006;1:236-246 


\section{Abstract}

Background: Exclusive breastfeeding for the first six months post-partum is promoted internationally as the preferred method of feeding infants. Infants of parents with a history of asthma in particular could benefit from a longer period (six months) of breastfeeding, since this may reduce the chance of developing an allergic disease. The aim of this study was to identify psychosocial behavioural determinants of the intended duration and actual initiation of breastfeeding in families with a predisposition to asthma.

Methods: This prospective study was part of a randomised trial in which breastfeeding for six months was promoted. The 89 women participating completed a breastfeeding questionnaire based on the Attitude-Social Influence-Self-efficacy model in the second trimester of their pregnancy. This served as the base-line measurement.

Results: Multiple lineair and logistic regression analyses showed that attitudinal beliefs were significantly associated with the intended duration to breastfeed $(p=0.01)$ and the intention was the strongest predictor for the actual initiation of breastfeeding (OR:8.2; 95\% CI:1.5-44.3).

Conclusion: Breastfeeding promotion needs to focus on the health advantages and other advantages of breastfeeding for six months, especially in high-risk groups, in order to increase the intention to breastfeed, which appeared to be a strong predictor for actual behaviour. 


\section{Introduction}

In the Netherlands, the prevalence of childhood asthma varies from 3-5\% and is the most common chronic childhood disease seen in general practice. ${ }^{1-2}$ Because the etiology of asthma is multifactorial, with genetic predisposition, immunologic profile, and allergic sensitization playing major roles, ${ }^{3}$ it is biologically plausible that breastfeeding may offer some protection against the occurrence of asthma by decreasing allergic sensitization and/or modulating the infant's immune system. ${ }^{4}$ Several review and birth cohort studies, evaluating the association between breastfeeding and asthma and/or other respiratory illnesses, have shown consistently protective effects, particularly with exclusive breastfeeding for at least six months after birth. ${ }^{5-6}$ Some studies showed that the protective effect of exclusive breastfeeding is even stronger if a family history of allergic disease is present. ${ }^{7-8}$ Nevertheless, some controversy about the protective effect of breastfeeding against asthma remains, since a few studies found no association or even suggest that breastfeeding is associated with an increased risk for childhood asthma in the presence of maternal asthma. ${ }^{9-10}$ Considering that the World Health Organisation (WHO) recommends exclusive breastfeeding for the first six months post-partum, since breastfeeding offers many additional health benefits, ${ }^{11-12}$ and the assumed protective effect in predisposed children, it seems important that parents with a history of asthma breastfeed exclusively for the first six months. Nevertheless, the average breastfeeding duration in the Netherlands remains far below the level of the recommended six months. The latest figures show that only $25 \%$ of Dutch women breastfeed their child exclusively at the age of six months. ${ }^{13}$

Although various studies have reported on demographic and psychosocial factors influencing breastfeeding behaviour (e.g. age, education, ethnicity, knowledge, parity, motivation, and intention), much of contemporary breastfeeding research lacks a theoretical framework as foundation. ${ }^{14-15}$

In the past 20 years, the Theory of Reasoned Action (TRA) ${ }^{16-18}$ and its revised version, the Theory of Planned Behaviour (TPB), ${ }^{19-27}$ were the most frequently applied social cognition models in breastfeeding studies. In these studies, attitudinal beliefs and perceived behavioural control were often found to be the significant predictors of feeding intentions and behaviour and the explained variance of intention ranged from 23 to $60 \%$. Furthermore, the self-efficacy theory ${ }^{28}$ has received attention in several breastfeeding studies. Maternal breastfeeding confidence appeared to be a powerful predictor for both breastfeeding initiation and duration. ${ }^{28-31} \mathrm{~A}$ potentially informative model used to describe the determinants of breastfeeding behaviour is the social-psychological Attitude-Social Influence-Self-Efficacy model (ASE model). ${ }^{32-33}$ This model has been successfully applied in several studies to explain various aspects of preventive health behaviour, such as fruit and vegetable consumption, ${ }^{34}$ breast cancer screening, ${ }^{35}$ and smoking cessation ${ }^{36}$ and recently also in predicting breastfeeding initiation. ${ }^{37}$ The ASE model has been influenced 
by several social cognition models and concepts such as the $\mathrm{TRA}^{16}$ and TPB, ${ }^{19}$ concepts of social pressure ${ }^{38}$ and Bandura's Social Learning theory (SLT) and his constructs of modelling and self-efficacy ${ }^{39}$ (see Figure 5.1). The ASE model states, just as does the TRA $^{18-19}$ and its successor the TPB, ${ }^{23}$ that behaviour is a function of a person's intention. In the ASE model it is assumed that three types of proximal cognitive variables primarily determine behavioural intention: attitudinal beliefs (and emotions), social influences (social norms, social support and social pressure, and modelling) and self-efficacy expectations. The model also postulates that intention predicts subsequent behaviour. Furthermore, the distal or external variables, such as behavioural factors (e.g. previous experience and knowledge) and socio-demographic variables (e.g. age, educational level) are assumed to be moderated by the three proximal factors (attitudinal beliefs, social influences and selfefficacy). Nevertheless, it has been acknowledged that behaviours that have become habitual or were experienced before (past behaviour) may have a direct effect on future behaviour as well. ${ }^{36,40}$ The ASE model and TPB partly overlap with respect to the concepts that are integrated, but differ in the way these concepts are measured; especially perceived behavioural (PBC) control and self-efficacy expectations. ${ }^{33}$ The PBC is a multidimensional construct and includes both perceptions of difficulty and perceptions of control over the behaviour. Nevertheless, Ajzen ${ }^{41}$ argued that the PBC and self-efficacy constructs are 'quite similar'. The ASE model uses the construct of self-efficacy instead of the PBC since in many studies it appeared that measures tapping solely perceived difficulty (self-efficacy) tend to be more predictive with both intentions and behaviour than measures which tap both perceived controllability and difficulty. ${ }^{42-43}$

The purpose of this paper is to examine the associations between both the variables of the ASE model and the intended duration and the actual initiation of breastfeeding in women who expect a child at high-risk to develop an allergic disease. The results of this study could be used to inform existing breastfeeding promotion programmes, which subsequently can be tested for improvement in breastfeeding rates.

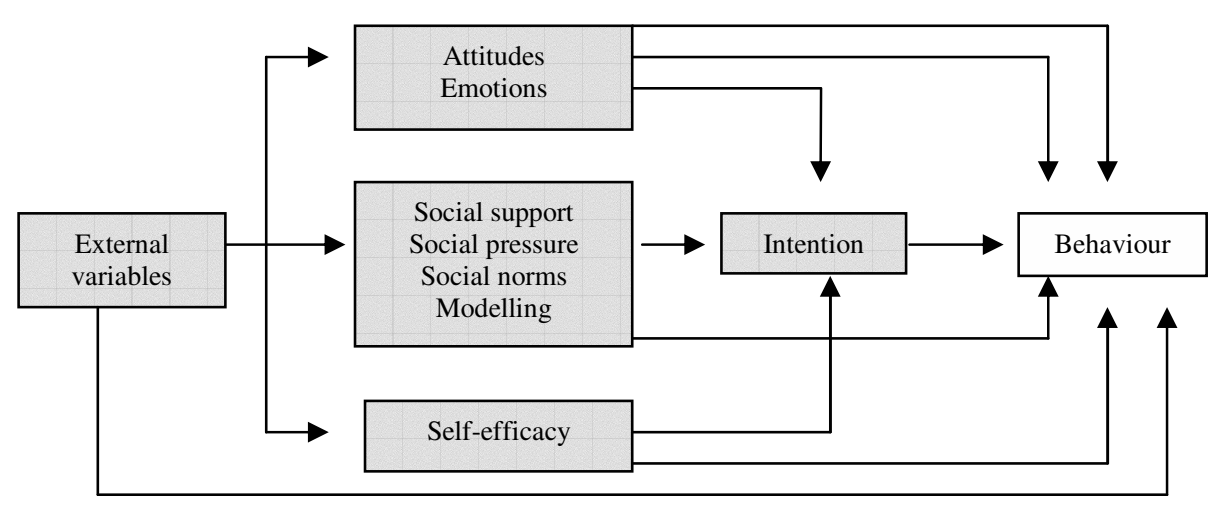

Figure 5.1 The ASE model ${ }^{33}$ 


\section{Methods}

\section{Participants and study design}

The study was started in 2002 in the south-eastern part of the Netherlands. Families were eligible when (1) the mothers were less than 7 months pregnant and (2) at least one firstdegree relative (mother, biological father, or sibling) had asthma that had been diagnosed by a doctor. Families were recruited by means of advertisements in local papers and posters in the practices of participating midwives. A family was excluded in case of intra-uterine or neonatal death, serious birth defects (illness or malformation), breast surgery that made mothers unable to breastfeed, major language barriers, or moving outside the Netherlands. Cluster randomisation at family practice level was carried out since the intervention could not be performed blindly and to avoid communication between the two study groups. A family practice was assigned using a randomisation list prepared by the statistical adviser when the first potential participant of a particular practice received information about the study. It was not possible to randomise after consent of the participant since the study information differed for both groups. Once the family practice had been allocated randomly as either a control or intervention practice, every family recruited afterwards that also attended that particular practice was automatically assigned to the same group. This clusterrandomised design resulted in 89 participating families who attended 84 different practices. The analyses were based at individual level rather than at cluster level since this is an almost one-to-one match.

The families in the intervention group of the trial were visited twice prenatal and once postnatal. During the visits the trained research assistant provided basic information about breastfeeding and asthma and other allergies (including a leaflet which was based on experiences of the target group and the social-psychological ASE model). The nutritional message was to breastfeed exclusively for six months and to postpone solid foods until the child had reached the age of six months. The families in the control group received the usual care according to the guidelines of the Dutch College of General Practitioners ${ }^{44}$ in which breastfeeding is recommended for six months to all babies in the Netherlands.

The ASE breastfeeding questionnaires were mailed to the participants (control and intervention group) and were completed early in pregnancy (between $3^{\text {rd }}$ and $6^{\text {th }}$ month) prior to exposure to the study intervention, and were collected during the first home visit, which took place before the $7^{\text {th }}$ month of pregnancy. Written informed consent was obtained from all participants. The Medical Ethical Committee of Maastricht University and the Maastricht University Hospital approved the study. 


\section{Data collection}

The ASE questionnaire on breastfeeding behaviour ${ }^{45}$ was developed on the basis of a literature search and two previous studies. The literature search, using Psychlit and Medline, identified additional important behavioural, psychosocial and external determinants regarding the intention to breastfeed. The first study identified salient beliefs regarding breastfeeding among asthmatic families through seven focus group interviews. ${ }^{45}$ The most important influencing factors regarding initiation and continuation of breastfeeding were health advantages for the baby, bonding, social support, modelling, knowledge about all the aspects of breastfeeding and breastfeeding confidence. ${ }^{45}$ This needs assessment gave meaning to the ASE concepts and external determinants, and as a result they were translated into measurable variables. In the second study, the questionnaire was piloted for readability and comprehensibility among 150 Dutch-speaking women who had a history of asthma and were pregnant or had recently given birth. The items needed only minimum adjustment as a result of the received comments. Exploratory factor analysis was conducted to summarize patterns of correlations among items and determine the plausible underlying structures of the questionnaire. The Kaiser-Meyer-Olkin measure of sampling adequacy exceeded the recommended 0.60 and a factor loading of 0.32 was required for an item to be retained for further analysis. ${ }^{46}$ More detailed information about the factor analysis is described elsewhere. ${ }^{47}$ The internal consistency estimates of the various concepts, using Cronbach's alpha, ranged from 0.79 to $0.89 .^{47}$ The prenatal breastfeeding questionnaire assessed the following variables.

\section{Definitions of the predictor variables}

\section{ASE Attitudinal beliefs}

A bipolar five-point scale was used to assess the positive and negative attitudinal beliefs (29 items) about breastfeeding behaviour with end points of totally agree $(+2)$ and totally disagree (-2). The positive attitudinal beliefs referred to what women might expect to gain by breastfeeding exclusively for six months, such as "Breastfeeding for six months will protect my child from developing eczema". The negative beliefs contained statements about negative consequences of breastfeeding for six months. An example is "Breastfeeding my child for six months requires a lot of effort". $(\alpha=0.87)$. Positive and negative emotions (10 items) were measured on five-point scales and contained the end points never (1) and very often (5). Women reported to what extent they anticipated positive or negative emotions regarding succeeding or failing to breastfeed exclusively for six months, for example "If I succeeded in breastfeeding for six months I would feel very proud". $(\alpha=0.91)$. A mean score was calculated for the attitudinal beliefs and emotions. 


\section{ASE Social influences}

Social norms were measured on bipolar five-point scores by one general item and eleven sub-questions assessing the normative beliefs of significant other people regarding breastfeeding ( $\alpha=0.86$ ). An example is "My mother thinks I should really breastfeed my child (+2) or should really not breastfeed my child" (-2). A mean score was calculated for each participant.

The extent of social support that women expected if they intended to breastfeed was measured on bipolar five-point scales (5 questions), with end points of totally agree $(+2)$ and totally disagree (-2). An example is "If I breastfeed my child, I can expect to receive enough practical help". ( $\alpha=0.71)$.

Social pressure was measured by one general item and four sub-questions on a five-point scale with end points never (5) and very often (1). An example is "Has anyone ever put pressure on you to bottle-feed your child?" $(\alpha=0.73)$. A mean score was calculated for both constructs.

Modelling was assessed by six questions, forming one modelling index score (yes/no; 0-6). This measured whether respondents knew other women who had breastfed their child, such as their mother, sister or a colleague.

\section{ASE Self-efficacy expectations}

Self-efficacy expectations were assessed by means of sixteen items in which respondents were asked to evaluate how certain they were to breastfeed for six months during different situations (e.g. when their child is sick, during holidays, when the mother is not feeling well), on bipolar five-point likelihood scales with end points of very certain $(+2)$ and very uncertain $(-2)$. $(\alpha=0.92)$. A mean score was calculated for the sixteen items.

\section{ASE Intention}

The item "Do you intend to breastfeed your child?" measured intention on a dichotomous scale (yes/no).

\section{Breastfeeding knowledge}

Breastfeeding knowledge was measured by twenty multiple-choice questions (right/wrong/ don't know). Item content included techniques for nursing a newborn, nutrition during lactation, milk supply, sore nipples, the law concerning breastfeeding during work time, and safe milk storage. Possible scores on the test ranged from 0 to 20, with a higher score reflecting greater knowledge about breastfeeding. 


\section{Previous breastfeeding experience}

Two items were used to measure the women's previous breastfeeding experience, "Did you ever breastfeed in the past?" and "How many weeks did you breastfeed your previous child ?" The two questions resulted in three categories: 1) no, primiparous 2) multiparous (0-5 weeks breastfeeding experience) and 3) multiparous ( $\geq 6$ weeks breastfeeding experience).

\section{Socio-demographic variables}

Information was obtained from the questionnaire about socio-demographic variables, such as maternal age, maternal educational level, maternal intended future employment status, duration of maternity leave, maternal smoking status, made choice for breastfeeding or formula before pregnancy, asthma level. Information about the following biomedical factors was gathered during a home visit three months post-partum: method of delivery, infant gender, infant birth weight, and place of delivery.

\section{Definition of the outcome variables}

\section{Intended duration}

Intended duration of breastfeeding was measured by asking the women to state the number of weeks they intended to exclusively breastfeed their child (number of weeks/ do not know yet). Women who responded with "I do not know yet" were considered to have zero weeks of intention.

\section{Initiation of breastfeeding}

The initiation of breastfeeding was measured by a self-report diary card which had been used in a previous study. ${ }^{48}$ The breastfeeding questionnaire, which was filled in at three months post-partum, contained control questions about breastfeeding behaviour. The diary cards were matched with the control questions in order to provide reliable and valid outcomes.

\section{Statistical analyses}

Values of Cronbach's alpha were computed to evaluate the internal consistency of the attitudinal beliefs, social influences and self-efficacy scores. Since this study contained 89 participants it was necessary to reduce the number of variables to be entered into the final analysis. 
A multiple lineair regression analysis with backward elimination was, therefore, carried out to determine which external determinants were significant predictors of the intended duration to breastfeed. The same procedure was carried out for the three main constructs of the ASE variables. The significant external variables (knowledge and choice breastfeeding before pregnancy) and the three ASE variables (attitudes, social norm and self-efficacy) were entered in two blocks in the final model. Multiple logistic regression analyses with backward elimination were carried out in order to determine which external variables and ASE variables were significant predictors of the initiation of breastfeeding. The significant external variables (previous experience, maternal smoking, intended employment status, knowledge and exposure to intervention), the ASE variables (attitudes, social norm and self-efficacy) and intention to breastfeed were entered in three blocks. The variable intention to breastfeed appeared to be more associated to the actual initiation than the variable intended duration. According to the ASE model, intention mediates the ASE variables and could, therefore, not be entered in a model with the ASE variables together, so the final regression analysis was performed with the significant external variables and intention to breastfeed in order to predict breastfeeding initiation. The baseline data from the intervention and control groups was combined for predicting the intention to breastfeed for six months since the data was collected prior to commencement of the study intervention. The exposure to the intervention programme was treated as a possible confounder in predicting the actual initiation. Statistical significance was assumed for $\mathrm{p}$ values $\leq 0.05$. All statistical analyses were performed using SPSS version 11.0.

\section{Results}

\section{Characteristics of participants}

A total of 113 families indicated interest in the study and received information. The families with no family history of asthma according to their general practitioner $(n=2)$, women who had experienced a miscarriage $(n=2)$ and women who had had breast surgery and were unable to breastfeed $(n=3)$ were excluded. Seventeen families did not give consent for a variety of reasons. The characteristics of the 89 participating women are presented by randomisation in Table 5.1. Maternal age in both groups was around 31 years, and the educational level was rather high in both groups (around 54\% could be regarded as having a high level of education). Almost $87 \%$ of the women in both groups had a positive intention to start breastfeeding and the average intended duration to breastfeed was around 13 weeks for the women in the intervention group and almost 18 weeks for the women in the control group. Furthermore, the majority of women $(67 \%)$ made their choice for breastfeeding or formula before pregnancy and only a few women in this study smoked during their pregnancy (4\%). 
Most of the women intended to return to work after their maternity leave (87\%) for an average of 19 hours per week, after a mean of 14 weeks of maternity leave.

Table 5.1 Socio-demographic and psychosocial characteristics of the participating mothers-infant pairs by randomisation ( $\mathrm{N}=89$ ), scales, number of items, item range, mean (SD) and Cronbach's alpha.

\begin{tabular}{|c|c|c|}
\hline & $\begin{array}{l}\text { Intervention } \\
(\mathrm{n}=44)\end{array}$ & $\begin{array}{l}\text { Control } \\
(\mathrm{n}=45)\end{array}$ \\
\hline Maternal age at birth of child & $31.0(4.1)$ & $31.9(3.6)$ \\
\hline \multicolumn{3}{|l|}{ Maternal education level ${ }^{(a)}$} \\
\hline Low & $1(2.3)$ & $4(8.9)$ \\
\hline Intermediate & $19(43.3)$ & $17(37.8)$ \\
\hline High & $24(54.4)$ & $24(53.3)$ \\
\hline Return to work after leave (yes) & $39(88.6)$ & $39(86.7)$ \\
\hline Duration of leave after birth (weeks) & $13.9(4.9)$ & $14.7(11.3)$ \\
\hline Hours work after leave (per week) & $19.4(10.1)$ & $18.1(10.1)$ \\
\hline \multicolumn{3}{|l|}{ Asthma level } \\
\hline Single (mot or fat. or sibling) & $43(97.7)$ & $44(97.8)$ \\
\hline Double (mot.+ fat. and/or sibling) & $1(2.3)$ & $1(2.2)$ \\
\hline Smoking during pregnancy (yes) & $2(4.5)$ & $2(4.4)$ \\
\hline \multicolumn{3}{|l|}{ Breastfeeding experience } \\
\hline Primiparous & $23(52.3)$ & $14(31.1)$ \\
\hline $0-5$ weeks experience & $5(11.4)$ & $10(22.2)$ \\
\hline$\geq 6$ weeks experience & $16(36.4)$ & $21(46.7)$ \\
\hline Feeding decision made before preg. & $31(70.5)$ & $29(64.4)$ \\
\hline \multicolumn{3}{|l|}{ Medical setting of birth ${ }^{(b)}$} \\
\hline Home & $14(31.8)$ & $18(40.9)$ \\
\hline Hospital & $30(68.2)$ & $26(59.1)$ \\
\hline \multicolumn{3}{|l|}{ Delivery $^{(b)}$} \\
\hline Vaginal & $34(77.3)$ & $41(93.2)$ \\
\hline Caesarean & $10(22.7)$ & $3(6.8)$ \\
\hline Birth weight in grams & $3388(590)$ & $3470(484)$ \\
\hline \multicolumn{3}{|l|}{ Gender of infant ${ }^{(c)}$} \\
\hline Boy & $20(43.5)$ & $24(52.2)$ \\
\hline Girl & $26(56.5)$ & $22(47.8)$ \\
\hline Intention to initiate breastfeeding & $37(84.1)$ & $40(88.9)$ \\
\hline Intended duration (weeks) & $13.2(15.5)$ & $17.7(22.9)$ \\
\hline
\end{tabular}




\begin{tabular}{|c|c|c|c|c|c|c|}
\hline & $\begin{array}{l}\text { Intervention } \\
(\mathrm{n}=44)\end{array}$ & $\begin{array}{l}\text { Control } \\
(n=45)\end{array}$ & Scale & $\begin{array}{l}\text { Items } \\
\text { (n) }\end{array}$ & Item range & $\begin{array}{l}\text { Cron } \\
\text { bach's } \\
\alpha\end{array}$ \\
\hline Attitudes & $0.42(0.60)$ & $0.52(0.50)$ & +2 to $-2^{1)}$ & 29 & $-1.2-1.8$ & 0.87 \\
\hline Emotions & $2.8(0.89)$ & $2.9(0.89)$ & $1-5^{2)}$ & 10 & $1.3-5.0$ & 0.91 \\
\hline Social norms & $0.68(0.57)$ & $0.65(0.46)$ & +2 to $-2^{3)}$ & 12 & $-0.42-2.0$ & 0.86 \\
\hline Social support & $1.25(0.54)$ & $1.11(0.76)$ & +2 to $-2^{4)}$ & 5 & $-1.0-2.0$ & 0.71 \\
\hline Social pressure & $4.5(0.55)$ & $4.7(0.47)$ & $1-5^{5)}$ & 5 & $2.8-5.0$ & 0.73 \\
\hline Modelling & $2.5(1.5)$ & $2.7(1.2)$ & $0-6$ & 6 & $0-6$ & NA \\
\hline Self-efficacy & $0.55(0.71)$ & $0.78(0.55)$ & +2 to $-2^{6)}$ & 14 & $-1.6-2.0$ & 0.92 \\
\hline Breastfeeding knowledge & $13.7(3.5)$ & $13.9(3.2)$ & $0-20$ & 20 & $6-20$ & NA \\
\hline \multicolumn{7}{|c|}{$\begin{array}{l}\text { a) low: completed primary school and vocational school, intermediate: completed intermediate secondary or vocational school, } \\
\text { and high: completed the highest level of secondary or vocational school or university. }\end{array}$} \\
\hline \multicolumn{7}{|l|}{ b) one missing value } \\
\hline \multicolumn{7}{|c|}{ c) total of 92 children due to three sets of twins } \\
\hline \multicolumn{7}{|c|}{${ }^{1)}+2=$ totally agree, $-2=$ totally disagree with advantages or with disadvantages of breastfeeding } \\
\hline \multicolumn{7}{|c|}{ 2) $1=$ never, $5=$ very often experiencing negative or positive emotions concerning breastfeeding } \\
\hline \multicolumn{7}{|c|}{ 3) $+2=$ I should really breastfeed my child, $-2=$ I should really not breastfeed my child } \\
\hline \multicolumn{7}{|c|}{ 4) $+2=$ totally agree, $-2=$ totally disagree to receive enough social support } \\
\hline \multicolumn{7}{|c|}{ 5) $5=$ never, $1=$ very often felt social pressure concerning breastfeeding } \\
\hline \multicolumn{7}{|c|}{${ }^{6)}+2=$ very certain to breastfeed for six months, $-2=$ very uncertain to breastfeed for six months } \\
\hline NA $=$ Not Applicable & & & & & & \\
\hline
\end{tabular}

\section{Predictors of intended duration to breastfeed}

According to the final multiple lineair regression analysis only the attitudes appeared to be significantly associated with the intended duration to breastfeed $(p=0.01)$, see Table 5.2.

Table 5.2. Results of multiple lineair regression analyses with intended breastfeeding duration in weeks as dependent variable, Beta, SE (standard error), $\mathrm{t}, \mathrm{p}$-values $(\mathrm{n}=89)$

\begin{tabular}{lllll}
\hline Variable & Beta & SE & t & $p$ \\
\hline Block 1 & & & & \\
Breastfeeding knowledge & 2.1 & 0.61 & 3.5 & $0.00^{*}$ \\
Choice for breastfeeding made before pregnancy & 7.7 & 4.3 & 1.8 & 0.08 \\
Block 2 & & & & \\
Breastfeeding knowledge & 0.72 & 0.68 & 1.1 & 0.29 \\
Choice for breastfeeding made before pregnancy & -0.78 & 4.5 & -0.17 & 0.86 \\
Attitudes & 14.6 & 5.4 & 2.7 & $0.01^{*}$ \\
Social norm & 0.35 & 3.9 & 0.09 & 0.92 \\
Self-efficacy & 3.7 & 4.6 & 0.79 & 0.43 \\
\hline
\end{tabular}

$\mathrm{R}^{2}=0.34, \mathrm{~F}=8.6 ; \mathrm{df}=5,83, p=0.00$

${ }^{*} p \leq 0.01$ 


\section{Predictors of breastfeeding initiation}

The intention to breastfeed taken early in pregnancy was predictive for the actual initiation of breastfeeding. Out of the women intending to breastfeed $88 \%(68 / 77)$ actually started with breastfeeding, while 33\% (4/12) of the women who had not intended to breastfeed also started with breastfeeding. The strongest independent predictor among the external determinants in the multivariate logistic regression was the level of breastfeeding knowledge, measured in the second trimester of pregnancy and was, thus, not influenced by the intervention programme. None of the variables appeared to make a significant contribution to initiation when the three ASE factors were added. The final model with intention as a determinant controlling for the external variables showed that intention was the significant predictor of breastfeeding initiation (OR: $8.2,95 \% \mathrm{CI}: 1.5-44.3, p=0.02$ ), see Table 5.3.

Table 5.3 Results of hierarchical multiple regression analyses with actual initiation as dependent variable, B's, Odds Ratios (OR), 95\% Confidence Interval (95\% CI) (n=89), *p $<0.05$

\begin{tabular}{|c|c|c|c|}
\hline Variable & $B$ & OR & $95 \% \mathrm{CI}$ \\
\hline \multicolumn{4}{|l|}{ Block 1} \\
\hline \multicolumn{4}{|l|}{ Previous breastfeeding experience } \\
\hline Primiparous & Reference & Reference & Reference \\
\hline Multiparous (0-5 weeks experience) & -1.5 & 0.23 & $0.05-1.1$ \\
\hline Multiparous ( $>6$ weeks experience) & 0.70 & 2.0 & $0.33-12.4$ \\
\hline Breastfeeding knowledge & 0.26 & 1.3 & $1.0-1.6 *$ \\
\hline Maternal smoking & 0.26 & 0.11 & $0.01-1.3$ \\
\hline Intended working status & 0.07 & 1.1 & $0.99-1.2$ \\
\hline Exposure to intervention group & 0.49 & 1.6 & $0.46-5.7$ \\
\hline \multicolumn{4}{|l|}{ Block 2} \\
\hline \multicolumn{4}{|l|}{ Previous breastfeeding experience } \\
\hline Primiparous & Reference & Reference & Reference \\
\hline Multiparous (0-5 weeks experience) & -1.1 & 0.32 & $0.06-1.8$ \\
\hline Multiparous (> 6 weeks experience) & -0.07 & 0.93 & $0.12-7.1$ \\
\hline Breastfeeding knowledge & 0.09 & 1.1 & $0.82-1.4$ \\
\hline Maternal smoking & -1.6 & 0.21 & $0.02-2.9$ \\
\hline Intended working status & 0.06 & 1.1 & $0.98-1.2$ \\
\hline Exposure to intervention group & 0.61 & 1.8 & $0.46-7.4$ \\
\hline Attitudes & 1.5 & 4.5 & $0.47-42.5$ \\
\hline Social norm & 0.73 & 2.1 & $0.32-13.6$ \\
\hline Self-efficacy & 0.01 & 1.1 & $0.17-7.5$ \\
\hline \multicolumn{4}{|l|}{ Block 3} \\
\hline \multicolumn{4}{|l|}{ Previous breastfeeding experience } \\
\hline Primiparous & Reference & Reference & Reference \\
\hline Multiparous (0-5 weeks experience) & -1.3 & 0.28 & $0.05-1.5$ \\
\hline Multiparous (> 6 weeks experience) & 0.29 & 1.3 & $0.19-9.4$ \\
\hline Breastfeeding knowledge & 0.18 & 1.2 & $0.93-1.5$ \\
\hline Maternal smoking & -2.1 & 0.12 & $0.01-1.6$ \\
\hline Intended working status & 0.06 & 1.1 & $0.98-1.2$ \\
\hline Exposure to intervention group & 0.82 & 2.3 & $0.56-9.3$ \\
\hline Intention to initiate breastfeeding & 2.1 & 8.2 & $1.5-44.3 *$ \\
\hline
\end{tabular}




\section{Discussion}

Breastfeeding exclusively for six months is important preventive health behaviour, despite the controversy about the outcomes of studies investigating the association between asthma and the protective effect of breastfeeding. From a public health point of view even a small protective effect would be important, since asthma is a highly prevalent chronic disease in children. $^{3}$

The objective of the present study was to examine prospectively which variables of the ASE model predict the intended duration and the actual initiation of breastfeeding in asthmatic families. The attitudinal beliefs were associated significantly with the intended duration and the breastfeeding intention was, in general, predictive for actual behaviour. It is difficult to compare the results of this study with other studies, since the target group here consisted of families in which a history of asthma was present a target group rarely studied before. The authors do not believe that this is a limitation of this study as it is particularly this high-risk group which might benefit from breastfeeding. ${ }^{9-10}$ Furthermore, many studies measured solely the intention to breastfeed and not the intended duration of breastfeeding. Since the target group in this study might benefit from exclusive breastfeeding for a longer period (six months) the researchers were especially interested in the determinants of long-term exclusive breastfeeding intention. Moreover, breastfeeding for at least six months requires other skills than breastfeeding for a few weeks, for example managing the combination of return to work and breastfeeding. ${ }^{49}$ In most studies, returning to work, appeared to be a barrier for starting and continuing to breastfeed. ${ }^{49,51}$ This study also showed that the intention to breastfeed was, in general, predictive for actual behaviour instead of the intended duration to breastfeed. It therefore seems that women who have a positive intention to breastfeed do, in general, start breastfeeding but do not necessarily have plans to breastfeed for a longer period of time. Finally, in contrast to many other studies, the definition "exclusive breastfeeding", as proposed in the recommendations made by the WHO, was used. Unfortunately, many studies used the less strict definition of breastfeeding, such as "any breastfeeding". Different definitions complicate the comparison of studies and furthermore the benefits of exclusive long-term breastfeeding are well known. ${ }^{17,20,25}$

As mentioned earlier, this study showed that maternal breastfeeding attitudes appeared to be a significant predictor of the intended breastfeeding duration. This finding is consistent with those of other studies in different populations. ${ }^{17-18,25}$ Nevertheless, most of these previous studies, which used a theoretical framework, showed that social norms and perceived behavioural control were also predictors of intention. An explanation could be that the outcome of those previous studies was the intention to breastfeed in general, rather than the intended duration to breastfeed, and that the target group in this study were highly educated, non-smoking asthmatic families, which were very motivated to breastfeed for a 
longer period of time, but had possibly an unrealistic positive view about long-term breastfeeding. Our pilot-study ${ }^{45}$ revealed that the majority of first-time mothers thought that breastfeeding is a natural behaviour which needs not much preparatory behaviour. It could be that this unrealistic confidence (in first-time mothers) resulted, for instance, in their scores at self-efficacy items not being discriminative enough to produce a significant predictor for intention. On the other hand, the construct of perceived behavioural control measures besides the perceived difficulty of the desired behaviour also the perceived ability of control. Therefore, it is difficult to compare the results with studies that used the PBC construct.

In our study group $81 \%$ of the women actually started to breastfeed. This percentage is comparable with the national initiation rates. Furthermore, this study showed that a positive intention to breastfeed is significantly associated with actual behaviour, in line with the assumption of the ASE model. Several previous studies also confirmed that intention is strongly associated with actual behaviour. ${ }^{15,37}$ Preliminary data show that our newly developed educational breastfeeding programme appeared to be effective in promoting exclusive breastfeeding for six months ( $48 \%$ vs. $27 \%, p=0.03)$. The complete results of the trial is described elsewhere. ${ }^{53}$

A limitation of this study is the open character of recruitment, on a volunteer basis, which may have contributed to the relatively high level of education of the mothers $(54 \%$ had a high level of education) and the low number of mothers who smoked during pregnancy (around 5\%). This may have had a positive influence on the motivation to start breastfeeding and may have restricted the external validity of this study. Despite this limitation, the present findings provide support for the belief that it is important that breastfeeding educational programmes motivate families early in pregnancy to breastfeed in order to increase breastfeeding intentions, since this study provided evidence that a positive intention is a strong predictor for actual behaviour.

\section{Acknowledgements}

This study was funded by a grant from the Dutch Asthma Foundation (3.2.99.39) and ZonMw (2300.0009). The authors would like to express their thanks to the research assistant, Anita Legtenberg, who contributed to the conception and design of the study. They are also grateful to Tessa Essing who imported the data and participated in the questionnaire pilot study. 


\section{References}

1. Metsemakers JFM, Hoppener P, Knottnerus JA, et al. Computerized health information in the Netherlands: a registration network of family practices. Br J Gen Pract 1992;42:102-106.

2. Knottnerus JA, Metsemakers J, Hoppener P, et al. Chronic illness in the community and the concept of 'social prevalence'. Fam Pract 1992;9:15-21.

3. Sears M. Epidemiology of childhood asthma. Lancet 1997;250:1015-1020.

4. Wold AE, Adlerberth I. Does breastfeeding affect the infant's immune responsiveness? Acta Paediatr 1998;87:19-22.

5. Kull I, Wickman M, Lilja G, et al. Breastfeeding and allergic diseases in infants- a prospective birth cohort study. Arch Dis Child 2002;87:478-481.

6. Oddy WH, Sly PD, de Klerk NH, et al. Breast feeding and respiratory morbidity in infancy: a birth cohort study. Arch Dis Child 2003;88:224-228.

7. Gdalevich M, Mimouni D, Mimouni M. Breastfeeding and the risk of bronchial asthma in childhood: A systematic review with meta-analysis of prospective studies. J Pediatr 2001;139:261-266.

8. Odijk van J, Kull I, Borres MP, et al. Breastfeeding and allergic disease: a multidisciplinary review of the literature (1966-2001) on the mode of early feeding in infancy and its impact on later atopic manifestations. Allergy 2003;58:833-843.

9. Sears MR, Greene. JM, Willan AR, et al. Long-term relation between breastfeeding and development of atopy and asthma in children and young adults: a longitudinal study. Lancet 2002:360:901-907.

10. Wright AL, Holberg CJ, Taussig LM, et al. Factors influencing the relation of infant feeding to asthma and recurrent wheeze in childhood. Thorax 2001;56:192-197.

11. WHO/UNICEF. The Innocenti declaration on the protection, promotion and support of breastfeeding. In Breastfeeding in the 1990's: A global initiative meeting in Florence, Italy and New York. Geneva, Switzerland. Geneva: WHO/UNICEF, 1990.

12. World Health Organization. Infant and Young Child Nutrition; Global strategy for Infant and Young Child Feeding. Executive Board Paper EB 109/12. WHO, Geneva, 2002.

13. Lanting CI, van Wouwe JP, Reijneveld SA. Infant milk feeding practices in the Netherlands and associated factors. Acta Paediatr 2005;94:935-942.

14. Scott JA, Landers MCG, Hughes RM, et al. Factors associated with breastfeeding at discharge and duration of breastfeeding. J Paediatr Child Health 2001:37;254-261.

15. Donath SM, Amir LH. Relationship between prenatal infant feeding intention and initiation and duration of breastfeeding: a cohort study. Acta Paediatr 2003:92;352-356.

16. Ajzen I, Fishbein M. Understanding attitudes and predicting social behavior. Englewood Cliffs: Prentice Hall 1980.

17. Kloeblen AS, Thompson NJ, Miner KR. Intent to breastfeed: the impact of attitudes, norms, parity, and experience. Am J Health Behavior 2002:26;182-187.

18. Manstead AS, Proffitt C, Smart JL. Predicting and understanding mothers' infant-feeding intentions and behavior: testing the theory of reasoned action. J Pers Soc Psychol 1983;44:657-671.

19. Ajzen I. The theory of planned behavior. Organizational Behavior and Human Decision Processes 1991;50:179-211.

20. Avery M, Duckett L, Dodgson J, et al. Factors associated with early weaning among primiparas intending to breastfeed. Matern Child and Health J 1998;2:167-179.

21. Dick MJ, Evans ML, Arthurs JB, et al. Predicting early breastfeeding attrition. J Hum Lact 2002;18:21-28.

22. Dodgson, JE, Henly SJ, Duckett L, et al. Theory of planned behavior-based models for breastfeeding duration among Hong Kong mothers. Nurs Res 2003;52:148-158.

23. Duckett L, Henly S, Avery M, et al. A theory of planned behavior-based structural model for breastfeeding. Nurs Res 1998;47:325-336. 
24. Khoury AJ, Moazzem W, Jarjoura, et al. Breastfeeding initiation in low-income women: role of attitudes, support, and perceived control. Womens Health Issues 2005;15:64-72.

25. Wambach KA. Breastfeeding intention and outcome: a test of the theory of planned behavior. Res Nurs Health 1997;20:51-59.

26. Swanson V, Power KG. Initiation and continuation of breastfeeding: theory of planned behavior. J Adv Nurs 2005;50:272-282.

27. DiGiralamo A, Thompson N, Martorell R, et al. Intention or experience. Predictors of continued breastfeeding. Health Educ Behav 2005;32:208-226.

28. Dennis C-L. Theoretical underpinnings of breastfeeding confidence: a self-efficacy framework. J Hum Lact 1999;15:195-201.

29. Buxton K, Gielen A, Faden R, et al. Women intending to breastfeed: Predictors of early infant feeding experiences. Am J Prev Med 1991;7:101-106

30. Ertem IO, Votto N, Leventhal JM. The timing and prediction of the early termination of breastfeeding. Pediatrics 2002;107:543-548.

31. Blyth R, Creedy DK, Dennis CL, et al. Effect of maternal confidence on breastfeeding duration: an application of breastfeeding self-efficacy theory. Birth 2002;29:278-284.

32. De Vries H, Backbier E. Self-efficacy as an important determinant of quitting among pregnant women who smoke: the phi-pattern. Prev Med 1994;23:167-174.

33. De Vries H, Mudde AN. Predicting stage transitions for smoking cessation applying the Attitude-Social influence-Efficacy model. Psychol Health 1998;13:369-385.

34. Brug J, Lechner L, de Vries H. Psychological determinants of fruit and vegetable consumption. Appetite 1995;25:285-296.

35. Lechner L, de Vries H, Offermans H. Participation in a breast cancer screening program: influence of past behavior and determinants on future screening participation. Prev Med 1997;26:473-482.

36. De Vries H, Backbier E, Kok G, et al. The impact of social influences in the context of attitude, selfefficacy, intentions and previous behavior as predictors of smoking onset. J Appl Soc Psychol 1995;25:237257.

37. Kools EJ, Thijs C, de Vries H. The behavioral determinants of breastfeeding in the Netherlands: predictors for the initiation of breastfeeding. Health Educ Behav 2005;6: 809-824.

38. Evans RI. Smoking in children: developing a social psychological strategy of deterrence Prev Med 1976;5:122-127.

39. Bandura A. Social foundations of thought and action: a social cognitive theory. Englewood Cliffs: Prentice Hall 1986.

40. Triandis HC. Interpersonal behavior. Montery, CA: Brooks/Cole, 1977.

41. Ajzen I. Perceived behavioral control, self-efficacy, locus of control, and the theory of planned behavior. $J$ Appl Soc Psychol 2002a;32:1-20.

42. Trafimow D, Sheeran P, Conner M, et al. Evidence that perceived behavioral control is a multidimensional construct: perceived control and perceived difficulty. Br J Soc Psyc 2002;41:101-121.

43. Motl RW, Dishman RK, Saunders RP, et al. Examining social-cognitive determinants of intention and physical activity among black and white adolescent girls using structural equation modeling. Health Psych 2002;32:459-467.

44. Dirksen WJ, Geijer GMM, de Haan M, de Koning G, Flikweert S, Kolnaar BGM. (1998). NHG-Standaard Astma bij Kinderen (eerste herziening) [NHG-standard Asthma in children (first revision)]. Huisarts en wetenschap 411:130-143.

45. Gijsbers B, Mesters I, Legtenberg AGH, et al. Factors influencing breastfeeding practices and postponement of solid food to prevent allergic disease in high-risk children: results from an explorative study. Patient Educ Couns 2005; 57:15-21.

46. Tabachnick BG, Fidell LS. (1991). Using multivariate Statistics. Harpers-Collins, New York.

47. Essing TMJ, Gijsbers B, Mesters I. Breastfeeding and asthma, extended essay, Maastricht University, 2003. 
48. Schönberger HJ, Maas T, Dompeling E, Knottnerus JA, van Weel C, van Schayck CP. Compliance of asthmatic families with a primary prevention program of asthma and effectiveness of measures to reduce inhalant allergens - a randomised trial. Clin Exp Allergy 2004;34:1024-1031.

49. Dennis, CL. Breastfeeding initiation and duration: 1990-2000 literature review. JOGNN 2002;3:12-32.

50. Vogel AM. Intended plans for breastfeeding duration: a simple tool to predict breastfeeding outcome. Acta Paediatr 2003;92:270-271.

51. Scott JA, Binns CW. Factors associated with the initiation and duration of breastfeeding: a review of the literature. Breastfeed Rev 1999;7:5-16.

52. Lawson K, Tulloch MI. Breastfeeding duration: prenatal intentions and postnatal practices. J Adv Nurs 1995;22:841-849.

53. Gijsbers B, Mesters I, Knottnerus JA, Kester ADM, van Schayck CP. The success of an educational program to promote exclusive breastfeeding for 6 months in families with a history of asthma: A randomised controlled trial. Pediatr Asthma Allergy Immunol. 2006;19:214-222. 



\section{6}

\section{Factors associated with the duration of exclusive breastfeeding in asthmatic families}




\begin{abstract}
This study was part of a randomised controlled trial in which verbal and written advice about exclusive breastfeeding for six months was provided to Dutch women expecting a child with a high-risk of developing asthmatic traits. Eighty-nine women completed a theory-based self-report questionnaire between the $3^{\text {rd }}$ and $6^{\text {th }}$ month of pregnancy, which served as the base-line measurement. The aim of this study was to examine the factors that influence the duration of exclusive breastfeeding. Cox multiple regression analysis showed a positive significant association between the duration of exclusive breastfeeding and the mother's breastfeeding knowledge $(p<0.01)$, her intended hours of work per week after maternity leave $(p<0.01)$, and her age $(p \leq 0.05)$. Short-term, that is less than 5 weeks, or no previous breastfeeding experience of multiparous women appeared to be negatively associated with the duration of breastfeeding $(p<0.001)$. Furthermore, women who received the educational programme were more likely to succeed in breastfeeding exclusively for six months than the control group ( $48 \%$ vs. $27 \%, p<0.05)$. This study suggests that extra educational support is beneficial, and especially necessary for multiparous women with an earlier short-term, less than 5 weeks, or no breastfeeding experience, since they are at risk of discontinuing exclusive breastfeeding before completing the advisable six-month period.
\end{abstract}




\section{Introduction}

Exclusive breastfeeding is internationally the preferred way of feeding infants during the first six months of their lives, and is recognized as being one of the most natural and best forms of preventive medicine ${ }^{1-2}$ The impact of breastfeeding on the development on allergies has been investigated for a long period of time. Exclusive breastfeeding has proved to protect against infection in infants, ${ }^{3-4}$ but the protective effect against respiratory illnesses remains controversial. ${ }^{5-9}$ Differences in study design, statistical methods and possible biases have complicated the interpretation of many studies. ${ }^{10}$ Nevertheless, a protective effect of exclusive breastfeeding for a longer period ( $>4$ months) on asthmatic traits in children at the age of 4 and 6 years has been demonstrated in a few studies. ${ }^{11-12}$ Moreover, it appeared that exclusive breastfeeding is especially beneficial for children with a predisposition for asthma, due to the preventive effect on the development of allergic symptoms. ${ }^{13-15}$

Even though recent Dutch figures indicate an increase in breastfeeding rates, the latest statistics still show that only $25 \%$ of Dutch mothers feed their children mainly breast milk during the first six months. ${ }^{16}$ Moreover, in a recent Dutch randomised trial (PREVASC study) that focused on families with a history of asthma, only $10 \%$ of the women in the experimental group, in which mothers were strongly advised to give exclusive breast milk for up to six months, actually did continue to breastfeed exclusively for six months. ${ }^{17}$ Factors that are responsible for cessation of breastfeeding have been studied previously. ${ }^{18-22}$ However, relatively few of these studies were founded on a theoretical framework even though using a framework can be helpful in explaining how the factors are related to each other, which is important when attempting to influence breastfeeding behaviour. ${ }^{23-25}$ Moreover, the influence of psychosocial factors on the duration of exclusive breastfeeding have seldom been studied, while attitudes, social influence and self-efficacy are more modifiable than socio-demographic factors and can, therefore, provide valuable information for future breastfeeding support programmes. ${ }^{18-20}$ This study was intended to rectify this situation by using the Attitude-Social influence-self-Efficacy model (ASEmodel). ${ }^{24-25}$ This approach was novel in that the ASE factors in relation to the duration of breastfeeding were collected from a specific target group, who could benefit in particular from breastfeeding exclusively for six months. The ASE-model has been successfully applied in several studies to explain various aspects of preventive health behaviour, such as, breast cancer screening, ${ }^{26}$ smoking cessation ${ }^{27}$ and recently also in predicting breastfeeding initiation. ${ }^{28}$ The ASE model has been influenced by several social cognition models and concepts such as the Theory of Planned Behaviour, ${ }^{29}$ concepts of social pressure $^{30}$ and Bandura's Social Learning theory (SLT) and his constructs of modelling and self-efficacy. ${ }^{31}$ The ASE model states, just as the TPB, that behaviour is a function of a person's intention. ${ }^{32}$ In the ASE model it is assumed that three types of proximal cognitive 
variables primarily determine behavioural intention: attitudinal beliefs, social influences, and self-efficacy expectations. The model also postulates that intention predicts subsequent behaviour. Furthermore, the distal or external variables, such as behavioural factors (e.g. previous experience and knowledge) and socio-demographic variables (e.g. age) are assumed to be moderated by the three proximal factors.

The aim of this study was to investigate which factors measured in the second trimester of pregnancy were predictors for the duration of exclusive breastfeeding in this specific group of women. The results of this present study will be used to improve the educational breastfeeding programme provided to families with a history of asthma.

\section{Method}

\section{Design and study population}

The study population participated in a cluster randomised controlled trial, which was started in 2002 in the south-eastern part of the Netherlands. Families were eligible when (1) the mothers were less than 7 months pregnant, and (2) at least one first-degree relative (mother, biological father, or sibling) had asthma that had been diagnosed by a doctor. Families were recruited from March 2002 till March 2003 using posters and flyers put up at the practices of participating midwives and advertisements in local papers. A family was excluded in case of intra-uterine or neonatal death, serious birth defects (illness or malformation), breast surgery of mother, major language problems, or moving outside the Netherlands. The participants were randomised at the family practice level in order to reduce the possibility of contamination. This cluster randomised design resulted in 89 participating families who attended 84 different practices. The analyses were based at individual level rather than at cluster level since this is an almost one-to-one match.

Written informed consent was obtained from all participants. The Medical Ethical Committee of Maastricht University and the Maastricht University Hospital approved the study.

\section{Intervention: an educational breastfeeding programme}

The nutritional message given by the educational programme was to breastfeed exclusively for six months and to postpone giving solid foods until the child reaches the age of six months. The families in the intervention group were visited twice prenatal and once postnatal. The trained research assistant provided basic information about breastfeeding, asthma and allergies, including a leaflet, during these visits. The educational programme was based on the principles of the ASE model ${ }^{24-25}$ and on the results of previously held focus group interviews among participants of the PREVASC study. ${ }^{17}$ 
The barriers and problems that families experienced concerning breastfeeding behaviour were discussed during the focus group interviews. Important topics arising from the focusgroups were integrated in a booklet. The booklet included practical information regarding breastfeeding and expressing milk alternated with the personal experiences of three mothers and one father that were used as models.

The families in the control group were visited once prenatal but received no information about breastfeeding, asthma and allergies. They received the usual care according to the guidelines of the Dutch College of General Practitioners ${ }^{33}$ in which breastfeeding is recommended for six months for all babies in the Netherlands.

\section{Data collection}

\section{Definition of the predictor variables}

Data concerning maternal and family characteristics were obtained from the mothers through a self-report breastfeeding questionnaire. ${ }^{34}$ This questionnaire, which was based on the ASE model, was piloted for readability and comprehensibility among 150 Dutchspeaking women who had a history of asthma and were pregnant or had recently given birth. ${ }^{35}$ The values of Cronbach's alpha for the internal consistency estimates of the various concepts ranged from 0.75 to $0.89 .{ }^{35}$ The questionnaire, which was filled in between the $3^{\text {rd }}$ and $6^{\text {th }}$ month of pregnancy, elicited the demographic information: e.g. maternal age, maternal educational level, and maternal intended future employment status. In the Netherlands the maternity leave has a legally minimum duration of sixteen weeks. The maternity leave begins 4-6 weeks before the expected date of birth. Information about the biomedical factors was gathered during a home visit three months post-partum. The ASE model components were measured as follows:

\section{ASE Attitudinal beliefs}

A bipolar five-point scale was used to assess the positive and negative attitudinal beliefs (29 items) about breastfeeding behaviour with end points of totally agree $(+2)$ and totally disagree (-2). The positive attitudinal beliefs referred to what women might expect to gain by breastfeeding exclusively for six months, such as "Breastfeeding for six months will protect my child from developing eczema". The negative beliefs contained statements about negative consequences of breastfeeding for six months. An example is "Breastfeeding my child for six months requires a lot of effort".

Positive and negative emotions (10 items) were measured on five-point scales and contained the end points never (1) and very often (5). Women reported to what extent they 
anticipated positive or negative emotions regarding succeeding or failing to breastfeed exclusively for six months, for example "If I succeeded in breastfeeding for six months I would feel very proud". A mean score was calculated for the attitudinal beliefs and emotions.

\section{ASE Social influences}

Social norms were measured on bipolar five-point scores by one general item and eleven sub-questions assessing the normative beliefs of significant other people regarding breastfeeding. An example is "My mother thinks I should really breastfeed my child $(+2)$ or should really not breastfeed my child" (-2). A mean score was calculated for each participant.

The extent of social support that women expected if they intended to breastfeed was measured on bipolar five-point scales (5 questions), with end points of totally agree $(+2)$ and totally disagree (-2). An example is "If I breastfeed my child, I can expect to receive enough practical help".

Social pressure was measured by one general item and four sub-questions on a five-point scale with end points never (5) and very often (1). An example is "Has anyone ever put pressure on you to bottle-feed your child?" A mean score was calculated for both constructs.

Modelling was assessed by six questions, forming one modelling index score (yes/no; 0-6). This measured whether respondents knew other women who had breastfed their child, such as their mother, sister or a colleague.

\section{ASE Self-efficacy expectations}

Self-efficacy expectations were assessed by means of sixteen items in which respondents were asked to evaluate how certain they were to breastfeed for six months during different situations (e.g. when their child is sick, during holidays, when the mother is not feeling well), on bipolar five-point scales with end points of very certain $(+2)$ and very uncertain (2). A mean score was calculated for the sixteen items.

\section{ASE Intention}

The item "Do you intend to breastfeed your child?" measured intention on a dichotomous scale (yes/no). 


\section{ASE Intended duration}

Intended duration of breastfeeding was measured by asking the women to state the number of weeks they intended to exclusively breastfeed their child (number of weeks/ do not know yet). Women who responded with "I do not know yet" were considered to have zero weeks of intention.

\section{ASE Intention-to-prepare}

Women were asked if they intended to read information, or prepare themselves otherwise to breastfeed for six months. Answers were on a bipolar 5-point scale.

\section{Breastfeeding knowledge}

Breastfeeding knowledge was measured by twenty multiple-choice questions (right/wrong/ don't know). Item content included techniques for nursing a newborn, nutrition during lactation, milk supply, sore nipples, the law concerning breastfeeding during work time, and safe milk storage. Possible scores on the test ranged from 0 to 20, with a higher score reflecting greater knowledge about breastfeeding.

\section{Definition of the outcome variable}

According to a recent study, ${ }^{36}$ in which the validity of maternal recall of breastfeeding practice was investigated, the ideal study design would be to assess breastfeeding patterns prospectively form birth and follow children over time to provide valid outcomes. In our study the parents registered their child's feeding behaviour daily on a diary card during the first six months post-partum. This diary card was also used in a previous study. ${ }^{17}$ Daily, the parents marked one of the following options: 1) breast milk, 2) formula, 3) breast milk and formula, 4) breast milk and solids (fruit or vegetables), 5) formula and solids, 6) breast milk and formula and solids. The breastfeeding questionnaire, contained control questions about breastfeeding behaviour and the introduction of solids. For example: "What was the first feeding your child received after birth?", and "How old was your child when you first introduced solids?" The diary cards were matched with the control questions in order to provide reliable and valid outcomes. Exclusive breastfeeding was defined according to the guidelines of the World Health Organisation (WHO) as a situation in which no other types of milk or solids were given except vitamins and minerals. ${ }^{1-2}$ The duration of exclusive breastfeeding was counted in weeks for the analysis. 


\section{Procedures}

The questionnaires were mailed to the participants between the $3^{\text {rd }}$ and $6^{\text {th }}$ month of pregnancy. The questionnaires were filled in before the first home visit took place and were collected during that particular visit.

\section{Data analysis}

Survival analysis was used to examine the duration of exclusive breastfeeding as it provides a good understanding of breastfeeding behaviour over time. This type of analysis was also used due to the presence of censored data. The term censored data refers to data from the women who continued to breastfeed exclusively beyond the advised 6 months (26 weeks). The duration of the non-starting mothers was set at 0.1 weeks; otherwise these women would be excluded from the analysis. Differences in baseline characteristics between the women who continued to breastfeed for at least six months compared to the women who discontinued prematurely were measured by several univariate Cox regression analyses.

Multiple Cox regression analysis with backward elimination was carried out to estimate the independent contribution and the corresponding hazard ratios (HR) of each considered external variable with respect to the duration of exclusive breastfeeding. A final multiple Cox regression analysis was used to determine which variables (including the external variables that contributed with statistical significance) were significantly associated with the duration of exclusive breastfeeding. The HR and the corresponding 95\% confidence intervals (CI) were calculated for these variables. The external variables of maternal age, hours of paid employment per week after maternity leave, decision on breastfeeding, breastfeeding knowledge and breastfeeding experience were entered together with the ASE variables in the final model. The variable "exposed to the breastfeeding programme" was treated as a possible confounder.

The data of the base-line measurement was used in the analyses for the present paper in order to avoid any effect on the psychosocial variables due to the intervention programme. Statistical significance was assumed for $\mathrm{p}$-values $\leq 0.05$. SPSS (version 11.0) was used for analysis. 


\section{Results}

\section{Participants}

A total of 113 families indicated interest in the study and received project information. The following participants were excluded: families with no family history of asthma according to their general practitioner $(n=2)$, women who had experienced a miscarriage $(n=2)$, and women who had had breast surgery and were unable to breastfeed $(n=3)$. Seventeen families did not return the informed consent form so that a final total of 89 families were enrolled in this study. The characteristics of the 89 women are shown in Table 6.1. The mean age of the women was 31.5 years. Less than half of the women were expecting their first child $(42 \%)$ and almost $87 \%$ of the women had a positive intention to start breastfeeding, with 36 (40\%) women intending to breastfeed for a period of six months. A high level of education was found for more than half of the women $(54 \%)$. The majority of the women $(67 \%)$ made their decision on breastfeeding before pregnancy and only a few women participating in this study smoked during their pregnancy (4\%). Most of the women had the intention of returning to work after their maternity leave (87\%) for an average of 19 hours per week, after a mean of 14 weeks of maternity leave when the child was born. There was no statistically significant difference in time point to go back to work for women with different educational levels. 
Table 6.1 Sociodemographic, biomedical and psychosocial characteristics of the participating mother-infant pairs. Hazard Ratios (HR), 95\% Confidence Intervals (95\% CI), ASE variables, scales, number of items and Cronbach's alpha $(\alpha)$ are shown.

\begin{tabular}{|c|c|c|c|c|c|c|}
\hline & $\begin{array}{l}\mathrm{N}=89 \\
(\%)\end{array}$ & $\mathrm{M}$ & $\begin{array}{l}\geq 6 \\
\text { months } \\
\text { bf } \\
(n=33)\end{array}$ & $\begin{array}{l}<6 \\
\text { months } \\
\text { bf } \\
(\mathrm{n}=56)\end{array}$ & HR & $95 \% \mathrm{CI}^{(\mathrm{a})}$ \\
\hline \multicolumn{7}{|l|}{ Sociodemographic factors } \\
\hline Maternal age in years at birth of child & & 31.5 & 32.3 & 31.0 & 0.93 & $0.86-1.00$ \\
\hline \multicolumn{7}{|l|}{ Maternal education level ${ }^{(\mathrm{b})}$} \\
\hline Low & 5.6 & & 6.1 & 5.4 & 1.00 & \\
\hline Intermediate & 40.4 & & 33.3 & 44.6 & 1.44 & $0.44-4.79$ \\
\hline High & 53.9 & & 60.6 & 50.0 & 0.96 & $0.29-3.16$ \\
\hline Intention to return to work & 87.6 & & 39.7 & 60.3 & 1.48 & $0.72-3.02$ \\
\hline Intended hrs work after maternity leave & & 18.7 & 21.7 & 17.0 & 0.98 & $0.95-1.00$ \\
\hline Maternity leave in weeks after birth & & 14.7 & 15.5 & 14.2 & 0.99 & $0.95-1.03$ \\
\hline \multicolumn{7}{|l|}{ Asthma level } \\
\hline Single (moth. or fath. and/or sibling) & 97.7 & & 96.9 & 98.2 & 1.00 & \\
\hline Double (moth.+ fath. and/or sibling) & 2.3 & & 3.1 & 1.8 & 0.88 & $0.12-6.36$ \\
\hline Smoking during pregnancy (yes) & 4.5 & & 0 & 7.1 & 2.68 & $0.95-7.33$ \\
\hline \multicolumn{7}{|l|}{ Biomedical factors } \\
\hline \multicolumn{7}{|l|}{ Medical setting of birth ${ }^{(c)}$} \\
\hline Home & 36.4 & & 42.4 & 32.7 & 1.00 & \\
\hline Hospital & 63.6 & & 57.6 & 67.3 & 1.25 & $0.71-2.20$ \\
\hline \multicolumn{7}{|l|}{ Delivery ${ }^{(\mathrm{c})}$} \\
\hline Vaginal & 85.2 & & 90.9 & 81.8 & 1.00 & \\
\hline Caesarean & 14.8 & & 9.1 & 18.2 & 1.24 & $0.72-2.84$ \\
\hline Birth weight in grams & & 3430 & 3338 & 3482 & 1.00 & $1.00-1.00$ \\
\hline \multicolumn{7}{|l|}{ Gender of infant ${ }^{(d)}$} \\
\hline Boy & 47.8 & & 57.6 & 48.2 & 1.00 & \\
\hline Girl & 52.2 & & 42.4 & 51.8 & 1.10 & $0.65-1.86$ \\
\hline \multicolumn{7}{|l|}{ Intervention programme } \\
\hline Control group & 50.6 & & 36.4 & 58.9 & 1.00 & \\
\hline Intervention group & 49.4 & & 63.6 & 41.1 & 0.59 & $0.35-1.00 *$ \\
\hline \multicolumn{7}{|l|}{ Psychosocial factors } \\
\hline Primiparous & 41.6 & & 45.5 & 39.3 & 1.00 & \\
\hline $0-5$ weeks experience & 16.9 & & 3.0 & 25.0 & 3.44 & $1.66-6.56^{* *}$ \\
\hline$\geq 6$ weeks experience & 41.6 & & 51.5 & 35.7 & 0.83 & $0.46-1.53$ \\
\hline Feeding decision before pregnancy & 67.4 & & 78.8 & 60.7 & 0.47 & $0.28-0.82 * *$ \\
\hline Intention to start breastfeeding & 86.5 & & 97.0 & 80.4 & 0.25 & $0.13-0.54 * *$ \\
\hline Intention to breastfeed for six months & 40.4 & & 51.5 & 33.9 & 0.54 & $0.31-0.95^{*}$ \\
\hline Known models who breastfeed (0-6) & & & 2.9 & 2.4 & 0.87 & $0.71-1.07$ \\
\hline Breastfeeding knowledge (0-20) & & & 15.2 & 12.9 & 0.89 & $0.82-0.95 * *$ \\
\hline
\end{tabular}


Continuation Table 6.1

\begin{tabular}{llllllll}
\hline ASE-variables & Scale & Items $(\alpha)$ & $\geq 6$ months & $<6$ months & HR & $95 \%$ CI \\
\hline Attitudes & +2 to $-2^{1)}$ & 29 & $(0.87)$ & 0.62 & 0.38 & 0.47 & $0.30-0.79^{*}$ \\
Emotions & $1-5^{2)}$ & 10 & $(0.91)$ & 3.06 & 2.74 & 0.78 & $0.58-1.05$ \\
Social norm & +2 to $-2^{3)}$ & 12 & $(0.86)$ & 0.80 & 0.58 & 0.51 & $0.30-0.93^{*}$ \\
Social support & +2 to $-2^{4)}$ & 5 & $(0.71)$ & 1.16 & 1.19 & 1.07 & $0.71-1.64$ \\
Social pressure & $1-5^{5)}$ & 4 & $(0.73)$ & 4.53 & 4.67 & 1.26 & $0.74-2.18$ \\
Self-efficacy & +2 to $-2^{6)}$ & 16 & $(0.92)$ & 0.86 & 0.55 & 0.52 & $0.36-0.80^{* *}$ \\
Intention-to-prepare & +2 to $-2^{7)}$ & 3 & $(0.69)$ & 0.79 & 0.66 & 0.88 & $0.71-1.12$ \\
\hline$* p \leq 0.05, * * p \leq 0.01$ & & & & & & &
\end{tabular}

$* p \leq 0.05, * * p \leq 0.01$

a) From univariate Cox regression analyses

b) low: completed primary school and vocational school, intermediate: completed intermediate secondary or vocational school, and high: completed the highest level of secondary or vocational school or university

c) One missing value

d) Total of 92 children due to three sets of twins

${ }^{1)}+2=$ totally agree, $-2=$ totally disagree with advantages or with disadvantages of breastfeeding

2) $1=$ never, $5=$ very often experiencing negative or positive emotions concerning breastfeeding

3) $+2=$ I should really breastfeed my child, $-2=$ I should really not breastfeed my child

4) $+2=$ totally agree, $-2=$ totally disagree that enough social support received

${ }^{5} 5=$ never, $1=$ very often felt social pressure concerning breastfeeding

$\left.{ }^{6}\right)+2=$ very certain to breastfeed for six months, $-2=$ very uncertain to breastfeed for six months

${ }^{7)}+2=$ totally agree should prepare yourself, $-2=$ totally disagree should prepare yourself

\section{Initiation and duration of exclusive breastfeeding}

Initiation of breastfeeding occurred in 78 (88\%) mother-infant pairs, and $62 \%$ and $37 \%$ of the infants were still being breastfed exclusively at the ages of 3 months and 6 months respectively.

\section{Control factors}

Demographic, biomedical factors and the exposure to the educational breastfeeding programme were analysed as possible confounders in relation to the duration of exclusive breastfeeding. When evaluated separately, only participation in the intervention group was significantly related to the duration of exclusive breastfeeding. In the simultaneous Cox regression analysis, which also included the psychosocial factors, the membership of the intervention group, the mother's future intended employment status and her age appeared to be statistically significant in relation to the duration of exclusive breastfeeding. 


\section{Study variables}

The HR estimated in the univariate Cox regression analysis are shown in Table 6.1. The mothers who continued to breastfeed exclusively for six months were more likely to have made the feeding choice before pregnancy $(p<0.01)$, to have a higher breastfeeding knowledge $(p<0.001)$, to have a positive intention to start breastfeeding $(p<0.001)$, to have a positive intention to breastfeed for six months $(p<0.05)$, to have more positive attitudes $(p<0.01)$, to have a higher social norm $(p<0.05)$, and a higher level of self-efficacy $(p<0.01)$ than the women who did not succeed in breastfeeding exclusively for six months. The mothers who discontinued breastfeeding before six months had either a previous short-term experience of breastfeeding or none at all. The HR estimated in the final Cox regression analysis are shown in Table 6.2 and separately in Figure 6.1. The following factors had a statistically significant, positive association with the duration of breastfeeding in the multivariate analysis: amount of hours of paid employment after maternity leave $(p<0.01)$, maternal age $(p \leq 0.05)$ and the women's breastfeeding knowledge $(p<0.01)$. A negative association with duration of breastfeeding was found for multiparous women with no or short-term breastfeeding experience $(p<0.001)$. Finally, participation in the intervention group had a significant positive association with the duration of exclusive breastfeeding $(p<0.05)$. It appeared that $48 \%$ of the women who received the educational programme continued to breastfeed exclusively for six months, compared to $27 \%$ of the controls.

Table 6.2 Factors shown to influence the duration of exclusive breastfeeding identified in the multiple Cox regression analysis

\begin{tabular}{lllll}
\hline & B & SE & Hazard Ratio (HR) & 95\% CI \\
\hline Experience & & & & Reference \\
$\quad$ Primiparous & Reference & Reference & Reference & $1.94-10.92^{* * *}$ \\
Multiparous (0-5 weeks experience) & 1.53 & 0.44 & 4.61 & $0.57-3.75$ \\
$\quad$ Multiparous ( $\geq 6$ weeks experience) & 0.38 & 0.48 & 1.31 & $0.77-0.98^{*}$ \\
Higher breastfeeding knowledge & -0.14 & 0.06 & 0.87 & $0.85-1.00^{*}$ \\
Higher maternal age & -0.08 & 0.04 & 0.92 & $0.93-0.99 * *$ \\
More hours work per week & -0.05 & 0.02 & 0.96 & $0.26-0.95^{*}$ \\
after maternity leave & & & & 0.50 \\
Exposure to breastfeeding programme & -0.70 & 0.33 & &
\end{tabular}



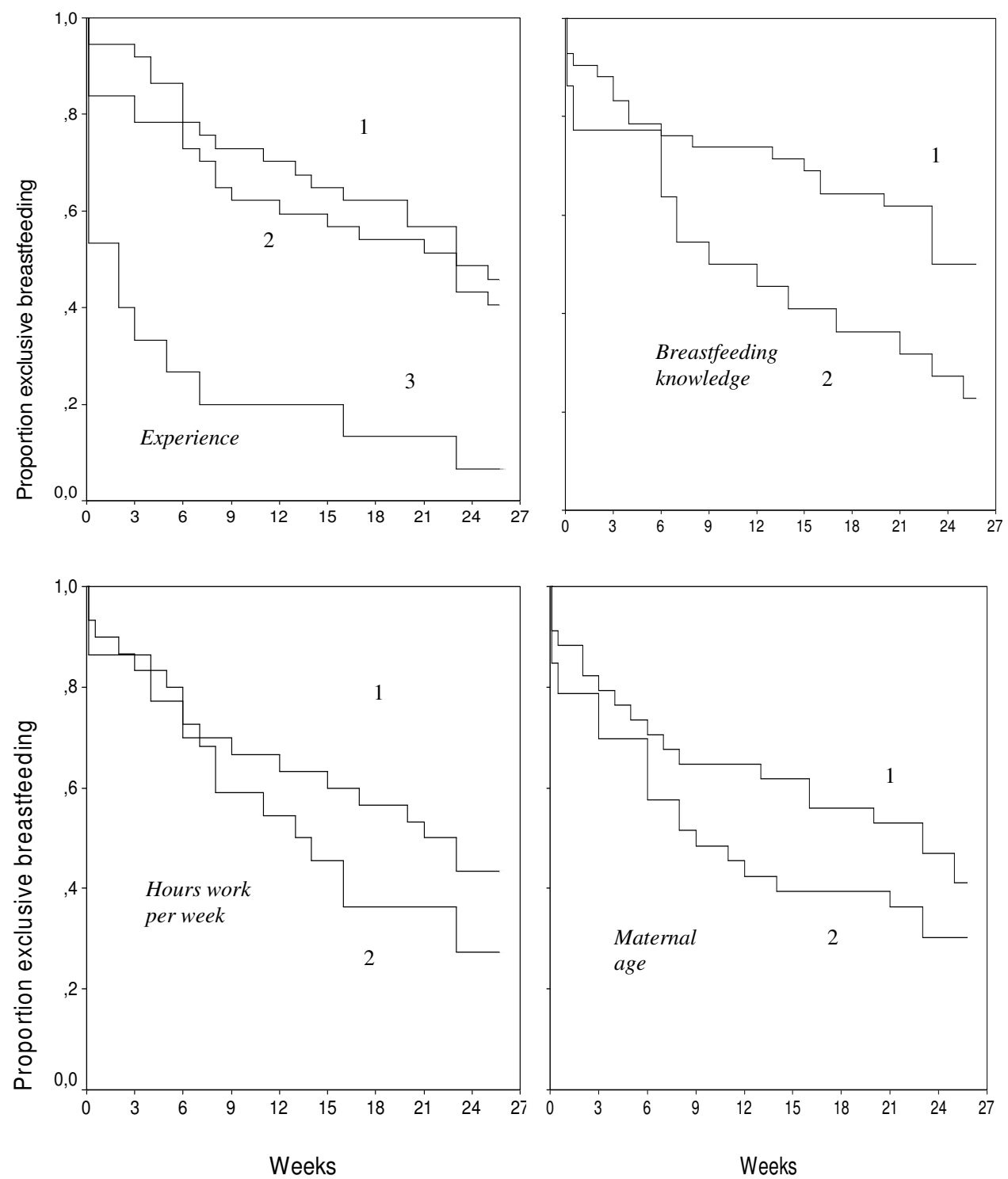

Figure 6.1 Proportion exclusive breastfeeding in relation to experience, knowledge, hours work per week, and maternal age. Numbers next to the curves refer to the categorisation. Experience: (1) multiparous $\geq 6$ weeks experience, (2) primiparous, (3) multiparous 0-5 weeks experience. Breastfeeding knowledge: (1) $15-20$ correct answers $\left(66^{\text {th }}\right.$ percentile), (2) 0-12 correct answers ( $33^{\text {rd }}$ percentile). Hours work per week after maternity leave: $(1) \geq 22$ hours per week $\left(66^{\text {th }}\right.$ percentile), $(2) \leq 16$ hours per week $\left(33^{\text {rd }}\right.$ percentile). Maternal age: $(1) \geq 33$ years $\left(66^{\text {th }}\right.$ percentile), $(2) \leq 30$ years $\left(33^{\text {rd }}\right.$ percentile). 


\section{Main reasons to stop breastfeeding exclusively}

The main reason for giving up exclusive breastfeeding, in both groups, appeared to be the perception that the amount of breastfeeding has been decreased. Thereafter, the obligation to return to work made many mothers introduce formula feeding. All reasons are listed in Table 6.3.

Table 6.3 Reasons for quitting exclusive breastfeeding before six months (78/89 women started to breastfeed)

\begin{tabular}{lll}
\hline Reasons & Intervention $(\mathrm{n}=18)$ & Control $(\mathrm{n}=27)^{*}$ \\
\hline Breastfeeding decreases & $5(28 \%)$ & $4 \quad(15 \%)$ \\
Return to work & $3(17 \%)$ & $2(7 \%)$ \\
Infant gained too less weight & $2(11 \%)$ & $1(4 \%)$ \\
Loss of freedom & $2(11 \%)$ & $1(4 \%)$ \\
Bad drinking technique infant & $1(6 \%)$ & $1 \quad(4 \%)$ \\
Medicine use mother & $1(6 \%)$ & $1 \quad(4 \%)$ \\
Hospital admission infant & $1(6 \%)$ & $1(4 \%)$ \\
Expressing milk was too difficult & $0(0 \%)$ & $2(7 \%)$ \\
Combination of complaints & $0(0 \%)$ & $3(11 \%)$ \\
Breastfeeding was painful & $0(0 \%)$ & $2(7 \%)$ \\
Infant was crying too much & $0(0 \%)$ & $1 \quad(4 \%)$ \\
Infant refused breast & $0(0 \%)$ & $1 \quad(4 \%)$ \\
Flat nipple & $0(0 \%)$ & $1 \quad(4 \%)$ \\
\hline
\end{tabular}

* one missing value

\section{Discussion}

Breastfeeding exclusively is important preventive health behaviour, despite the controversy about the outcomes of studies investigating the association between asthma and the protective effect of breastfeeding. From a public health point of view even a small protective effect would be important, since asthma is a highly prevalent chronic disease in children and breastfeeding behaviour is modifiable by breastfeeding programmes. ${ }^{37}$

The purpose of this paper was to investigate which factors measured in the second trimester of pregnancy were predictors for continuing to breastfeed exclusively for six months in this specific group of women. Firstly, it is no surprise that earlier, successful, breastfeeding experience influences the duration of breastfeeding the next child. However, this study showed that not only no earlier breastfeeding, but also a short previous breastfeeding experience in multiparous women, both predict early cessation of breastfeeding their next child. Unfortunately, other studies did not measure the duration or the quality of earlier experiences, so that in general these studies conclude that any previous breastfeeding experience was positively associated with breastfeeding the next child. ${ }^{38-41}$ It is informative that earlier negative or short-term breastfeeding experiences are predictors for future early 
cessation. These experiences of women cannot be undone, but discussing the things that went wrong with a health professional, for example, a midwife or general practitioner, may help to overcome barriers in the future. Therefore, it seems relevant to always ask women with previous breastfeeding experience about the quality and duration of this.

Secondly, the number of hours per week the mother planned to return to paid employment was positively associated with the duration of exclusive breastfeeding. This is remarkable since most studies reported a negative association between the intention to return to work after maternity leave and the duration of breastfeeding or no association at all. ${ }^{42-44}$ An explanation could be that working mothers in industrialised countries such as the Netherlands, who are ambitious concerning their working career, might also be better organizers than women who stay at home or who only return part-time to their job. In addition, another hypothesis is full-time working mothers' may have a feeling of guilt not spending enough time with their child and compensate by offering their child the best possible nutrition.

Thirdly, this study confirmed the importance of mother's breastfeeding knowledge as has been shown in previous studies. ${ }^{45-50}$ A higher knowledge level early in pregnancy was associated with a longer duration of exclusive breastfeeding. Therefore, an important goal for educational programmes is to inform women early in pregnancy about the advantages, and more importantly to prepare them for common problems regarding breastfeeding, and to outline a realistic picture and not to give fantasy stories.

Fourthly, maternal age was found to be a predictor for continuation of breastfeeding just as was found in previous studies. Age above 25 years has been repeatedly associated with a longer duration of breastfeeding. ${ }^{18-19}$ It is probable that older women know more about the benefits of breastfeeding and have more realistic outcome expectations. ${ }^{51}$

Finally, it seems remarkable that not a single ASE factor in the final multiple regression analysis was significantly associated with the duration of exclusive breastfeeding, although the univariate analysis showed that self-efficacy, attitudes, social norm and intention do have a significant relation with the duration of exclusive breastfeeding. A recent prospective study, which measured social cognition model components, showed in a multivariate analysis that mother's knowledge, her intention, previous breastfeeding experience, and self-efficacy appeared to be associated with exclusive breastfeeding duration up to 4 months. ${ }^{49}$ Swanson and Power $^{23}$ used the TPB and concluded that subjective norms were important determinants for continuation to breastfeed exclusively the first six weeks. We failed to show any independent association between exclusive breastfeeding duration for up to six months and a social cognition model component, such as self-efficacy or subjective norms, in a multivariate model. Nevertheless, the ASE factors are implicitly associated with the duration of exclusive breastfeeding for up to six months, since the educational ASE model breastfeeding programme appeared to be a significant contributor in the final multivariate model. 
The majority of women (88\%) participating in this study started breastfeeding. The proportion of children who still received breast milk exclusively after six months was $37 \%$. It could be that the predisposition for asthma in the families may have made these women more knowledgeable and sensitive about the preventive effects of exclusive breastfeeding and was, therefore, responsible for the relatively high breastfeeding rate in this study. The authors do not believe that this is a limitation of this study as it is particularly this high-risk group which might benefit from breastfeeding. On the other hand, a substantial proportion of the participants belonged to a relatively higher educated study group and had a low smoking status so that this may restrict the external validity. It is known from other breastfeeding studies that non-smoking women with a high educational level are more motivated to start breastfeeding than women with a lower educational level who smoke. ${ }^{52-54}$ Furthermore, the breastfeeding programme introduced to half of the women and/or the exposure of the psychosocial determinants assessment (instrument reactivity) in all women by means of the extended breastfeeding questionnaires might have influenced the overall breastfeeding prevalence and duration. Moreover, taking part in a trial can motivate people to do well since they are part of a scientific project in which they are being followed. Finally, the modest sample size $(n=89)$ might have limited the extent to which significant associations between the independent variables and the duration of exclusive breastfeeding could be detected.

In summary, the findings illustrate that it is essential to ask women about their previous breastfeeding experience - in terms of duration and quality - and to discuss reasons for previous failures or barriers. These women might not have the motivation and the tools to face the common problems. Women's confidence should be boosted, so that they will be strong enough to overcome early-stage breastfeeding problems. Clear and realistic breastfeeding information ('it is not easy, but worthwhile') given early in pregnancy will motivate and prepare women to start and to continue to breastfeed exclusively for up to six months. Implications for future intervention are the need to emphasise the benefits of longer continuation of breastfeeding and to prepare women psychologically and practically so that they will succeed in breastfeeding for a longer period. The special breastfeeding educational programme for families with a predisposition for asthma helps to improve breastfeeding rates and should be actively included in the prenatal activities of the midwives or general practitioners and public health nurses for this specific target group. 


\section{Acknowledgements}

The authors would like to express their thanks to the research assistant, Anita Legtenberg, who contributed to the conception and design of the study. They are also grateful to Marieke Vriend who assisted in importing the data and to dr. A.D.M. Kester for his statistical advice. This study was funded by a grant from the Dutch Asthma Foundation (3.2.99.39) and ZonMw (2300.0009). 


\section{References}

1. WHO/UNICEF. The Innocenti declaration on the protection, promotion and support of breastfeeding. In Breastfeeding in the 1990's: A global initiative meeting in Florence, Italy and New York. Geneva, Switzerland. Geneva: WHO/UNICEF, 1990.

2. World Health Organization (2002). Infant and Young Child Nutrition; Global strategy for Infant and Young Child Feeding. Executive Board Paper EB 109/12. WHO, Geneva.

3. Wright AL, Tausing LM, Ray GC, et al. The Tuscon Children's Respiratory Study II. Lower respiratory tract illness in the first year of life. Am J Epidemiol 1998;129:1232-1246.

4. Howie PW, Forsyth JS, Ogston SA, et al. Protective effect of breastfeeding against infection. BMJ 1990;300:11-16.

5. Sears MR, Greene JM, Willan R, et al. Long-term relation between breastfeeding and development of atopy and asthma in children and young adults: a longitudinal study. Lancet 2002;360:901-907.

6. Sly PD, Holt PG. Breast is best for preventing asthma and allergies- or is it? [editorial]. Lancet 2002;360:887-888.

7. Becquet R, Leroy V, Salmi LR. Breastfeeding, atopy, and asthma [letter]. Lancet 2003;361:174-176.

8. Boelens JJ. Breastfeeding, atopy, and asthma. [letter]. Lancet 2003;361:174-175.

9. Murray E. Breastfeeding, atopy, and asthma. [letter]. Lancet 2003;361:174-176.

10. Oddy WH, de Klerk NH, Sly PD, et al. The effects of respiratory infections, atopy, and breastfeeding on childhood asthma. Eur Respir J 2002;19:899-905.

11. Oddy WH, Holt PG, Sly PD, et al. Association between breastfeeding and asthma in 6 year old children: findings of a prospective birth cohort study. BMJ 1999;319:815-819.

12. Kull I, Almquist C, Lilja G, et al. Breast-feeding reduces the risk of asthma during the first 4 years of life. $J$ Allergy Clin Immunol 2004;114:755-760.

13. Gdalevich M, Mimouni D, Mimouni M. Breast-feeding and the risk of bronchial asthma in childhood: A systematic review with meta-analysis of prospective studies. J Pediatr 2001;139:261-266.

14. Saarinen MA, Kajosaari M. Breastfeeding as prophylaxis against atopic disease: prospective follow-up study until 17 years old. Lancet 1995;346:1065-1069.

15. Van Odijk J, Kull I, Borres MP, et al. Breastfeeding and allergic disease: a multidisciplinary review of the literature (1966-2001) on the mode of early feeding in infancy and its impact on later atopic manifestations. Allergy 2003;58:833-843.

16. Lanting CI, van Wouwe JP. Breastfeeding in the Netherlands 2005: a provisional report. TNO-report; KVL JPB2005.212.

17. Schönberger HJ, Maas T, Dompeling E, et al. Compliance of asthmatic families with a primary prevention programme of asthma and effectiveness of measures to reduce inhalant allergens - a randomised trial. Clin Exp Allergy 2004;34:1024-1031.

18. Scott JA, Aitkin I, Binns CW, et al. Factors associated with the duration of breastfeeding amongst women in Perth, Australia. Acta Ped 1999;88:416-421.

19. Scott JA, Landers MC, Hughes RM, et al. Factors associated with breastfeeding at discharge and duration of breastfeeding. J Paediatr Child Health 2001;37:254-261.

20. Riva E, Banderali G, Agostoni C, et al. Factors associated with initiation and duration of breastfeeding in Italy. Acta Paediatr 1999;88: 411-415.

21. Anderson AS, Guthrie CA, Alder EM, et al. Rattling the plate- reasons and rationales for early weaning. Health Educ Res 2001;4:471-479.

22. Digirolamo A, Thompson N, Martorell R, et al. Intention or experience? Predictors of continued breastfeeding. Health Educ Behav 2005;32:208-226.

23. Swanson V, Power KG. Initiation and continuation of breastfeeding: theory of planned behavior. J Adv Nurs 2005;50:272-282. 
24. De Vries H, Backbier E. Self-efficacy as an important determinant of quitting among pregnant women who smoke: the phi-pattern. Prev Med 1994;23:167-174.

25. De Vries H, Mudde AN. Predicting stage transitions for smoking cessation applying the Attitude-Social influence-Efficacy model. Psychol Health 1998;13:369-385.

26. Lechner L, de Vries H, Offermans H. Participation in a breast cancer screening program: influence of past behavior and determinants on future screening participation. Prev Med 1997;26:473-482.

27. De Vries H, Backbier E, Kok G, et al. The impact of social influences in the context of attitude, selfefficacy, intentions and previous behavior as predictors of smoking onset. J Appl Soc Psychol 1995;25:237257.

28. Kools EJ, Thijs C, De Vries H. The behavioral determinants of breastfeeding in the Netherlands: predictors for the initiation of breastfeeding. Health Educ Behav 2005;6:809-824.

29. Ajzen I. The theory of planned behavior. Organizational Behavior and Human Decision Processes 1991; 50:179-211.

30. Evans RI. Smoking in children: developing a social psychological strategy of deterrence Prev Med 1976; 5:122-127.

31. Bandura A. Social foundations of thought and action: a social cognitive theory. Englewood Cliffs: Prentice Hall 1986.

32. Manstead AS, Proffitt C, Smart JL. Predicting and understanding mothers' infant-feeding intentions and behavior: testing the theory of reasoned action. J Pers Soc Psychol 1983;44:657-671.

33. Dirksen, WJ, Geijer GMM, de Haan M, et al. NHG-standard Asthma in children (first revision). Huisarts en wetenschap 1998;411:130-143.

34. Gijsbers B, Mesters I, Legtenberg AHG, et al. Factors influencing breastfeeding practices and postponement of solid food to prevent allergic disease in high-risk children: results from an explorative study. Patient Educ Couns 2005;57:15-21.

35. Essing TMJ, Gijsbers B, Mesters I. Breastfeeding and asthma, extended essay, Maastricht University, 2003.

36. Li R, Scanlon KS, Serduala MK. The validity and reliability of maternal recall of breastfeeding practice. Nutr Rev 2005;63:103-110.

37. Sears MR. Epidemiology of childhood asthma. Lancet 1997;350:1025-1020.

38. Barber CM, Abernathy T, Steinmetz B, et al. Using a breastfeeding prevalence survey to identify a population for targeted programs. Can J Pub Health 1997;13:242-245.

39. Bourgoin G, Lahaie R, Rheaume B, et al. Factors influencing the duration of breastfeeding in the Sudbury region. Can J Pub Health 1997;88:238-241.

40. Humenick S, Hill P, Spielberg R. Breastfeeding and health professional encouragement. J Hum Lact 1998;14:305-310.

41. Nagy E, Orvos H, Pal A, et al. Breastfeeding duration and previous experience. Acta Paediatr 2001;90:5156.

42. Papinczak TA, Turner CT. An analysis of personal and social factors influencing initiation and duration of breastfeeding in large Queensland maternity hospital. Breast Rev2000;8:25-33.

43. Williams PL, Innis SM, Vogel AM, et al. Factors influencing infant feeding practices of mothers in Vancouver. Can J Public Health 1999;90:114-119.

44. Piper S, Parks P. Predicting the duration of lactation: Evidence from a national survey. Birth 1996;23:7-12.

45. Duckett L, Henley S, Avery M, et al. A theory of planned behaviour-based structural model for breastfeeding. Nur Res 1998;47:325-336.

46. Chezem J, Friesen C, Boettcher J. Breastfeeding knowledge, breastfeeding confidence, and infant feeding plans: effect on actual feeding practices. J Obstet Gynecol Nenonatal Nurs 2003;32:40-47.

47. Avery M, Duckett L, Dodgson J, et al. Factors associated with early weaning among primiparas intending to breastfeed. Matern Child Health J 1998;3:167-179.

48. Wambach KA. Breastfeeding intention and outcome: a test of the theory of planned behaviour. Res Nurs Health 1997;20:51-59. 


\section{Chapter 6}

49. Kronborg H, Veath M. The influence of psychosocial factors on the duration of breastfeeding. Scan J Public Health 2004;32:210-216.

50. Mitra AK, Khoury AK, Hinton AW, et al. Predictors of breastfeeding intention among low-income women. Matern Child Health J 2004;8:65-70.

51. Lawson K, Tulloch MI. Breastfeeding duration: prenatal intentions and postnatal practices. $J A d v$ Nurs 1995;22:841-849.

52. Ford K, Labbok M. Who is breast-feeding? Implications of associated social and biomedical variables for research on the consequences of method of infant feeding. Am J Clin Nutr 1990;52:451-456.

53. Scott JA, Binns CW. Factors associated with the initiation and duration of breastfeeding: a review of the literature. Breastfeed Rev 1999;7:5-26.

54. Ynvge A, Sjostrom M. Breastfeeding determinants and a suggested framework for action in Europe. Public Health Nutr 2001;4:729-739 
7

General discussion 



\section{General discussion}

This thesis describes the effectiveness of a novel breastfeeding (BF) educational programme, aimed at stimulating mothers to breastfeed their newborns for six months, and assesses relevant predictors for initiation and continuation of BF during this period. This study originates from an asthma prevention programme (PREVASC), whose goal was to prevent asthma in high-risk children by avoiding exposure to several allergens simultaneously, such as environmental tobacco smoke, house dust mite and food allergens. With regard to food allergens, compliance with breastfeeding for the duration of six months appeared to be very low. ${ }^{1}$ Therefore, the main aim of the present study was to develop a programme that would be able to increase the proportion of women that would continue to breastfeed for the full six months.

This chapter will describe the main findings of this research project, examine methodological issues, discuss the results in the context of the implications for practice, and propose future research questions. When $\mathrm{BF}$ is mentioned in this chapter, it means exclusive BF, without introducing solids or other liquids.

\section{Main findings}

The first study aimed at assessing relevant factors that influenced the initiation and completion of six-month BF among asthmatic families where the woman had recently delivered a child. This qualitative study used focus-group interviews, which revealed that health advantages for the baby, social support, modelling (seeing other women breastfeed), knowledge about all the aspects of $\mathrm{BF}$ and $\mathrm{BF}$ confidence were related to the decision to breastfeed and to continue long-term BF (Chapter 2). The results of the qualitative study served as a guideline for developing a new BF educational programme.

The aim of the second study was to evaluate the effectiveness of our newly developed theory-driven BF educational programme. The theory-based programme included pre- and postnatal home visits combined with a booklet. The intervention appeared to be effective as compared to the control group in increasing the proportion of women who completed breastfeeding for the first six months (Chapter 3). Furthermore, we investigated which elements contributed to success and emerged as factors influenced by exposure to the programme. Attitudinal beliefs and BF knowledge appeared to have been significantly increased in those women who took part in the BF programme (Chapter 4).

Our final aim was to investigate which factors from the Attitude-Social influence-Selfefficacy (ASE) model were able to predict the intended duration, initiation and continuation of BF behaviour in asthmatic families (Chapters 5 and 6). The intended duration was significantly associated with attitudinal beliefs. Furthermore, intention during pregnancy 
was the strongest predictor for actual initiation of BF. These results confirmed the assumption of the ASE model that intention is the most important predictor for actual behaviour and mediates the influences of other predictors. Positive significant associations were found between the continuation of BF and the mother's BF knowledge, the number of weekly hours she intended to work after maternity leave, and her age. No previous or not more than five weeks' BF experience by multiparous women appeared to be negatively associated with the continuation of BF. Moreover, the most often mentioned reason for stopping BF was that the women had the feeling that their amount of breast milk had decreased, followed by their return to work as the second most common reason.

\section{Methodological considerations}

Some methodological issues and possible limitations, but also the strengths of the study, should be taken into account when interpreting the findings.

\section{Recruitment and identification of high-risk infants}

Since general practitioners (GPs) and midwives in the south of the Netherlands were overloaded with scientific projects, we were forced to conduct an 'open recruitment' in order to include the required participants in a defined time period. We put up posters in more than a hundred midwife practices and advertised in local papers. As might be expected, this procedure resulted in an overrepresentation of highly educated participants. Before these women could be included in the study, their GP had to confirm their high-risk status, i.e., the occurrence of asthma in father, mother or sibling(s). This is a strong point of our study since several other intervention studies recruited high-risk infants on the basis of self-reported asthma/allergy in first-degree relatives with the risk of recall bias. ${ }^{2-3}$

\section{Design and randomisation}

Another strength of this study was the longitudinal randomised controlled design. The follow-up period lasted until six months post partum and was longer than most comparable studies regarding $\mathrm{BF}^{4-5}$

The trial families were allocated to either the intervention or control groups by means of pre-randomisation in clusters. These clusters were based on the ZIP code of the location of the participating families' GP. A family practice was assigned to the control or intervention group using a randomisation list prepared by the statistical adviser when the first potential participant of a particular practice received information about the study. Once the family practice had been allocated randomly as either a control or intervention practice, every family recruited thereafter which also attended that particular practice was automatically 
assigned to the same group. This pre-randomisation in clusters was carried out to avoid communication between the two study groups since the intervention (promoting BF) could not be performed blindly. Furthermore, the control group was not informed about the comparison with the intervention group (when asked for informed consent), but was told that the aim of the study was to explore what causes the development of asthma in children. This method was used because it was the only reliable way to avoid contamination and unwanted exchange of information on food allergen exposure between the intervention and the control groups. ${ }^{1}$

The cluster-randomised design resulted in 89 participating families, who attended 84 different practices. The analysis was based at individual level rather than at cluster level since this was an almost one-to-one match.

\section{Representativeness of the study population}

In Chapter 3 we reported that the number of smoking and low-educated mothers in our study was not representative as compared to the Dutch population at large. However, level of education was no predictor for initiation or duration of BF. Both relatively high- and low-level education groups benefited from the intervention. Furthermore, the initiation rate in our study group was $81 \%$ and was comparable to the $78 \%$ in the Dutch population in 2002-2003. ${ }^{6}$ Still, non-representativeness might reduce the external validation or, in other words, the extrapolation to the general Dutch population. Implementation in daily practice will need to reveal whether the programme is also effective in low-educated and smoking women and in other regions in the Netherlands. Apparently there are large regional differences in BF rates in the Netherlands. In the southern regions - where the study took place - BF prevalence at six months is one of the lowest in the country. This must be taken into account when interpreting the results of the different parts of this study.

In addition, it is important to keep in mind that the present BF educational programme was written for women pregnant with a predisposed child who were willing to breastfeed. Those who did not even want to consider BF require a different approach from the programme presented in this thesis. The goal of the current programme was to enable motivated women to breastfeed for the full six months.

\section{Hawthorne effect and instrument reactivity}

Despite efforts to avoid "spontaneous" preventive behaviour in the control group by means of cluster randomisation and not informing the control group about the intervention, the socalled "Hawthorne effect" ${ }^{7}$ in which the very fact of participating in a research project leads to higher compliance rates could have increased the BF duration rates in both groups. Moreover, changes in BF behaviour may be induced by the questionnaires (instrument 
reactivity). Thus, the relatively high percentage of women in the control group who succeeded in breastfeeding for six months (27\%) may be due to a possible intervention effect from repeatedly filling out questionnaires about BF for six months. The completion of such questionnaires might have triggered and influenced the feeding choice and $\mathrm{BF}$ duration of the pregnant women in the control group, but this provides no explanation for the even higher percentage in the intervention group. Both intervention and control groups received the same questionnaires.

\section{Definition of BF outcome and assessment of BF behaviour}

In many studies, the definition of BF is not clear. Studies often use the definition of "any BF" or "complementary BF" despite the recommendation of the WHO to breastfeed exclusively for at least six months. Also the term "mainly breastfed" appears often and means that infants were not only given breast milk but probably solid foods as well. This makes comparison of effectiveness studies difficult. One strong point of the present study was the use of the definition of BF according to the guidelines of the WHO as a situation in which no other types of milk or solids were given except vitamins and minerals. ${ }^{8-9}$ To minimise the chance of recall bias we used pre-printed diaries. Each day the parents marked one of the following options: 1) breast milk, 2) formula, 3) breast milk and formula, 4) breast milk and solids (fruit or vegetables), 5) formula and solids, and 6) breast milk and formula and solids. Hopefully future studies will also use the definition as formulated by the WHO and record infant feeding data daily to improve comparability of programme results.

\section{What this research adds}

Three issues will be highlighted, which involve implications for daily practice or recommendations for future research.

\section{Increasing BF compliance}

Internationally, several studies have been performed in which BF promotion programmes are evaluated in primary care settings. However, they have shown mixed results for effectiveness. ${ }^{10-12}$ It is difficult to identify what type of intervention and which procedures are more likely to effectively promote and support BF during the pre- and postnatal periods because of the wide variety of approaches tested. The most frequent strategies identified were home visits with individual face-to-face contacts, group sessions, phone calls, printed material, and a combination of two or more strategies. ${ }^{10}$ The timing of the intervention was another differing issue, together with the kind of BF outcome measured. Two studies 
showed that the isolated use of printed material, such as booklets given to the pregnant women, were not effective. The difference between the success rate of the intervention and control group after six months appears to be only $7 \%$ in one study (59\% vs. $52 \%)$ and $4 \%$ in the other (48\% vs. $44 \%) .{ }^{13-14}$ Also, strategies with no or brief face-to-face contact, such as interventions based on telephone support, failed to be effective (RR 0.92 [0.78-1.08]; five trials, 1168 women). ${ }^{12}$ According to a recent review study, the most effective interventions generally combined face-to-face information, guidance and support, spanning the pre- and postnatal period (mean difference I-C $=13 \%, 95 \%$ CI $1-25) .{ }^{11}$

These review results were confirmed by our BF programme, which is a theory-driven intervention based on pre- and postnatal face-to-face contacts supported by an educational booklet, since it appeared to be effective in promoting $\mathrm{BF}$ for the full six months (I-C= $21 \%, p<0.05){ }^{15}$

In the Netherlands this is the first effectively controlled study in which an educational programme significantly increased the proportion of women breastfeeding for six months.

The strong points of our programme are:

- Targeted information about the barriers to continuing to breastfeed for six months due to a systematically performed problem analysis

- Provision of realistic information, preparation of women and their partners for all the possible risk situations, and provision of solutions

- Theory- and evidence-based strategies used to communicate the key message

- Intervention starting at the beginning of the second trimester of pregnancy

- Prenatal and postnatal visits

- Supportive attitude by home visitors

The study of Kools et al, ${ }^{4}$ performed in 2000-2002, is the only Dutch BF study that can be compared to our BF programme. Our programme shows resemblance to the programme of Kools et $\mathrm{al}^{4}$ but also differs on several aspects. To give an overview of the two programmes, a short summary is displayed in Table 7.1 to make clear the components of both programmes.

The results of the study of Kools et $\mathrm{al}^{4}$ showed that their programme was not effective in contrast to our positive outcome. ${ }^{15}$ In the study of Kools et al, ${ }^{4}$ there was no difference in the rates of continuation after three months of BF between the intervention and control group. Since the programme consists of several different components it is difficult to make clear why the programme was not effective, but the authors made several suggestions. ${ }^{4}$ 
Table 7.1 components of two BF programmes

\begin{tabular}{|c|c|c|}
\hline Components programme & BF programme Gijsbers et al & BF programme Kools et al \\
\hline Participants & $\begin{array}{l}\text { Asthmatic families living in the } \\
\text { south of the Netherlands }\end{array}$ & $\begin{array}{l}\text { General population living in the south } \\
\text { of the Netherlands }\end{array}$ \\
\hline Goal & $\begin{array}{l}\text { Increasing } \% \text { women who still } \\
\text { breastfeed exclusively after } 6 \\
\text { months postpartum }\end{array}$ & $\begin{array}{l}\text { Increasing } \mathrm{BF} \% \text { from } 21 \% \text { to } 31 \% \text { at } \\
3 \text { months postpartum }\end{array}$ \\
\hline Programme development & Intervention mapping protocol & ABC-planning model \\
\hline Theoretical model & ASE model & ASE model \\
\hline \multirow[t]{3}{*}{ Focus } & $\begin{array}{l}\text { Focus on supporting pregnant } \\
\text { women and their partner }\end{array}$ & Focus on supporting care givers \\
\hline & $\begin{array}{l}\text { Preparation during pregnancy, } \\
\text { inform about future problems } \\
\text { and give solutions to increase } \\
\text { their knowledge }\end{array}$ & $\begin{array}{l}\text { Identification of problems which can } \\
\text { be written in booklet and consequently } \\
\text { access to lactation consultants }\end{array}$ \\
\hline & & $\begin{array}{l}\text { Training of all participating caregivers } \\
\text { to increase cooperation between } \\
\text { different caregivers }\end{array}$ \\
\hline Tools & $\begin{array}{l}\text { Two prenatal }\left(3^{\text {rd }} \text { and } 7^{\text {th }}\right. \\
\text { month) home visits and one } \\
\text { postnatal home visit and new } \\
\text { developed booklet based on } \\
\text { experiences of target group }\end{array}$ & $\begin{array}{l}\text { One prenatal ( } 7^{\text {th }} \text { month) and one } \\
\text { postnatal home visit, booklet to write } \\
\text { in problems and access to lactation } \\
\text { consultant }\end{array}$ \\
\hline
\end{tabular}

BF continuation in the workplace

Our main target was to extend BF duration to six months. Only $10 \%$ of the women in the experimental group of the PREVASC study, on which the present study is based, achieved this recommendation as compared to $48 \%$ of the women in our experimental group and $27 \%$ of the controls. ${ }^{15}$ This is a major increase, but there could still be room for improvement. In a separate study, described in Chapter 6, we evaluated those factors that have a significant association with the duration of BF. BF knowledge, BF experience and the intention to return to work were important positive predictors for a longer duration of $\mathrm{BF}$. We were triggered by the positive relationship of the intended job status, since returning to work appears high on the list of main reasons for stopping BF. Interestingly women, who indicated at three months' pregnancy that they intended to work for more than 22 hours a week after maternity leave, breastfed longer than women who intended to work less than 22 hours. Another Dutch intervention study on BF found the same positive association. The authors of that study wondered if the intended working status was also actually carried out. Unfortunately, we did not ask either whether these women actually did return to work and, instead, just depended on their intended working hours. An effort should be made to collect those data since this could make the relationship between 
working status and BF duration clearer. One Dutch observational study about BF behaviour reported that the actual return to a full-time job was negatively associated with the duration of BF. ${ }^{16}$ Forty-four percent of the mothers with no job or less than a part-time job mainly breastfed their infant at four months, versus $29 \%$ in the group of mothers with a full-time job. An international study also found that at four months postpartum, $10 \%$ of the full-time working mothers were still breastfeeding, compared with $28 \%$ of the mothers who were not employed. ${ }^{17}$ Furthermore, a Canadian study showed that mothers' prenatal BF plans differed significantly from the actual duration of BF. Of 61 mothers only 16 breastfed for the length of time they had intended to prenatally. ${ }^{18}$ Apparently a positive intention and a good preparation beginning during pregnancy were not enough to combine BF or expressing milk with a full-time job. The results of the national BF campaign "BF deserves time" revealed that women who expressed milk during work time were faced with opposition from colleagues and employers. One out of four persons thought it was not normal for women to receive space and time to express milk during working hours. It must be noted that the questionnaire was filled in mainly by men between the ages of 16 and 24 years of age, and who belonged to the low to intermediate educational level. ${ }^{19}$

It has generally been suggested that differences in the mean duration of BF between European countries was attributable to the length of paid pregnancy leave for working mothers. In the Nordic European countries, where paid pregnancy leaves last up to one year, excellent BF rates are found, with $80 \%$ of infants being breastfed at the age of six months. ${ }^{20}$ But it is not expected that the duration of maternity leave will be extended in the Netherlands any time soon. Therefore, other solutions will have to become available in order to counterbalance these barriers to continuing breastfeeding for the full six months. A possible solution could be found in more child care facilities near the workplace of the breastfeeding mother, so the mother could easily breastfeed their child during working hours. On the other hand the facilities to express milk at the workplace are still far from optimal and should be optimized.

\section{$B F$ in a multifaceted prevention context}

The recommendation to breastfeed for six months is one of the preventive recommendations for avoiding the development of asthma in high-risk children. Since asthma is a multifactorial disease in which a genetic predisposition but also several environmental triggers play a role, the prevention of childhood asthma requires a multifaceted approach. Recently, Van Schayck et al. ${ }^{21}$ showed in a meta-analysis that the effects of multifaceted allergen reduction programmes were greater in preventing childhood asthma traits than were those of mono-faceted programmes. These results suggest that multifaceted intervention programmes should have a much greater chance of success than studies using a monofaceted approach. 
The PREVASC programme from which our study originated acknowledged this approach, and focused on a simultaneous and combined reduction in the four main environmental exposures (tobacco smoke, nutrition, house dust mite and pet allergens) which are each independently related to asthma. The extent of adherence to avoiding cow milk protein, or in other words BF the first six months was disappointing in the PREVASC study. Only $10 \%$ of the women in the experimental group managed to breastfeed for the recommended period. ${ }^{1}$ It was striking and disappointing to discover that compliance figures were not a major topic treated in the published papers about the effect of multifaceted programmes. Only a few multifaceted programmes explicitly reported the compliance figures for the preventive measure recommendations, including dietary recommendations. ${ }^{1,22}$ One positive exception was the CAAP study, ${ }^{22}$ whose authors reported that $93 \%$ of the women in the intervention and $92 \%$ of the control groups initiated BF. At eight months after birth, differences in the intervention and control groups were significant (61\% vs. 50\%, $p=0.02)$. Unfortunately it is not clear which BF definition was used and how the women were encouraged to perform BF. In most studies on asthma prevention, little if any information is given for the definition of compliance, the extent of adherence to the preventive recommendations and the assessment of compliance behaviour. ${ }^{23-24}$ It is quite possible that the effect on the prevention of asthma/allergies was underestimated since compliance with the dietary recommendations was far from optimal. Therefore, it would seem to be important for evaluation of asthma preventive programmes to take into account noncompliance when assessing the preventive effectiveness of any study outcome. Moreover, it often remains unclear which tools (home visits or booklets or a combination) were used to motivate families to carry out the preventive recommendations, such as BF for the first six months. In addition, it is possible that the compliance rates were considerably low, as in the PREVASC study. Therefore, our BF programme could fill this gap so as to increase compliance with the dietary preventive recommendations and so to enlarge the effectiveness of the multifaceted prevention programmes.

\section{Conclusions}

In conclusion, our research has provided an effective theory-based approach towards promoting BF for six months in a high-risk group. The combination of pre- and postnatal home visits and an educational booklet led to significantly higher compliance rates after six months. More insight is needed into the obstacles for continuing to breastfeed in the work place, since this appears to be a major reason that employed women discontinue BF. Finally, multifaceted prevention programmes can benefit from our BF programme, which increases the rate of compliance rate with the dietary recommendations and, with it, the effect size for preventing asthma in childhood. 


\section{Recommendations}

Here we will distinguish between the recommendations for supporting BF in practice and our suggestions for future research.

\section{Recommendations for practice}

In the Netherlands approximately $80 \%$ (2002) of all pregnant women visit a midwife in their first trimester. During pregnancy this percentage decreases to $53 \%$, because women are referred to a gynaecologist in case of medical reasons. ${ }^{25}$ For women with low-risk pregnancies, standard maternity care in the Netherlands includes an average of eleven or twelve antenatal visits to a midwife. Standard care after normal childbirth (at home or in hospital) includes five or six visits at home from the midwife over the following ten to twelve days, along with the help of maternity care assistants for an average six hours a day for seven or eight consecutive days. Standard maternity care is concluded with a visit to the midwife six weeks postpartum. ${ }^{26}$ After birth $97 \%$ of the mothers with a newborn visit the free services of the child health care organisation on a regular basis (monthly, in the first year). Knowing this, midwives are probably the most convenient health professionals to introduce the $\mathrm{BF}$ programme early in pregnancy. The detection of women pregnant with a predisposed child can be performed easily, since questions about medical conditions are already common practice during the preliminary interview. An affirmative answer to the standard question of whether the woman herself, her partner or any of her previous children has or has had a history of asthma could be a simple tool to start talking about the benefits of BF, especially in order to prevent the high-risk infant from developing asthma. When the woman has a positive attitude about BF, the possibility of a BF educational intervention can be introduced. It should be noted that if women that are pregnant with a child at high risk of developing asthma, express their wish to give formula instead of $\mathrm{BF}$, information about the possibility of hypo-allergenic formulas and postponing solids for the first six months can be given instead. Hypo-allergenic is the first choice formula for predisposed children, just as is postponing solids till the infant is six months in order to minimise the chance of developing asthma or allergies. However, irrespective of the woman's feeding choice, they should be treated with respect and not left with a feeling of guilt if they do not choose to breastfeed.

Since continuation of BF for six months is recommended, postnatal care would seem to be essential. Therefore, good coordination of the care chain is needed or, in other words, a smooth transition from the prenatal to the postnatal period, since different health care professionals provide care to the (future) mother-infant pairs. Maternity assistants or health professionals working in childcare organisations can fulfil this needed activity. Even in the 
upcoming preconception counselling hours, attention should be paid to the feeding choice of the future child. Also the benefits of breastfeeding should be mentioned, since the majority of women make the feeding choice before they get pregnant. ${ }^{16}$

\section{Recommendations for future research}

The most important recommendation for future research is to reveal whether midwives or other health professionals are able to implement the effective BF programme in daily practice.

Furthermore, future studies should focus on the barriers that BF mothers encounter when returning to work, especially in respect to how colleagues react to women who express milk during work time. This is necessary, since returning to work is still a major reason for discontinuing $\mathrm{BF}$, despite the motivation of women to continue long term.

One recommendation for future multifaceted prevention programmes is to make use of effective programmes for increasing the compliance with the recommended preventive measures and to report these compliance figures explicitly, instead of just the clinical effectiveness of the asthma outcomes.

Finally, at national level there is more and more attention being paid to the many health benefits of BF. Illustrative of this are intensive BF media campaigns supported by the government that have been launched and the different groups of health professionals (GPs, maternity assistants, midwives and paediatricians) who support the national guidelines in which BF for six months is recommended as the optimal feeding for an infant, especially in high-risk families. Health professionals seem poised for action! They are the ones that must provide pregnant women and their partners with our evidence-based BF educational programme so that they are prepared for the challenge to breastfeed exclusively for the full six months. 


\section{References}

1. Schönberger HJ, Dompeling E, Knottnerus JA, Maas T, Muris JW, et al. The PREVASC study: the clinical effect of a multifaceted educational intervention to prevent childhood asthma. Eur Resp J 2005;25:660-670.

2. Arshad SH, Stevens M, Hide DW. The effect of genetic and environmental and factors on prevalence of allergic disorders at the age of two years. Clin Exp Allergy 1993;23:504-511.

3. Bosken CH, Hunt WC, Lambert WE, Samet JM. A parental history of asthma is a risk factor for wheezing and nonwheezing respiratory illnesses in infants younger than 18 months of age. Am J Respir Crit Care Med 2000;161:1810-1815.

4. Kools EJ, Thijs C, Kester ADM, van den Brandt PA, de Vries H. A breast-feeding promotion and support program a randomised trial in the Netherlands. Prev Med 2005;40:60-70.

5. Morrow AL, Lourdes Guerrero M, Shults J, Calva JJ, Lutter C, Ruiz-Palacios GM, et al. Efficacy of homebased peer counselling to promote exclusive breastfeeding: a randomised controlled trial. Lancet 1999;353:1226-1231.

6. Central Bureau of Statistics, StatLine. URL: http://statline.cbs.nl (2007-9-9).

7. Lied TR, Kazandjian VA. A Hawthorne strategy: implications for performance measurement and improvement. Clin Perform Qual Health Care 1998;6:201-204.

8. WHO/UNICEF. The Innocenti declaration on the protection, promotion and support of breastfeeding. In Breastfeeding in the 1990's: A global initiative meeting in Florence, Italy and New York. Geneva, Switzerland. Geneva: WHO/UNICEF, 1990.

9. World Health Organization. Infant and Young Child Nutrition; Global strategy for Infant and Young Child Feeding. Executive Board Paper EB 109/12. WHO, Geneva, 2002.

10. De Oliveira M, Bastos Camacho L, Tedstone A. Extending breastfeeding duration through primary care: A systematic review of prenatal and postnatal interventions. J Hum Lact 2001; 17:326-343

11. Guise J, Palda V,Westhoff C, Chan B, Helfand M, Lieu T. The effectiveness of primary carebased interventions to promote breastfeeding: systematic evidence review and meta-analysis for the US Preventive Services Task Force. Ann Fam Med 2003;1:70-78.

12. Sikorski J, Renfrew M, Pindoria S,Wade A. Support for breastfeeding mothers: A systematic review. Paed Peri Epid 2003:17;407-417.

13. Currò V, Lanni R, Scipione F, Grimaldi V, Mastroiacovo P. Randomised controlled trial assessing the effectiveness of a booklet on the duration of breast feeding. Arch Dis Child 1997;76:500-504.

14. Hauck YL, Dimmock JE. Evaluation of an information booklet on breastfeeding duration: a clinical trial. $J$ Adv Nurs 1994;20:836-843.

15. Gijsbers B, Mesters I, Knottnerus JA, Kester ADM, van Schayck CP. The success of an educational program to promote exclusive breastfeeding for 6 months in families with a history of asthma: A randomised controlled trial. Pediatr Asthma Allergy Immunol 2006;19:214-222.

16. Lanting CI, van Wouwe JP, Reijneveld SA. Infant milk feeding practices in the Netherlands and associated factors. Acta Paediatr 2005;94:935-942.

17. Ryan AS, Martinez GA. Breastfeeding and the working mother: A profile. Pediatrics 1989;83:524.

18. Morse JM, Bottorff JL: Intending to breastfeed and work. J Obstet Gynecol Neonatal Nurs 1989;18:493.

19. Vis, C. Nameting publiekscampagne 'Borstvoeding verdient tijd',2006, CentERdata, Tilburg.

20. Lande B, Andersen LF, Baerug A, Trygg KU, Lund-Larsen K, Veierod MB, et al. Infant feeding practices and associated factors in the first six months of life: The Norwegian Infant Nutrition Survey. Acta Paediatr 2003;92:152-161.

21. Van Schayck CP, Maas T, Kaper J, Knottnerus JA, Sheikh A. Is there any role for allergen avoidance in the primary prevention of childhood asthma? J Allergy Clin Immunol 2007;119;1323-1328.

22. Chan-Yeung M, Fergusson A, Watson W, Dimich-Ward H, Rousseau R, et al. The Canadian childhood asthma primary prevention study: Outcomes at 7 years of age. J Allergy Clin Immunol 2005;116:49-55. 


\section{Chapter 7}

23. Schoetzau A, Gehring U, Franke K, Grubl A. Koletzo S, Berg von A, et al. Maternal compliance with nutritional recommendations in an allergy preventive programme. Arch Dis Child 2002;86:180-184.

24. Arshad SH, Bateman B, Sadeghnejad A, Gant C, Matthews SM. Prevention of allergic disease during childhood by allergen avoidance: The Isle of Wight prevention study. J Allergy Clin Immunol 2007;119:307313.

25. Wiegers TA, Janssen BM. Monitor verloskundige zorgverlening. Nivel 2006, Utrecht.

26. Wiegers TA. Adjusting to motherhood: Maternity care assistance during the postpartum period: How to help new mothers cope. J Neon Nurs 2006;12:163-171. 
Summary 



\section{Summary}

\section{Chapter 1 General introduction}

The research project described in this thesis originates from the PREVASC programme (PREVention of ASthma in Children). The PREVASC project is an ongoing research programme that focuses on the multifaceted primary prevention of asthma in high-risk children and has different research goals. Newborns with asthmatic parent(s) have a hereditary predisposition and therefore are particularly at risk to develop asthma complaints. According to several prospective birth cohorts and systematic reviews exclusive breastfeeding (BF) for six months has a protective effect on the development of childhood asthma but it appears to be difficult to complete the first six months. Therefore, the main focus of this thesis is to find and validate a way to increase the number of women who continue to breastfeed exclusively for the first six months of their infant's life. For this purpose we developed a theory-based educational breastfeeding programme.

In this first Chapter, an overview of the prevalence of childhood asthma in the Netherlands is presented, along with the different health benefits of $\mathrm{BF}$, especially the relationship between exclusive BF and prevention of childhood asthma. In addition, other BF promotion programmes are being discussed and the definition of BF that was used is clarified. Furthermore, the factors that are associated with the initiation and continuation of exclusive BF according to recent literature are being presented, as well as the main theoretical model on which the educational programme is based. Finally, the outline of this thesis is presented.

\section{Chapter 2 Breastfeeding behaviour in asthmatic families: results from an explorative study}

Because of the absence of information on BF behaviour in asthmatic families, we conducted seven focus group interviews to gain insight into the feelings, opinions and perceived barriers regarding BF behaviour in asthmatic families. Forty-three households who had participated in the PREVASC programme, which promotes exclusive BF to prevent their child from developing allergic symptoms, were recruited. The content of the interviews was analysed line-by-line supported by a qualitative computer programme. We conclude that the most influencing factors regarding initiation and continuation of BF were health advantages for the baby, bonding, social support, modeling, BF confidence and knowledge about all the aspects of BF. Furthermore, it appears that various risk situations can turn up in different phases. Therefore, it seems important to divide the educational material in phases accordingly. Moreover, the key message of the programme should be that BF for the first six months is a challenge. Therefore a good preparation started early in 
pregnancy for both the woman and her partner is indispensable. The conclusions of this pilot-study form an important part of the problem analysis which was the first necessary step to develop a BF educational programme that fits the needs of the target group.

\section{Chapter 3 The educational programme - a randomised controlled trial}

A randomised controlled trial (RCT) was conducted to investigate the effectiveness of the newly developed BF educational programme. In order to recruit participants for the RCT, posters were put up in several practices of midwives and ads in local papers were inserted in the south-eastern part of the Netherlands. Of the 113 families that came forward, 89 families appeared to be eligible (less than 7 months pregnant and at least one first-degree relative had asthma that had been diagnosed by a doctor) and were randomised.

During the home visit of the women in the intervention group (twice before the births of their babies and once after) they received written and oral advice about all aspects of BF and storing and expressing milk. All parents registered their child's feeding history on a diary card during the first six months post-partum.

The proportion of women who continued to breastfeed exclusively the first 6 months after birth was significantly higher in the intervention group than among the control group (48\% vs. 27\%). We conclude that in asthmatic families the theory-based BF programme is effective in improving the exclusive BF rates during the first six months after birth. A next step will be to implement this programme to make it available for health professionals who support pregnant women whit a familial history of asthma.

\section{Chapter 4 The effective educational programme: its content and why it may work}

Our systematically developed and theory based educational breastfeeding programme, which combines pre- and postnatal home visits and a booklet, appeared to be effective in promoting exclusive BF for at least six months in asthmatic families. In this Chapter we described the content and design process of the effective programme in detail. Furthermore, we were interested in the effects of the theory-based educational programme on psychosocial variables to be able to explain why the BF rates were increased. The programme is guided by the Intervention Mapping protocol and is based on the AttitudeSocial influences-self-Efficacy model (ASE model). Since we wanted to know why the programme is effective, the participants completed follow-up questionnaires on $\mathrm{BF}$ behaviour and determinants at 3 and 7 months prepartum and 3 and at 6 months postpartum. Repeated measurement analyses with the two groups (intervention and control) showed that BF knowledge and attitudinal BF beliefs significantly increased in women who were exposed to the programme compared to women in the control group. 
Interestingly, social pressure from the environment increased significantly in both groups after three months breastfeeding. Likewise over time the amount of self-efficacy and positive emotions significantly increased in both groups. According to the evaluation questionnaires, the users positively evaluated the educational programme (8 on a scale from 0 to 10$)$ on several points.

\section{Chapter 5 Factors associated with the intended duration and initiation of breastfeeding}

To identify which psychosocial variables of a theoretical framework can predict the intended duration and actual initiation of BF in a high-risk group fills a gap in present literature. According to the assumptions of the Attitude-Social Influence-Self-Efficacy model, three types of cognitive variables primarily determine behavioural intention: attitudinal beliefs, social influences (social norms, social support and social pressure, and modelling) and self-efficacy expectations. Also the model postulates that intention predicts subsequent behaviour. Furthermore, the external variables, such as behavioural factors (e.g. previous experience and knowledge) and socio-demographic variables (e.g. age and educational level) are assumed to be moderated by the three cognitive factors (attitudinal beliefs, social influences and self-efficacy). Around three months pregnancy (before the intervention started), the 89 participants completed a BF questionnaire which contained questions concerning the ASE- and external factors.

The results showed that attitudinal beliefs were significantly associated with the intended duration to breastfeed. The intention to breastfeed was the strongest predictor for the actual initiation of BF. We concluded that BF promotion needs to focus on the health and other advantages of BF for six months (attitudinal beliefs), especially in high-risk groups, in order to increase the intention to breastfeed, since that appears to be a strong predictor for actual behaviour.

\section{Chapter 6 Factors associated with the duration of exclusive breastfeeding}

Since exclusive BF for six months appears to be an advice that is hard to accomplish, we examined the factors that influence the duration of exclusive BF. We showed a significant positive association between the duration of exclusive BF and the mother's BF knowledge, her intended hours of work per week after maternity leave, and her age. Short-term, that is less than 5 weeks, or no previous BF experience of multiparous women appears to be negatively associated with the duration of exclusive BF. Apparently, having the intention to work more than 22 hours a week appears no reason to discontinue to breastfeed. Furthermore, we concluded that educational support is especially necessary for multiparous 
women with an earlier short-term, less than 5 weeks, or no BF experience, since they are at risk of quitting BF before the completion of the recommended six-month period.

\section{Chapter $7 \quad$ General discussion}

The final chapter of this thesis provided an overview of conclusions and comments over the findings. The present results showed the effectiveness of the newly developed theory based BF programme. Furthermore, we discussed the strengths and weaknesses of the study and recommendations were made for future research on the theme of $\mathrm{BF}$ in families with a history of asthma. 
Samenvatting 



\section{Samenvatting}

\section{Hoofdstuk 1 Introductie}

Het onderzoeksproject dat in dit proefschrift staat beschreven komt voort uit de PREVASK studie (PREVentie van AStma bij Kinderen). De PREVASK studie richt zich vooral op het tegelijkertijd vermijden van meerdere omgevingsinvloeden om astma te voorkómen bij kinderen die een verhoogd risico hebben om astma te ontwikkelen. Pasgeborenen met één of twee astmatische ouder(s) hebben een erfelijke kwetsbaarheid en daardoor meer kans om astmaklachten te ontwikkelen. Uit enkele internationale studies die kinderen vanaf hun geboorte volgen blijkt dat de kinderen die tenminste zes maanden lang uitsluitend borstvoeding krijgen minder astmaklachten ontwikkelen dan de kinderen die korter dan zes maanden of niet uitsluitend borstvoeding krijgen. Maar voor vrouwen in Nederland blijkt het erg moeilijk om het kind tot de leeftijd van zes maanden uitsluitend borstvoeding te blijven geven. Dat is de reden dat de focus van onderhavig onderzoek ligt op het ontwikkelen van een voorlichtingsprogramma om uiteindelijk meer vrouwen de eerste zes maanden hun kind uitsluitend borstvoeding te laten geven. Om dit te kunnen realiseren hebben we een borstvoedingsprogramma ontwikkeld dat is gebaseerd op twee pijlers: ten eerste op de borstvoedingservaringen van vrouwen die een kind hebben gekregen met een verhoogd risico op het ontwikkelen van astma. Ten tweede op een theoretische onderbouwing zoals die is beschreven in sociaal-psychologische modellen.

In het eerste hoofdstuk wordt onder andere een overzicht gegeven over het vóórkomen van astma in Nederland en worden de gezondheidsvoordelen van borstvoeding gepresenteerd, en dan vooral de relatie tussen uitsluitend borstvoeding geven en het voorkómen van astma bij kinderen. Aansluitend zullen andere borstvoedingsprogramma's worden besproken en zal de gehanteerde borstvoedingsdefinitie worden uitgelegd. Verder zullen de belangrijkste factoren worden genoemd die van invloed zijn op het starten en doorgaan van borstvoeding geven, en zullen de belangrijkste theoretische modellen worden besproken die zijn gebruikt bij het ontwikkelen van het borstvoedingsprogramma. Tot slot, zal de opbouw van dit proefschrift worden gepresenteerd.

\section{Hoofdstuk 2 Het geven van borstvoeding door astmatische gezinnen: resultaten van een verkennende studie}

Om meer inzicht te krijgen in de gevoelens, meningen en problemen die astmatische gezinnen ervaren m.b.t. het geven van borstvoeding werden er zeven focus groep interviews georganiseerd. Drieënveertig huishoudens die eerder hadden meegedaan aan de PREVASK studie, de studie die gezinnen aanmoedigt om zes maanden uitsluitend 
borstvoeding te geven om astma bij kun kind te voorkomen, deden mee aan de groepsinterviews. De inhoud van de interviews werd op band opgenomen en vervolgens zin voor zin geanalyseerd met behulp van een gespecialiseerd computerprogramma. We concludeerden dat de gezondheidsvoordelen voor de baby, de band met het kind, sociale steun uit de omgeving, andere vrouwen borstvoeding zien geven, zelfvertrouwen en kennis over alle aspecten van borstvoeding geven de meest belangrijke factoren waren die van invloed zijn op de keus om borstvoeding te gaan geven en het vol te houden. Daarbij bleek dat er verscheidene risicosituaties bestaan om voortijdig te moeten stoppen op verschillende momenten gedurende de zes maanden. Daarom is het belangrijk om het borstvoedingsprogramma te verdelen in verschillende periodes (tijdens zwangerschap, de eerste weken na de bevalling, en drie maanden na de bevalling) en per periode de mogelijke problemen en oplossingen te beschrijven. De hoofdboodschap van het programma luidt dat het een uitdaging is om zes maanden borstvoeding te geven en dat het daarom noodzakelijk is om je al vroeg in de zwangerschap samen met je partner gedegen voor te bereiden. De conclusies van deze pilot-studie vormden de eerste belangrijke stap om een dusdanig borstvoedingsprogramma te ontwikkelen dat zou aansluiten bij de behoefte van de doelgroep.

\section{Hoofdstuk 3 Het borstvoedingsprogramma - een gecontroleerde gerandomiseerde trial}

Om te onderzoeken of het nieuw ontwikkelde borstvoedingsprogramma effectief is werd een gecontroleerde gerandomiseerde trial uitgevoerd. Deelnemers werden geworven door posters op te hangen in verloskundige praktijken en advertenties te zetten in huis-aanhuisbladen in het zuidoosten van Nederland. Van de 113 gezinnen die zich aanmeldden bleken er 89 te voldoen aan de inclusiecriteria (vrouw minder dan 7 maanden zwanger, en tenminste één van de eerstegraads familieleden heeft of had astma dat door een arts bevestigd kan worden). Vervolgens werden deze 89 gezinnen d.m.v. een geblindeerde randomisatieprocedure verdeeld over de controle- en de interventiegroep. De ouders in de interventiegroep werden in de derde en zevende maand bezocht en binnen vier weken na de bevalling. Tijdens de huisbezoeken werd er mondeling advies gegeven over alle aspecten van het geven en kolven van borstvoeding, ondersteund door schriftelijke informatie. De ouders in de controlegroep ontvingen geen extra borstvoedingsadviezen.

Alle ouders registreerden in een voedingsdagboekje dagelijks welke voeding hun kind kreeg gedurende de eerste zes maanden na de geboorte.

Achtenveertig procent van de vrouwen die de borstvoedingsvoorlichting hadden gekregen hielden het vol om de eerste zes maanden uitsluitend borstvoeding te geven tegenover zevenentwintig procent van de vrouwen uit de controlegroep. We kunnen concluderen dat astmatische gezinnen die zes maanden borstvoeding willen geven baat kunnen hebben bij 
het nieuw ontwikkelde voorlichtingsprogramma. Een volgende stap is het programma beschikbaar te maken voor gezondheidszorgprofessionals (zoals verloskundigen, kraamhulpen, wijkverpleegkundigen, huisartsen en gynaecologen) zodat het in de praktijk toegepast kan worden.

\section{Hoofdstuk 4 Het effectieve borstvoedingsprogramma: de inhoud en waarom het programma kan werken}

Het systematische, op theorie gebaseerde voorlichtingsprogramma, bestaande uit pre- en postpartum huisbezoeken gecombineerd met een brochure blijkt effectief te zijn. De inhoud en het ontwerpproces van het borstvoedingsprogramma wordt in dit hoofdstuk in detail beschreven. Verder zijn we geïnteresseerd in de invloed op de psychosociale variabelen na blootstelling aan het programma om meer duidelijkheid te krijgen waarom het programma werkt, m.a.w. waarom meer vrouwen het volhielden om zes maanden borstvoeding te geven in vergelijking tot de controlegroep. Het voorlichtingsprogramma is gebaseerd op het sociaal-psychologische Attitude-Social influences-Self-Efficacy-model (ASE model) en het Intervention Mapping protocol werd gebruikt bij het ontwerpproces. De deelnemers vulden allemaal gedurende de zwangerschap en 3 en 6 maanden postpartum twee gedragsvragenlijsten in over borstvoeding. Daardoor werd het inzichtelijk wat het effect was van het programma op het gedrag van de deelnemers. Herhaalde metingen bij zowel de deelnemers van de interventie- als de controlegroep lieten zien dat de mate van kennis over borstvoeding en de positieve houding t.a.v. borstvoeding geven verhoogd was in de groep vrouwen die de voorlichting hadden ontvangen in vergelijking met de controlegroep. De sociale druk van de omgeving was in beide groepen 3 maanden postpartum fors gestegen. Ook steeg in beide groepen na verloop van tijd de mate van zelfvertrouwen en de hoeveelheid positieve emoties. Naar aanleiding van de evaluatielijsten kan gezegd worden dat de deelnemers van de interventiegroep de borstvoedingsvoorlichting positief hebben beoordeeld (8 op een schaal 1-10) op diverse onderdelen.

\section{Hoofdstuk 5 De voorgenomen borstvoedingsduur en het starten met borstvoeding; wat zijn voorspellende factoren?}

Door te onderzoeken welke psychosociale variabelen van het theoretische model verantwoordelijk zijn voor de keuze van borst- of flesvoeding en de borstvoedingsduur bij hoog-risico gezinnen werd een leegte gevuld in de hedendaagse onderzoeksliteratuur. Kijkend naar de veronderstellingen van het ASE-model, bepalen hoofdzakelijk drie soorten cognitieve variabelen de gedragsintentie, dit zijn: attitude (houding), sociale invloeden (sociale normen, sociale steun en sociale druk, en modeling) en zelfeffectiviteit. (zelfvertrouwen). Het model laat verder zien dat intentie het werkelijke gedrag voorspelt. 
Verder wordt verondersteld dat externe variabelen, (zoals eerdere ervaringen en kennis) en socio-demografische variabelen (zoals leeftijd en onderwijsniveau) worden gemodelleerd door de drie cognitieve factoren (attitude, sociale invloeden en zelfeffectiviteit).

Voordat de voorlichting plaatsvond (rond de derde maand van de zwangerschap), vulden de 89 deelnemende gezinnen een borstvoedingsvragenlijst in. Deze vragenlijst bevatte vragen over de ASE- en externe factoren. Een positieve houding m.b.t. het geven van borstvoeding bleek positief geassocieerd te zijn met de duur in weken die vrouwen voornemens zijn om borstvoeding te geven. De intentie om hun kind borstvoeding te geven in plaats van flesvoeding was de sterkste voorspeller dat het kind daadwerkelijk moedermelk kreeg. Dit is in overeenstemming met de veronderstellingen van het ASE-model.

\section{Hoofdstuk 6 Borstvoedingsduur; wat zijn de voorspellende factoren?}

Aangezien het moeilijk is om gedurende zes maanden uitsluitende borstvoeding te geven, werd onderzocht welke factoren van invloed zijn op de duur van borstvoeding geven. We konden aantonen dat er een positief verband bestaat tussen de duur van borstvoeding en de leeftijd van de moeder, de mate van borstvoedingskennis, en hoeveel uur de vrouw wilde gaan werken na haar verlof. Als de vrouw een eerder kind géén of korter dan 5 weken borstvoeding had gegeven was dat een risicofactor om bij een volgend kind ook eerder dan 6 maanden te stoppen met borstvoeding geven. Opvallend was dat de intentie om meer dan 22 uur per week na het verlof te gaan werken een positieve invloed heeft op de lengte van de borstvoedingsduur. Ook werd duidelijk dat extra ondersteuning en voorlichting noodzakelijk is bij vrouwen met eerdere kortdurende borstvoedingservaringen, aangezien zij het risico lopen om voortijdig te stoppen bij een volgend kind.

\section{Hoofdstuk $7 \quad$ Algemene discussie}

Het laatste hoofdstuk van dit proefschrift geeft een overzicht van de belangrijkste bevindingen van het onderzoeksproject. Het belangrijkste resultaat is de gebleken effectiviteit van het nieuw ontwikkelde borstvoedingsprogramma. Verder worden de sterke en zwakke kanten van de studie in kaart gebracht en worden er aanbevelingen gedaan voor toepassing in de praktijk en verder wetenschappelijk onderzoek m.b.t. het thema borstvoeding. 
Appendix 



\section{Brochure}

\section{ASTMA EN BORSTVOEDING}

Colofon: De uitgave van deze brochure is mede mogelijk gemaakt door een subsidie van het Nederlands Astma Fonds en ZonMw

Tekst:

Barbara Gijsbers (CAPHRI, Universiteit Maastricht)

Anita Legtenberg (CAPHRI, Universiteit Maastricht)

Universiteit Maastricht

Onderzoekinstituut: CAPHRI

Departement: Huisartsgeneeskunde en Health Education and Promotion

Postbus 616

6200 MD Maastricht

Tekst adviezen:

Ilse Mesters (Health Education and Promotion, Universiteit Maastricht)

(C) Niets uit deze uitgave mag worden verveelvoudigd en/of openbaar worden gemaakt op welke wijze dan ook zonder voorafgaande schriftelijke toestemming van de Universiteit Maastricht. 


\section{Inhoudsopgave}

1 Inleiding

2 Tijdens de zwangerschap

2.1 Voordelen van borstvoeding

2.2 Borstvoeding beschermt tegen astma

2.3 Hoelang borstvoeding?

2.4 Bijvoeden

2.5 Borstvoeding en het gebruik van astmamedicijnen door de moeder

2.6 Borstvoeding en de rol van vader

2.7 Borstvoedingstips voor als u gaat bevallen in het ziekenhuis

2.8 Keizersnede en borstvoeding geven

3 De eerste weken na de bevalling

3.1 Aanleggen van de baby

3.2 Fabeltjes over het geven van borstvoeding

3.3 Een voedingsschema of toch niet?

3.4 Signalen dat uw baby toe is aan drinken

3.5 Hoe weet $u$ of uw baby genoeg krijgt

3.6 Borstproblemen

3.7 Tips voor als u naar het consultatiebureau gaat

3.8 Koemelkallergie en de voeding voor de moeder

3.9 Darmkrampjes en borstvoeding

3.10 Borstvoeding geven in het openbaar

3.11 Borstvoeding en anticonceptie

$4 \quad$ Enkele maanden na de bevalling

4.1 Wanneer de eerste keer de fles proberen?

4.2 Flesweigeren

4.3 Het kolven van moedermelk

4.3.1 Hoe gaat u kolven?

4.3.2 De toeschietreflex

4.3.3 Toeschietreflex opwekken bij kolven

4.3.4 Hoe lang gaat u kolven?

4.3.5 Hoe vaak gaat u kolven?

4.3.6 Kolven met de hand

4.3.7 Hygiëne

4.3.8 Hoeveel afgekolfde melk geeft $\mathrm{u}$ aan uw kind?

4.3.9 Kolven en de wet

4.3.10 Waarin gekolfde moedermelk bewaren?

4.3.11 Bewaaradvies moedermelk

4.4 Introduceren van ander voedsel na zes maanden

4.5 Alternatieven voor borstvoeding

5 Adressen voor informatie over astma en/of borstvoeding 


\section{Inleiding}

Als u ervoor kiest om uw baby borstvoeding te geven, kiest u voor de allerbeste voeding voor uw kind. In deze brochure wordt aandacht geschonken aan alle onderdelen van het geven van borstvoeding. De brochure begint met de voorbereidingen tijdens de zwangerschap om het borstvoeding geven zonder problemen te laten verlopen. Ook vertellen enkele moeders en een vader over hun ervaringen met betrekking tot borstvoeding. Hieronder worden zij kort voorgesteld. Ook wordt er informatie gegeven over kolven en wordt er gesproken over het beste moment waarop u uw kind vaste voeding kunt gaan geven. Tenslotte vindt $\mathrm{u}$ achter in deze brochure namen en adressen van diverse instanties en websites waar $u$ informatie over astma en/of borstvoeding kunt krijgen.

Maak hieronder kennis met de mensen die in deze brochure vertellen over hun eigen ervaringen.

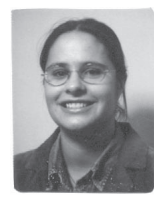

Jolanda (25),

is getrouwd met Pieter. Pieter heeft astma. Ze hebben samen 1 kind (Lotje). Jolanda werkt in een supermarkt. Jolanda heeft getwijfeld over borstvoeding geven, maar is nu blij dat ze heeft doorgezet.

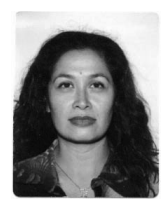

Sitia (30),

heeft sinds haar jeugd last van astma. Ze is getrouwd, maar haar man is vaak van huis door zijn werk. Ze stond er dus vaak alleen voor, maar is trots op zichzelf dat ze haar zoon Daantje de beste voeding heeft gegeven.

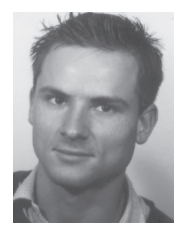

Frank (28),

woont samen met Lydia. Ze hebben samen besloten dat hun kindje borstvoeding zou gaan krijgen. Frank heeft tijdens de zwangerschap van zijn vriendin veel gelezen over borstvoeding geven.

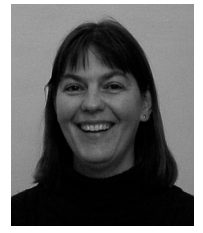

Marion (35),

heeft totdat haar eerste kindje geboren werd, gewerkt bij een accountantskantoor. Haar tweede kindje is in het ziekenhuis geboren. Ze heeft niet zo'n goede begeleiding bij het borstvoeding geven gekregen van het ziekenhuispersoneel. Marion is getrouwd met Maarten. 


\section{Tijdens de zwangerschap}

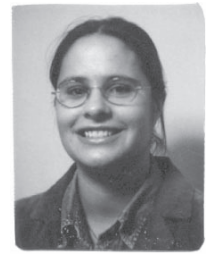

Jolanda besluit om borstvoeding te gaan geven

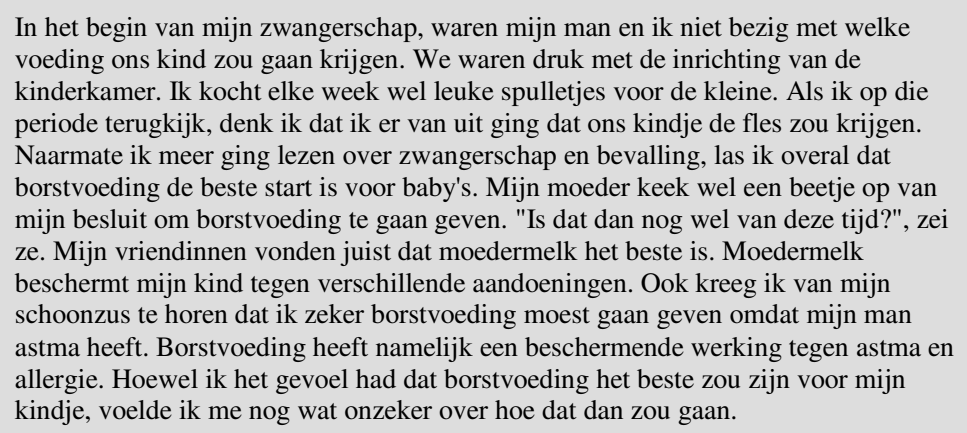
voeding ons kind zou gaan krijgen. We waren druk met de inrichting van de kinderkamer. Ik kocht elke week wel leuke spulletjes voor de kleine. Als ik op die periode terugkijk, denk ik dat ik er van uit ging dat ons kindje de fles zou krijgen. Naarmate ik meer ging lezen over zwangerschap en bevalling, las ik overal dat borstvoeding de beste start is voor baby's. Mijn moeder keek wel een beetje op van mijn besluit om borstvoeding te gaan geven. "Is dat dan nog wel van deze tijd?", zei ze. Mijn vriendinnen vonden juist dat moedermelk het beste is. Moedermelk beschermt mijn kind tegen verschillende aandoeningen. Ook kreeg ik van mijn schoonzus te horen dat ik zeker borstvoeding moest gaan geven omdat mijn man astma heeft. Borstvoeding heeft namelijk een beschermende werking tegen astma en allergie. Hoewel ik het gevoel had dat borstvoeding het beste zou zijn voor mijn kindje, voelde ik me nog wat onzeker over hoe dat dan zou gaan.

\section{$2.1 \quad$ Voordelen van borstvoeding}

Er kunnen verschillende redenen zijn om voor het geven van borstvoeding te kiezen. In deze brochure noemen we er een aantal:

- Een kind dat borstvoeding krijgt, heeft veel minder last van allergische aandoeningen. Dit is vooral zo als uw baby minimaal de eerste zes maanden alleen borstvoeding krijgt. Dat wil zeggen zonder bijvoeding in de vorm van kunst- of potjesvoeding.

Het colostrum, dit is de moedermelk die de eerste dagen na de bevalling door uw borsten wordt gemaakt, bevat extra veel antistoffen. Daardoor wordt uw baby beter beschermd tegen infectieziekten.

- Kinderen die minimaal 3 à 4 maanden borstvoeding hebben gekregen hebben minder vaak last van oorontsteking, luchtweginfecties, maag- en darmstoornissen en diarree. Ze hebben door de borstvoeding een betere opbouw van het afweersysteem.

- De samenstelling van moedermelk is uniek en precies op de behoefte van uw baby afgestemd. Het bevat namelijk alle noodzakelijke voedingsstoffen die uw baby de eerste 6 maanden nodig heeft. Moedermelk voor een 4 maanden oude baby is dan ook anders van samenstelling dan moedermelk voor een pasgeborene. De moedermelk groeit als het ware mee met de baby.

- Er wordt door het geven van borstvoeding een optimale hersengroei bij uw baby bevorderd. Dit komt doordat moedermelk het aminozuur taurine bevat, dat belangrijk is voor de ontwikkeling van het centrale zenuwstelsel.

- Moedermelk is licht verteerbaar. Borstgevoede baby's krijgen daardoor bijna nooit een verstopping. De ontlasting ruikt minder en is altijd zacht, ook als het meerdere dagen wegblijft.

- Moedermelk is direct en op de juiste temperatuur beschikbaar. 
- Een voordeel voor moeders die borstvoeding hebben geven is dat de kans op borstkanker en kanker aan de eierstokken vóór de overgang bij de moeder vermindert. Hoe langer de moeder heeft gevoed, des te kleiner de kans is. Ook zal de moeder minder snel osteoporose (botontkalking) krijgen.

- Tenslotte zal uw lichaam zich sneller herstellen door borstvoeding te geven. De baarmoeder trekt zich door het zuigen aan de borst snel samen, waardoor het vloeien na de bevalling korter zal duren.

\section{$2.2 \quad$ Borstvoeding beschermt tegen astma}

Baby's van ouders die een allergische aandoening hebben zoals astma, hebben 4 tot 5 keer zo veel kans om ook allergieën of astma te ontwikkelen. Juist voor deze kinderen is het belangrijk dat ze de eerste zes maanden alleen borstvoeding krijgen (dus geen vast voedsel of kunstvoeding). Onderzoek heeft aangetoond dat als moeders de eerste zes maanden alleen borstvoeding geven, de kans op het ontstaan van astma bij hun baby aanzienlijk wordt verminderd. Krijgt het kindje toch astmaklachten dan zijn ze vaak minder ernstig.

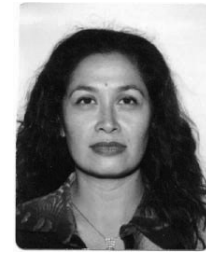

Sitia over het hebben van astma en het geven van borstvoeding
Voor mij stond al voordat ik zwanger werd vast, dat ik borstvoeding zou gaan geven. Ik heb namelijk vanaf mijn jeugd al last van astma. Ik wist dat moedermelk een beschermende werking heeft tegen allerlei allergieën en astma. Tijdens mijn zwangerschap heb ik veel gelezen over borstvoeding en heb ik geprobeerd mij zo goed mogelijk voor te bereiden. Ik heb veel gehad aan een voorlichtingsvideo waarop je van dichtbij kon zien hoe borstvoeding geven precies gaat. Nadat ik de video gezien had, voelde ik me beter in staat om borstvoeding te geven. Ik zag eigenlijk voor het eerst (van dichtbij) hoe borstvoeding geven gaat. In de video worden ook de eventuele problemen genoemd die je tijdens het voeden kunt tegenkomen. Maar er wordt ook benadrukt dat vrouwen zich niet moeten laten afschrikken door al die verhalen over tepelkloven, borstontstekingen en zo. Slechts een klein deel van de moeders die borstvoeding geven, krijgt hier last van. Mochten die problemen zich voordoen, dan zijn er allerlei oplossingen en middelen voor. Ik moet zeggen dat het geven van borstvoeding niet eenvoudig is. Maar het is me toch enorm meegevallen. En elke keer als het even tegen zat dacht ik: kom op, doe het voor Daantje.

\subsection{Hoe lang borstvoeding?}

Het is van belang dat u minimaal de eerste zes maanden uw baby alleen borstvoeding geeft. Borstvoeding bevat het complete pakket aan voedings- en afweerstoffen dat uw baby de eerste zes maanden nodig heeft.

Omdat het afweersysteem van uw baby zich het eerste half jaar nog volop ontwikkelt, zorgt $\mathrm{u}$ er met borstvoeding voor dat uw baby optimaal beschermd is. Na ongeveer zes maanden is uw baby pas toe aan andere voeding, zoals bijvoeding of vaste voeding (zie voor meer informatie verderop in deze brochure). Als u uw baby toch voor de zesde maand andere voeding dan borstvoeding geeft, neemt de beschermende werking op de ontwikkeling van een allergie en astma af. 


\subsection{Bijvoeden}

Moedermelk bestaat voor meer dan 90\% uit water. Baby's die goed aan de borst drinken, hebben geen extra water nodig, ook niet in de zomer als het bloedheet is. Als ze niet goed aan de borst drinken, hoeven ze ook geen extra water, maar is het beter om het kind vaker aan te leggen. Het bijvoeden met water belemmert namelijk het natuurlijke proces van vraag en aanbod. Het kan uw baby een verzadigd gevoel geven of slaperig maken met als gevolg dat uw baby niet meer goed aan de borst drinkt. Doordat uw baby per keer minder aan de borst drinkt, zal uw lichaam ook weer minder melk aanmaken. Het is dus belangrijk dat uw baby goed aan de borst blijft drinken om de hoeveelheid melk niet te laten afnemen.

Er is nog een andere belangrijke reden om uw baby nog geen water of andere voeding uit een flesje te laten drinken. Uit een flesje drinken is iets anders dan aan de borst drinken. Het drinken uit een flesje kan de eerste weken daardoor verwarrend zijn voor uw baby. Ze kunnen door het drinken uit flesjes een verkeerd drinkpatroon aan de borst ontwikkelen. Dit kan als gevolg hebben, dat de baby niet genoeg moedermelk binnenkrijgt en het aanmaken van de melk afneemt. Het is daarom erg belangrijk dat uw baby eerst het drinken aan de borst goed leert.

Mocht uw baby om medische redenen moeten worden bijgevoed, dan is het verstandig dit te doen met behulp van een bekertje, lepeltje of voedingsspuitje en niet met behulp van een flesje.

\subsection{Borstvoeding en het gebruik van astmamedicijnen door de moeder}

Astmamedicijnen (luchtwegverwijders en ontstekingsremmers) worden meestal geïnhaleerd. Ze werken zeer plaatselijk en slechts een kleine hoeveelheid komt in de moedermelk. De meeste baby's hebben hier geen last van, hoewel enkelen er gevoelig voor kunnen zijn en er onrustig van kunnen worden. Het kan dan nodig zijn de dosering van de medicatie te verlagen of het gebruik er van tijdelijk te onderbreken. Bespreek dit met uw (huis)arts.

Het kan zijn dat uw astmaklachten tijdens de zwangerschap zullen veranderen. Sommige aanstaande moeders merken dat zij in deze periode minder benauwd zijn, daarentegen zijn er ook aanstaande moeders die juist meer klachten krijgen.

\subsection{Borstvoeding en de rol van vader}

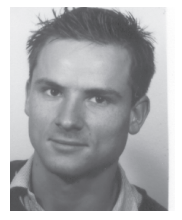

Frank over zijn bijdrage aan het geven van
Mijn vriendin en ik hebben samen besloten dat ons kind borstvoeding zou krijgen. Mijn vriendin dacht eigenlijk dat ik graag wilde dat we voor flesvoeding zouden kiezen. Ik zou dan ook ons kindje kunnen voeden.

Natuurlijk vond ik het wel jammer dat ik een kleinere rol speelde in de voeding van Eefje de eerste tijd. Maar ik heb ook genoten als ik mijn vriendin en haar zo samen zag. Ik heb zelf wel het gevoel dat ik erg betrokken was bij het hele borstvoedingsgebeuren. Ik heb tijdens de zwangerschap van mijn vriendin veel gelezen. Daardoor heb ik het gevoel dat ik haar ook goed heb kunnen steunen tijdens de zwangerschap, maar ook de tijd daarna. Als er wel eens problemen waren, wist ik vaak de oplossing omdat ik dat ergens gelezen had. Zo hebben we samen een mooie periode beleefd en heb ik me absoluut niet buitengesloten gevoeld zoals je wel eens hoort van andere vaders. 
De vader speelt ondanks dat hij zelf het kind niet voedt, een belangrijke rol tijdens de eerste levensweken van het kind. Het geven van voeding is namelijk maar één van de vele onderdelen van het verzorgen van het kind. Baden, luier verschonen en het spelen met het kind zijn leuke en mooie manieren om het nieuwe lid van de familie goed te leren kennen.

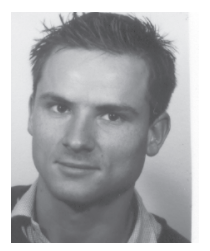

De eerste weken na de bevalling vond ik een mooie tijd. Mijn vriendin en ik hadden een prima rolverdeling. Als er kraamvisite kwam en het was tijd om de kleine te voeden, dan hield ik me bezig met het bezoek zodat mijn vriendin in alle rust Eefje kon voeden.

Frank over zijn bijdrage

aan het geven van borstvoeding

\subsection{Borstvoedingstips voor als $u$ gaat bevallen in het ziekenhuis}

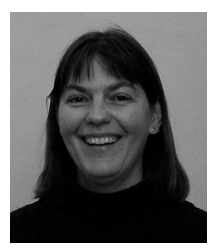

Marion over het geven van borstvoeding in het ziekenhuis
Mijn tweede kindje is geboren in het ziekenhuis. Van tevoren had ik zowel bij de verloskundige als bij de verpleegkundigen aangegeven dat ik erg graag borstvoeding wilde geven aan mijn kind. Niettemin hebben ze maar erg weinig gedaan om me hierin te steunen. Het viel me na de bevalling op dat elke baby een flesje kunstvoeding kreeg, terwijl die moeders ook borstvoeding wilden geven. Gelukkig had ik één verpleegkundige als medestander die me hielp met de borstvoeding. Zij hield ook het bijvoeden met kunstvoeding tegen. Ik heb met verbazing ervaren wat het beleid omtrent borstvoeding in dat ziekenhuis was. Het verwonderde me ook dat weinig moeders zich echt verzetten als een verpleegkundige hun kind ongevraagd kunstvoeding gaf. Ik ging ervan uit dat het verplegend personeel wel weet wat ze doen. Maar als het gaat om borstvoeding moet je als moeder sterk in je schoenen staan en voor je zelf opkomen. Het leek meer op gemakzucht van het personeel om snel te beginnen met flesvoeding. Ik kan me voorstellen dat er ook ziekenhuizen zijn waar wel goede begeleiding wordt gegeven. Jammer genoeg heb ik dat niet mogen ervaren.

\section{Tips:}

- Ga er van uit dat borstvoeding de beste keuze is.

- Bespreek uw keuze voor borstvoeding als dat mogelijk is voor de bevalling met de verloskundige/verpleegkundigen en/of artsen.

- Zorg er voor dat u binnen een uur na de bevalling uw kindje aanlegt, om de borstvoeding op gang te brengen.

- Laat de artsen en/of verpleegkundigen uw baby geen flesje kunstvoeding geven als daar geen dringende medische reden voor is.

- Mocht er toch bijgevoed worden, laat uw kind dan niet drinken uit een flesje, maar met behulp van een bekertje, voedingsspuitje of lepeltje.

- Neem een kolf mee naar het ziekenhuis en probeer tussen de voedingen te kolven als uw kindje nog niet aan de borst kan. Zo blijft uw melkvorming op gang en kunt u uw kind de afgekolfde moedermelk geven. 
- Laat u niet door een verpleegkundige of kraamhulp op een schema van 7 voedingen om de drie à vier uur zetten. Voed naar behoefte.

- Het is verstandig om voor de zekerheid zelf hypo-allergene melk (bv. Nutrilon Hypo Allergeen) mee te nemen naar het ziekenhuis. Niet elk ziekenhuis heeft namelijk hypoallergene voeding op voorraad. Mocht het borstvoeden niet meteen lukken, dan kunt $\mathrm{u}$ de hypo-allergene voeding aan uw kind geven, in plaats van de standaard kunstvoeding.

\section{$2.8 \quad$ Keizersnede en borstvoeding geven}

Het kan natuurlijk voorkomen dat er plotseling besloten wordt dat uw kindje met een keizersnede ter wereld zal worden gebracht. Als uw kindje met een keizersnede geboren is, wil dat niet zeggen dat $\mathrm{u}$ geen borstvoeding zou kunnen geven. Wel is het zo dat $\mathrm{u}$ en uw kind na de narcose even moeten bijkomen. De narcose is niet schadelijk voor uw baby, maar uw baby is door de narcose misschien de eerste uren iets minder alert en daardoor minder goed aan de borst te krijgen. Bovendien heeft uzelf net een operatie ondergaan en kunt $\mathrm{u}$ last hebben van uw buikwond, wat het aanleggen natuurlijk niet makkelijker maakt.

Bespreek in het ziekenhuis, dat u graag wilt dat uw baby zo snel mogelijk na de bevalling wordt aangelegd. Na een keizersnede kan een baby vaak binnen drie uur worden aangelegd.

\section{De eerste weken na de bevalling}

\subsection{Aanleggen van de baby}

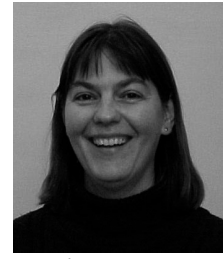

Marion over het geven van borstvoeding en het steeds opnieuw proberen
Ik ben een moeder van twee gezonde dochters van 3 en 1 jaar oud. Ik kan wel zeggen dat ik onderhand een borstvoedingsdeskundige ben geworden. Bij de eerste ben ik tegen nogal wat problemen aangelopen doordat ik zelf niet voldoende voorbereid was op het geven van borstvoeding. Ik had wel het geluk dat ik een kraamhulp had getroffen die veel ervaring met borstvoeding geven had. $\mathrm{Zij}$ heeft me door de eerste paar dagen gesleept. Het was mijn eerste kind, dus ik had geen enkele ervaring en ik wist niet waar ik aan begon. Vol goede moed probeerde ik mijn dochter aan te leggen na de bevalling. Ik hoopte maar dat mijn baby zelf wel wist wat er moest gaan gebeuren. Borstvoeding geven is toch iets natuurlijks, dat hoef je toch niet te leren, dacht ik toen nog. Van tevoren had ik me nooit gerealiseerd dat mijn kindje niet wist hoe het moest drinken. De eerste dagen waren de kraamhulp en ik soms wel een uur bezig om een klein beetje melk te geven. De melk kwam niet gemakkelijk op gang en mijn baby wist niet hoe het moest drinken. Zij vond het veel leuker om op haar tong te sabbelen. De eerste week is ze afgevallen, maar na twee weken lukte het voeden al aardig en zat ze alweer op haar geboortegewicht. Het duurt dus best een tijdje voordat het borstvoeden vanzelf gaat. Ik heb geleerd dat je de moed niet moet opgeven, en dat je steeds opnieuw moet proberen. 
Borstvoeding geven is gezond. Het is goed voor de baby, goed voor de moeder en de meeste moeders ervaren het als prettig om te doen. Maar vooral de eerste dagen zal het niet altijd vanzelf gaan. Zowel de baby als de moeder moeten het leren. Door de baby vaak aan te leggen - minimaal 7 á 8 keer per 24 uur of vaker - wordt de vorming van melk goed op gang gebracht. Het belangrijkste wat geoefend moet worden, is het aanleggen. Bij goed aanleggen gaat het om twee dingen. Op de plaatjes hieronder wordt dit geïllustreerd.

\section{Aanleggen van de baby}

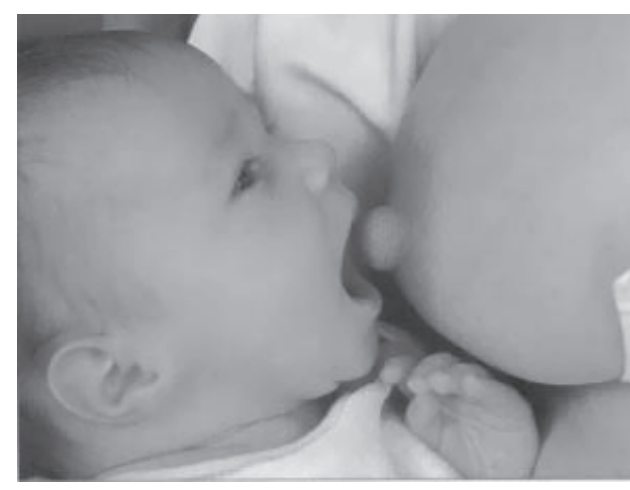

1. De baby wordt zo bij de borst gelegd dat hij/zij er goed bij kan.

2. Uw baby neemt een deel van de borst in de mond door zijn/haar mond goed open te doen.

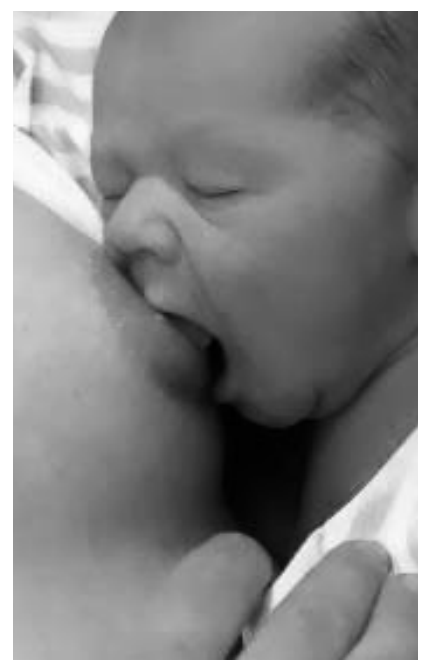

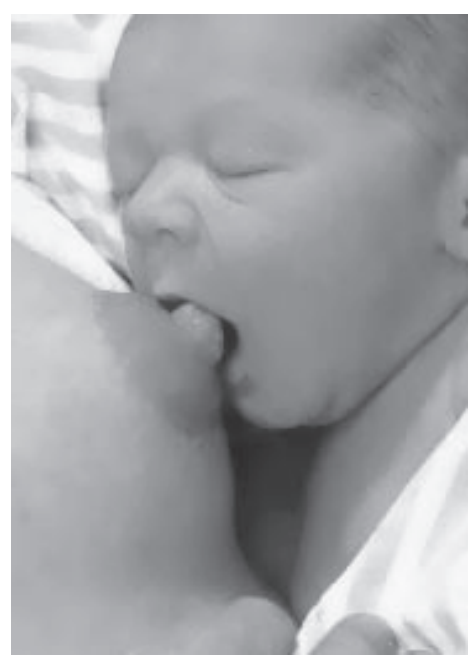

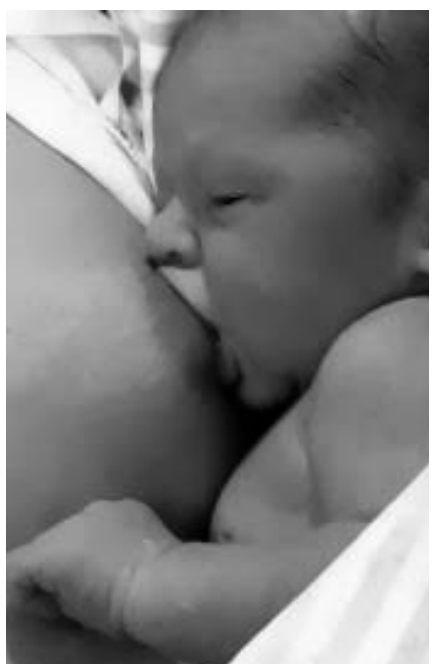


Als uw baby goed is aangelegd, verdwijnt uw tepel diep in het mondje van uw baby. Dit kan even pijnlijk zijn, maar na enkele momenten gaat dit over omdat de tepel dan vast ligt achter in het mondje van uw baby. De baby kan dan drinken zolang hij/zij zelf wil. Als het wel pijn blijft doen, dan ligt de tepel niet goed in het mondje van uw baby en kan uw tepel worden beschadigd. Om dat te voorkomen, kunt u uw baby van de borst halen en opnieuw aanleggen. U kunt uw baby laten stoppen met drinken door een vinger in de mondhoek van uw baby te doen, zodat het vacuüm verbroken wordt (zie onderstaand plaatje).

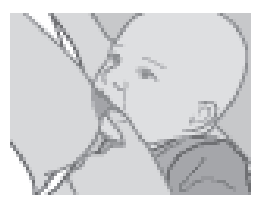

Dit is de basis van het geven van borstvoeding. Goed aanleggen is belangrijk. U krijgt zo geen zere tepels, de borst wordt goed leeg gedronken waardoor de borstvoeding goed op gang kan komen en blijven.

\subsection{Fabeltjes over het geven van borstvoeding}

- Pijnlijke tepels (tepelkloofjes), zouden ontstaan door het te lang aanleggen van de baby. Dit is absoluut een fabeltje. Pijnlijke tepels kunnen ontstaan door het verkeerd aanleggen van de baby.

- Voedende moeders zouden zelf melk moeten drinken om de melkproductie op gang te houden. Dit is een fabel, want het maakt niet uit of de moeder wel of geen melk drinkt. De samenstelling en de hoeveelheid borstvoeding zal daardoor niet veranderen. Het komt zelfs bijna nooit voor dat de melk van moeders onvoldoende voedingsstoffen bevat. Zelfs onder zeer slechte omstandigheden, zoals bij een hongersnood, hebben moeders nog melk van voldoende kwaliteit voor hun baby's.

- Bruin bier zou helpen om de toeschietreflex te stimuleren. Dit wordt vaak gezegd maar het tegenovergestelde is waar. Alcohol heeft juist een remmende invloed op de toeschietreflex en ook op de vorming van melk. Bovendien filteren de borstklieren tijdens de eerste dagen na de bevalling nog nauwelijks de stoffen die de moeder tot zich neemt. Pas na een paar weken zijn de borstklieren zo ontwikkeld, dat ze min of meer een barrière vormen voor sommige giftige stoffen uit het lichaam van de moeder. Eventueel zou het middel oxytocine, een neusspray, gebruikt kunnen worden om de toeschietreflex te stimuleren. U kunt dit krijgen op recept via de huisarts. 


\subsection{Een voedingsschema of toch niet?}

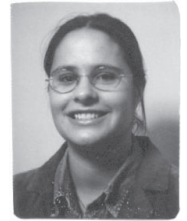

Jolanda over haar ongerustheid
De eerste weken was ik er niet gerust op of mijn kindje wel genoeg voeding binnen kreeg. Ze huilde namelijk regelmatig en ik wist niet of ze huilde omdat ze honger had of dat er iets anders was. Ze werd wel altijd weer rustig als ik haar ging voeden. Ook maakte ik me zorgen of ik haar niet teveel zou kunnen laten drinken. Gelukkig wist iemand van La Leche League (een borstvoedingsinstantie) mij gerust te stellen en te vertellen dat jonge baby's gemiddeld zo'n 6 voedingen per 24 uur nodig hebben. Maar dat de ene baby wat meer drinkt dan de andere en dat 7-8 voedingen per 24 uur ook heel normaal zijn bij baby's die een paar weken oud zijn.

Moedermelk is heel licht verteerbaar. Uw baby wordt, nadat de melk is verteerd vanzelf wakker van de honger, ook 's nachts. Natuurlijk zijn er ook baby's die 's nachts al vrij snel een langere periode doorslapen. Maar de meeste baby's hebben de eerste paar maanden tenminste één voeding in de nacht nodig. Als $\mathrm{u}$ die voeding weg zou laten, door bijvoorbeeld uw baby te laten huilen, krijgt hij een voeding minder en zal uw baby minder goed groeien. Doordat u minder voedt, is de kans ook groot dat de totale hoeveelheid moedermelk die uw lichaam maakt, afneemt. Dan krijgt uw baby niet alleen één voeding minder, maar ook minder tijdens de andere voedingen.

Het is een misverstand dat er steeds dezelfde periode tussen twee voedingen moet zitten. Soms zult u op bepaalde tijden, bijvoorbeeld rond etenstijd, erg druk zijn en dan ook wat minder melk hebben. Het is dan verstandig om weer een rustig moment af te wachten om de volgende voeding te geven. Het is belangrijk dat uw baby tevreden is na een voeding en pas weer laat merken dat hij/zij opnieuw wil drinken door bijvoorbeeld te huilen of onrustig te bewegen.

Vergeet vooral het principe van vraag en aanbod niet. Uw baby zal de vraag bepalen en na verloop van tijd komen de meeste baby's in een bepaald ritme waaraan u zich kunt aanpassen. Bedenk wel dat de meeste baby's ook om de paar weken weer van ritme kunnen veranderen. Ook is het belangrijk te weten dat een baby soms gewoon een paar dagen wat vaker wil drinken om het lichaam van de moeder aan te zetten tot meer melkvorming. Uw baby groeit immers en heeft dan ook meer voedingsstoffen nodig. Dit worden de regeldagen genoemd.

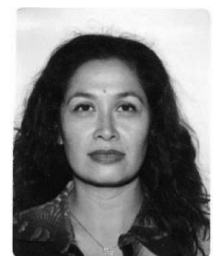

Ik had verwacht dat ik mijn baby volgens een bepaald schema moest gaan voeden. Maar ik merkte dat onze zoon de eerste weken wisselend gedrag vertoonde. Op een gegeven moment wilde hij 's nachts twee voedingen, maar een paar weken daarna sliep hij de nacht door en had hij pas rond zes uur's ochtends weer behoefte aan een voeding. Steeds als ik dacht een ritme gevonden te hebben, veranderde dit ritme weer. Maar, na ongeveer twee maanden waren mijn zoon en ik zo op elkaar ingespeeld en aan elkaar gewend dat ik enorm van het borstvoeding geven ben gaan genieten.

Sitia

over het

voeden volgens

schema 


\subsection{Signalen dat uw baby toe is aan drinken}

U hoeft met aanleggen niet te wachten tot 'het tijd is' of tot uw baby huilt van de honger. Wanneer uw baby altijd dicht bij $\mathrm{u}$ in de buurt is, zult $\mathrm{u}$ al gauw leren herkennen wanneer hij/zij honger heeft. Een baby heeft perioden van diepe en ondiepe slaap. In de ondiepe slaap begint hij/zij soms al smakkende geluidjes te maken of met zijn/haar tongetje te zoeken. Hij/zij wordt dan ook meteen wakker als hij/zij wordt opgetild. Sommige baby's beginnen op hun knuistjes te sabbelen, als ze honger krijgen. Ook onrustig bewegen kan betekenen dat uw baby aan een voeding toe is.

\subsection{Hoe weet u of uw baby genoeg krijgt}

Tijdens de eerste dagen moeten zowel u als uw baby nog 'leren' hoe borstvoeding werkt. U leert hoe u uw baby goed aanlegt. De baby leert hoe het goed de tepel in zijn/haar mondje neemt. Sommige moeders en baby's hebben het snel door, bij anderen duurt het wat langer. In normale omstandigheden heeft de baby genoeg reserves om de eerste paar dagen door te komen en is bijvoeding niet nodig.

Colostrum is de moedermelk die gedurende de eerste dagen na de bevalling door de borsten gemaakt wordt. De hoeveelheid colostrum is altijd voldoende. Na een aantal dagen gaan de borsten meer melk vormen. Dit wordt veroorzaakt door de hormoonomslag bij de moeder in de dagen na de bevalling. Door veel aan te leggen wordt de vorming van melk gestimuleerd. De melkvorming is - naast een hormonale kwestie - vooral een kwestie van vraag en aanbod. Door veel aan te leggen, worden de borsten vaak geleegd. Als de borsten 'leeg' zijn, wordt er een seintje naar de hersenen gegeven dat er weer melk gevormd moet worden.

Hoe weet u nu dat uw baby genoeg krijgt? U kunt op de volgende punten letten:

- Uw baby drinkt minimaal 7 à 8 keer per 24 uur.

- $\quad$ U hoort en/of ziet uw baby ritmisch slikken tijdens het drinken.

- U laat uw baby rustig de borst leegdrinken, zolang als hij wil en daarna naar wens nog de tweede borst.

- Uw borsten voelen na het voeden soepeler aan dan voor de voeding.

- Uw baby heeft minimaal 4 zware wegwerpluiers per dag, of minimaal 6 kletsnatte katoenen luiers.

- De eerste maanden komt uw baby tussen de 90 en 200 gram per week aan.

- Uw baby is alert en tevreden.

- Ongeveer vanaf de 3e dag zal uw baby zo'n 2-5 gele poepluiers (spuitluiers) per dag produceren. Vanaf 4-6 weken zal de ontlasting minder vaak komen omdat de darmen de voeding dan langer vast kunnen houden. Het aantal keren dat uw baby ontlasting krijgt, kan verschillen van meer keren per dag tot eens in de twee weken. Het voordeel van borstvoeding is dat uw kind weinig kans heeft om last van een verstopping (obstipatie) te krijgen. 


\subsection{Borstproblemen}

Het is een hardnekkig misverstand dat het normaal is dat het geven van borstvoeding vooral de eerste weken pijn doet. Borstproblemen zoals borstontstekingen, tepelkloven en spruw (een schimmelinfectie bij moeder of baby) komen soms bij borstvoedende vrouwen voor. Er zijn verschillende folders die een goede uitleg geven wat te doen bij de verschillende problemen. Natuurlijk kunt u altijd terecht bij uw huisarts of verloskundige.

\subsection{Tips voor als $u$ naar het consultatiebureau gaat}

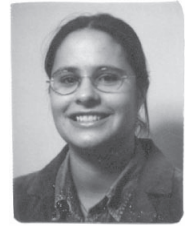

Jolanda over bijvoeden
Het zoontje van mijn zus is nu vier maanden oud en krijgt borstvoeding. Dat wil zeggen, deels. Toen Niels 6 weken oud was moest mijn zus volgens het consultatiebureau gaan bijvoeden, omdat Niels niet genoeg gegroeid was. Inmiddels zijn wij ook heel wat wijzer geworden als het gaat om borstvoeding. Ik weet nu dat mijn zus beter niet had kunnen bijvoeden. Zij zegt nu zelf ook: als ik vanaf het begin vaker had aangelegd en niet het schema van het aantal voedingen per dag had gevolgd dat voor 'fleskinderen' bedoeld was, had ik niet hoeven bijvoeden.

Wat ik zo jammer vind, is dat op het consultatiebureau bij mij in de buurt al snel gezegd wordt dat je kind niet genoeg aankomt en dat je dus moet gaan bijvoeden. Over vaker aanleggen en het verschil tussen fles- en borstvoeding wordt niet gesproken.

Tips:

- Leg allereerst aan het consultatiebureau uit dat er astma/allergie in de familie voorkomt. Vertel dat u daarom minimaal zes maanden alleen borstvoeding wilt geven. $\mathrm{Ga}$ er vanuit dat $\mathrm{u}$ ondertussen veel verstand heeft van borstvoeding geven.

- Soms leiden misverstanden bij hulpverleners over borstvoeding tot onduidelijke adviezen over borstvoeding. Er kan verwarring ontstaan over de voedingsschema's. Het kan zijn dat het consultatiebureau uit gaat van het voedingsschema voor flesvoeding. Baby's die borstvoeding krijgen, krijgen niet volgens een schema voedingen. De baby bepaalt zelf het voedingsritme.

\subsection{Koemelkallergie en de voeding voor de moeder}

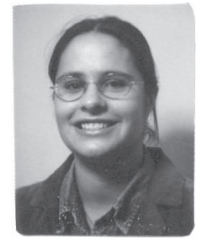

Jolanda over allergie bij het kind
Mijn dochter kreeg na twee maanden borstvoeding last van schilfertjes op haar hoofdhuid en rode vlekjes op haar hele lichaam. Snel daarna ontstonden er korsten en natte plekken. Volgens mijn huisarts en de kinderarts had onze dochter eczeem. Zij attendeerden mij erop dat mijn dochter mogelijk allergisch reageerde op wat ik at. Ik was op dat moment een groot gebruiker van melkproducten. Voedende moeders kunnen wel wat extra calcium gebruiken, dacht ik! Toch werd mij geadviseerd voorlopig alle melkproducten te laten staan omdat ze vermoedden dat mijn kind overgevoelig was voor koemelk (koemelkallergie). Ik geloofde er eigenlijk niet zo in, maar wilde het wel uitproberen. Ongelooflijk. Na een paar dagen was er al verbetering zichtbaar. Ik kon het niet geloven, maar na een aantal keren de proef op de som te nemen door wel weer zuivel te gebruiken, was het zo duidelijk als het maar zijn kon: zuivel was taboe! 
Er zijn baby's die extra gevoelig reageren op voedingsmiddelen die de moeder eet. Vooral in families waar allergieën, eczeem of astma voorkomt, merken moeders dat bepaalde dingen die zij eten of drinken last veroorzaken bij hun baby. Dit kan zich uiten in o.a. spugen, eczeem of onrustig gedrag. Koemelk en andere zuivelproducten, eieren, soja en andere peulvruchten, chocola en citrusvruchten zijn de meest voorkomende producten waar baby's overgevoelig op kunnen reageren.

Mocht $u$ een vermoeden hebben dat uw baby last heeft van voedingsmiddelen die $u$ eet, dan is het verstandig om te beginnen met het laten staan van zuivelproducten. Kijk vervolgens of dit effect heeft op uw baby. Het is wel raadzaam om een diëtiste te raadplegen die u kan begeleiden en adviseren over het te volgen dieet. Informeer vooraf of u hiervoor een verwijzing van uw (huis)arts nodig heeft. Achter in deze brochure vindt u namen en adressen van instanties waar $\mathrm{u}$ meer informatie kunt verkrijgen over bovenstaand onderwerp.

\subsection{Darmkrampjes en borstvoeding}

Veel baby's hebben in meer of mindere mate last van darmkrampjes. Dit hoeft zeker niet aan de borstvoeding te liggen die uw kind krijgt. Kinderen die flesvoeding krijgen kunnen ook last hebben van darmkrampjes. Wat vaak helpt is het drinken van venkelthee. U kunt de venkelthee zelf drinken, maar als uw baby al wel eens een flesje afgekolfde moedermelk krijgt, kunt u ook een scheutje venkelthee toevoegen aan het flesje. Venkelthee is te verkrijgen in reformhuizen en natuurwinkels.

\subsection{Borstvoeding geven in het openbaar}

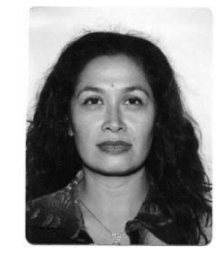

Sitia over het voeden tijdens bezoek
De eerste weken na de bevalling vond ik best een vermoeiende tijd. Vooral omdat ik er thuis vrijwel alleen voor sta. Mijn man is voor zijn werk door de week elders en is alleen de weekenden thuis. Het borstvoeding geven vond ik soms lastig te organiseren, vooral als ik bezoek had. Ik vond het vervelend om met het bezoek erbij mijn kindje te voeden, maar vond het ook niet fijn om even weg te gaan. Gelukkig attendeerde een goede vriendin mij erop dat er tegenwoordig mooie voedingsbloezen te koop zijn. Sinds ik die heb, voel ik me niet meer opgelaten als ik mijn kindje aan het voeden ben als er bezoek is.

\subsection{Borstvoeding en anticonceptie}

De meeste vrouwen gaan een week of zes na de bevalling weer een vorm van anticonceptie toepassen. De combinatiepil (bevat zowel oestrogenen als progesteron) wordt dan door veel huisartsen voorgeschreven. Echter, de combinatiepil heeft als groot nadeel dat de melkproductie flink kan teruglopen en geeft een verandering in de samenstelling van de moedermelk. Het is dus niet aan te raden als u van plan bent om zes maanden borstvoeding te geven te beginnen met de combinatiepil. Een alternatief zou de zogenaamde minipil zijn. Deze pil bevat alleen het hormoon progesteron en heeft de minste invloed op de hoeveelheid melk en de samenstelling van de melk. 
Veel mensen denken dat als ze borstvoeding geven ze niet in verwachting kunnen raken. Dit is slechts onder bepaalde voorwaarden waar en is dus niet voor honderd procent betrouwbaar. In de meeste gevallen zal het gebruik van een voorbehoedsmiddel noodzakelijk zijn. Ga er dus van uit dat het geven van borstvoeding geen veilige anticonceptiemethode is. Overleg tijdig met uw huisarts welke methode voor u het meest geschikt is.

\section{Enkele maanden na de bevalling}

\subsection{Wanneer de eerste keer de fles proberen?}

Bent $\mathrm{u}$ van plan om na uw zwangerschapsverlof weer aan het werk te gaan of wilt $\mathrm{u}$ eens een keer weg zonder uw baby, dan is het handig om uw baby te laten wennen aan een flesje moedermelk. Het kan onduidelijk zijn wanneer u moet beginnen met het introduceren van een flesje moedermelk. Doet $u$ dit te vroeg dan is er kans op tepel-speenverwarring, omdat drinken uit een fles een totaal andere techniek vereist dan drinken aan de borst. Baby's kunnen in de war raken en de borst gaan weigeren. Wacht $u$ echter te lang, dan heeft $u$ kans dat uw kind het flesje niet meer accepteert. Het is dus ook niet verstandig te vroeg een fopspeen aan uw baby te geven, omdat dit ook kan leiden tot tepel-speenverwarring.

Als de borstvoeding eenmaal goed op gang is gekomen en de baby drinkt lekker aan de borst dan is het moment aangebroken om eens een flesje afgekolfde moedermelk aan te bieden. Meestal zal dit zijn als uw baby 4 tot 5 weken oud is.

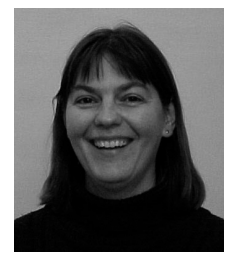

Marion over werken en kolven
Ik ben weer gaan werken na 11 weken. Ik kolf ongeveer $3 \mathrm{x}$ per werkdag op de tijden dat ik normaal de borst zou hebben gegeven. Ik kolf op mijn werkkamer. Die hoef ik gelukkig met niemand te delen. De deur doe ik dicht met een plakkertje erop, dat ik niet gestoord wil worden. Ik heb een elektrische kolfmachine en dat bevalt me erg goed. Ik heb het eerst handmatig geprobeerd, maar kreeg daardoor erg veel last van mijn arm.

Het kost me ongeveer een half uur per keer om zo'n 100-200 cc bij elkaar te sparen. De afgekolfde melk doe ik rechtstreeks in flesjes die dan de volgende dag naar het kinderdagverblijf gaan. Ik plak op elke fles een stickertje om aan te geven dat het om borstvoeding gaat. Dit om te voorkomen dat de flesjes in de magnetron opgewarmd worden. Zou de moedermelk in de magnetron worden opgewarmd, dan zou dat ten koste gaan van de kwaliteit van de beschermende stoffen en eiwitten die in de moedermelk zitten. Het bevalt mij al met al goed en ik hoop het nog lang vol te kunnen houden.

\subsection{Flesweigeren}

Mocht uw kindje toch het flesje moedermelk weigeren, dan is het niet aan te bevelen om te wachten met de borstvoeding totdat uw kindje wel uit het flesje wil drinken. Baby's proberen liever iets nieuws uit als ze tevreden zijn, dus als ze niet te veel honger hebben. U zou daarom het geven van de fles met afgekolfde moedermelk een uurtje na de voeding of halverwege een voeding kunnen uitproberen. Verder is het ook verstandig om niet te gauw van 'strategie' te wisselen. Kies 1 ding uit, en ga dat een paar dagen uitproberen. Door iedere keer te veranderen krijgt de baby geen tijd om er aan te wennen. 
Wat betreft de speen: de ervaring leert dat de zogenaamde platte spenen (dental speen) eerder door de baby geaccepteerd worden.

Er is ook een speen van Baby Care G, die een apart reservoir heeft, waardoor de manier van drinken iets op drinken uit de borst lijkt. Sommige baby's hebben die speen juist liever dan een 'normale' speen.

Mocht dit allemaal niet lukken, dan kunt u ook nog iets anders proberen: voeden met een spuitje, een lepeltje, of een bekertje. Dat laatste gaat meestal het makkelijkst. Het gaat als volgt: een kopje/bekertje tegen de onderlip van de baby zetten, schuin zodat de melk net aan tegen de onderlip komt. De baby drinkt dan als een poes de melk met de tong. Het is niet de bedoeling dat de melk naar binnen wordt gegoten, want dan kan de baby zich verslikken. Als de baby en de verzorger eraan gewend zijn geraakt, kan dit heel handig gaan. Veel baby's drinken op de dagen waarop ze niet aan de borst kunnen drinken minder dan men zou verwachten. Vaak wachten ze liever op hun moeder en halen ze het 's avonds in.

\subsection{Het kolven van moedermelk}

\subsubsection{Hoe gaat u kolven?}

Er zijn verschillende manieren om moedermelk te kolven. Er bestaan handmatige kolven, kolven die op batterijen werken en elektrische kolven. Sommige elektrische kolfapparaten kun je ook huren. De elektrische kolfapparaten zijn de zwaardere kolven, die vooral gebruikt worden door vrouwen die vaak en voor langere tijd kolven.

De meeste vrouwen kolven hun moedermelk met behulp van een kolfapparaat. Sommige vrouwen echter, vinden het makkelijker om met de hand te kolven. Ook als je een kolfapparaat gaat gebruiken, kan het toch nuttig zijn om te leren hoe je handmatig kunt kolven. Dit kan handig zijn op momenten dat de druk op de borsten toeneemt en je het kolfapparaat niet bij de hand hebt.

\subsubsection{De toeschietreflex}

Bij het geven van borstvoeding en bij het kolven speelt de toeschietreflex bij de moeder een grote rol. De toeschietreflex treedt op vlak nadat de baby is aangelegd. De reflex zorgt ervoor dat de melk die zich in de melkklieren achter in de borst heeft verzameld naar de holtes vlak achter de tepelhof stroomt. Zo kan de baby alle moedermelk uit de borst halen. Als de toeschietreflex niet zou optreden, zou er wel melk uit de borst komen, maar dat zou niet genoeg zijn voor de baby. Bovendien zou dit voornamelijk de voormelk zijn, de melk die zich al in de holtes vlak achter de tepelhof heeft verzameld. Deze melk bevat veel antistoffen, maar heeft een laag vetgehalte. De achtermelk, de melk die zich in de melkklieren bevindt, bevat meer vet en is daardoor voedzamer. 


\subsubsection{Toeschietreflex opwekken bij kolven}

Als de baby aan de borst ligt, dan gaat de melk vanzelf stromen. Maar als u gaat kolven zult $\mathrm{u}$ soms de toeschietreflex bewust op moeten wekken. Dit kunt $\mathrm{u}$ doen door te ontspannen en ervoor te zorgen dat $\mathrm{u}$ het niet koud heeft. Een paar keer diep in- en uitademen helpt vaak al goed.

Als u moeite heeft met het opwekken van de toeschietreflex, dan kunt u de volgende trucs toepasssen:

- uw borsten met warme handen masseren voordat u gaat kolven.

- $\quad$ een bandje afdraaien met daarop geluidjes van uw baby.

- kijken naar een foto van uw kind.

- iets warms drinken.

- afkolven met een dubbele kolf. Sommige vrouwen vinden dat dit de toeschietreflex bevordert. Bovendien gaat het kolven sneller.

- een positieve instelling ten opzichte van het afkolven is belangrijk. Negatieve gevoelens kunnen de toeschietreflex tegenwerken.

Als u ondanks alle bovenstaande tips toch nog problemen heeft met de toeschietreflex, dan zou $\mathrm{u}$ aan de huisarts om een speciale neusspray kunnen vragen. Deze neusspray bevat oxytocine, het hormoon dat de toeschietreflex opwekt. De meeste vrouwen die dit gebruiken, hoeven het maar een paar keer te gebruiken, daarna heeft het lichaam aangeleerd om zelf de toeschietreflex op te wekken tijdens het kolven.

\subsubsection{Hoe lang gaat $u$ kolven?}

U kunt met kolven doorgaan zolang de melk blijft stromen. Als u merkt dat er weinig meer uitkomt, stopt u. Doorgaan heeft geen zin, dat veroorzaakt dan alleen maar geïrriteerde of zelfs beschadigde tepels. U kunt dan beter stoppen met kolven en het later nog een keer proberen.

\subsubsection{Hoe vaak gaat u kolven?}

Het is het handigste om af te kolven op die momenten dat u normaal de borst zou geven. Maar uiteraard kunt $\mathrm{u}$ daar flexibel mee omgaan. Als u bijvoorbeeld op uw werk zit, dan zal niet ieder moment geschikt zijn om te kolven. Over het algemeen zult u per dag meer melk afkolven als u het kort maar vaak doet, dan wanneer u er enkele keren per dag langere tijd mee bezig bent. Maar dit is misschien niet altijd haalbaar. Als u bijvoorbeeld parttime werkt, kunt $\mathrm{u}$ wellicht volstaan met 1 keer kolven op uw werk. U kunt voordat u gaat werken uw kind een voeding geven, vervolgens op het werk 1 keer kolven en als u dan terugkomt van uw werk kunt u uw kind weer de borst geven.

\subsubsection{Kolven met de hand}

Sommige vrouwen vinden het makkelijker om met de hand te kolven. U heeft dan geen apparaat nodig en $\mathrm{u}$ kunt het overal doen! 
Het enige wat $\mathrm{u}$ nodig heeft is een schoon kommetje. De Marmet techniek is een veelgebruikte techniek om met de hand te kolven. Op het internet is informatie te vinden over deze techniek.

\subsubsection{Hygiëne}

Uiteraard moet $\mathrm{u}$ tijdens het kolven hygiënisch te werk gaan. $\mathrm{U}$ wilt uw melk immers bewaren om het aan uw kindje te geven. Zorg dus voor schone handen, een goed schoongemaakte kolf en een schone omgeving. Na het kolven maakt u meteen de kolf schoon. Alle onderdelen die met de melk in aanraking komen, moeten dagelijks schoongemaakt worden. Een gehuurde of geleende kolf dient altijd uitgekookt te worden voor gebruik. Het glazen of kunststof materiaal dient vijf minuten uitgekookt te worden, rubberen onderdelen één minuut.

\subsubsection{Hoeveel afgekolfde melk geeft $u$ aan uw kind?}

Vuistregel is dat een baby per etmaal $150 \mathrm{ml} x$ aantal $\mathrm{kg}$ lichaamsgewicht drinkt, met een maximum van 900-1000 ml. Dit deelt $\mathrm{u}$ door het aantal voedingen dat u per 24 uur geeft. Bijvoorbeeld als uw baby $4 \mathrm{~kg}$ weegt en 6 keer per dag drinkt, zou uw baby $150 \mathrm{ml} \times 4=$ $600 \mathrm{ml}$ per dag drinken gedeeld door 6, dat is $100 \mathrm{ml}$ per keer. Sommige baby's drinken minder uit een flesje dan je op grond van bovenstaande vuistregel zou verwachten, omdat ze de voorkeur geven aan de borst. Ze wachten dan liever tot hun moeder thuiskomt. Dit is niet iets om u zorgen over te maken, ze drinken dan later weer meer.

\subsubsection{Kolven en de wet}

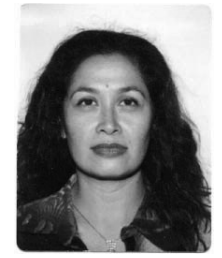

Sitia over werken, kolven en de wet
Tijdens mijn zwangerschap stond al vast dat ik borstvoeding wilde geven. Omdat ik werkte, had ik van tevoren al geïnformeerd naar een mogelijke plaats om te kolven. Die was aanwezig: de EHBO-kamer. Deze kamer kon ik afsluiten en er was water en stroom aanwezig. Ook mocht ik gebruik maken van de koelkast in het koffiekeukentje. Aardig om te weten: een werkgever is verplicht een vrouw de gelegenheid te geven haar kind te voeden tot het 9 maanden oud is. Kolven is hier een onderdeel van.

Het voeden of kolven mag maximaal een kwart van de werktijd in beslag nemen (inclusief evt. reistijd). Je hoeft hier dus niet extra voor te werken. Aan de kolfruimte zijn ook eisen gesteld. De ruimte moet afsluitbaar zijn en stromend water is verplicht. Een toilet is in het algemeen niet geschikt. Dit is geregeld in de arbeidswetgeving. Toen mijn dochter 5 weken was en goed aan de borst kon drinken, heb ik haar aan een flesje met gekolfde melk laten wennen. Dat was in het begin een drama! Ze wilde het flesje niet accepteren. Gelukkig had ze het na een aantal keren door. Inmiddels drinkt ze net zo makkelijk uit de fles als aan de borst. Het kolven op mijn werk (2x per dag) is een rustpunt. Leuk vind ik het niet, maar het is "voor een goed doel". Iedereen weet trouwens wat ik doe, als ik met mijn tasje naar boven ga. De melk vang ik op in flesjes die ik vervolgens op mijn werk in de koelkast zet. 's Avonds als ik thuis kom, gaat de melk voor de dag erna weer in de koelkast, of als ik het langere tijd niet nodig heb, in de vrieskist. 
Het is in de Arbeidstijdenwet bepaald dat een moeder die borstvoeding geeft bijzondere rechten heeft: het voedrecht. Hierin staat dat iedere werkgever de voedende moeder de mogelijkheid, de plaats en de tijd moet bieden om haar kind te voeden (op het werk, de crèche of thuis) of om haar melk af te kolven.

Dat houdt in dat u uw kind kunt laten brengen om het op uw werk in een daarvoor bestemde ruimte te voeden, dat $u$ zelf naar huis of naar de crèche gaat om daar uw kind te voeden. Of dat u kolft in een ruimte op uw werk. De tijd die u daarvoor nodig heeft, wordt tot werktijd gerekend en mag maximaal een kwart van de totale dagelijkse arbeidsduur bedragen. Als u dus een werkdag van 8 uur heeft, mag u daarvan 2 uur voor het voeden of kolven gebruiken en dat wordt door uw werkgever betaald. Deze bepaling geldt overigens totdat uw baby 9 maanden is, daarna gelden individuele afspraken tussen $u$ en uw werkgever.

Als u uw kindje op het werk voedt of als u wilt kolven, dient daarvoor gelegenheid te zijn. $\mathrm{Nu}$ is dat gemakkelijker gezegd dan gedaan, want er zijn veel bedrijven die daarvoor niet de nodige voorzieningen kunnen of willen treffen. Toch is een plek, waar $\mathrm{u}$ zich in alle rust terug kunt trekken, heel belangrijk. In overleg met de werkgever kan voor dit doel een speciale ruimte gereserveerd of ingericht worden. Let dan op de volgende punten: de ruimte moet warm, goed verlicht en afsluitbaar zijn, voldoende privacy bieden, stromend water en elektra hebben, één of meerdere comfortabele stoelen en een tafeltje en het liefst een eigen koelkast.

\subsubsection{Waarin gekolfde moedermelk bewaren?}

Onderstaande is van belang wanneer $u$ kolft om de moedermelk langere tijd te bewaren. Kolft u voor de dag erna, dan is het advies om de moedermelk niet in te vriezen.

U kunt de moedermelk direct in de flesjes invriezen. Dit heeft als voordeel, dat u niet hoeft over te gieten. Dat scheelt een hoop geknoei. Een ander voordeel van direct in de flesjes invriezen is, dat u een complete voeding meteen kunt ontdooien. Het heeft de voorkeur om het flesje de avond van tevoren in de koelkast te zetten, zodat de melk daar kan ontdooien en opgewarmd kan worden wanneer nodig. Het opwarmen gaat als volgt:

Vanuit de diepvries laat u eerst koud water stromen over het ingevroren flesje en geleidelijk voegt $\mathrm{u}$ warmer water toe totdat de melk ontdooid is en verwarmd is tot op lichaamstemperatuur. Als er geen warm stromend water aanwezig is kan er een pan met water worden verwarmd (niet te heet) en daar kan dan de melkfles worden ingezet. Ook kan een flessenwarmer worden gebruikt.

Het is af te raden om een magnetron te gebruiken omdat er dan waardevolle stoffen zoals de immuunstof IgA verdwijnen. Ook wordt de melk niet gelijkmatig verwarmd waardoor het binnenste gloeiend heet kan zijn. Om de melkdeeltjes weer onderling te vermengen is het goed om voorzichtig ronddraaiende bewegingen te maken zodat er niet onnodig hard 
geschud wordt. Zoals al eerder genoemd kan door hard schudden de structuur van de eiwitten uit elkaar vallen.

U kunt bij Hema, Kruidvat, DA of Etos relatief goedkoop prima flesjes kopen (ongeveer $€$ 1,50) om zo een kant-en-klaar diepvriesvoorraadje aan te leggen.

Invriezen kan ook nog op andere manieren. Alle kolfmerken hebben ook steriele zakjes. Hierin kunt $\mathrm{u}$ de melk ofwel rechtstreeks kolven (Avent: in een speciale, open fles waar je het zakje inhangt) of later overgieten (Medela, die overigens met wat kunst-en-vliegwerk ook rechtstreeks te gebruiken zijn). U kunt de datum op het zakje schrijven en met een bindertje afsluiten of een knoopje leggen en dan invriezen. Nadeel is dat $u$ dan moet overgieten en er op moet letten, dat u het zakje goed rechtop wegzet en dat het niet aan de bodem van het vriesvak vast vriest.

In beide gevallen zal er aanzienlijk melkverlies op kunnen treden. Tenslotte kunt u ook gebruik maken van ijsblokjesbakjes of -zakjes.

Voordeel hiervan is, dat u kleine porties in kunt vriezen die erg makkelijk zijn als er nog behoefte is aan een beetje extra melk. U makt de ijsblokjeshouder goed schoon in een sopje, spoelt het daarna met heet water af (uitkoken is niet aan te raden vanwege vervorming) en giet er, als het afgekoeld is, de koude melk in. Afdekken met huishoudfolie om vervuiling te voorkomen en dan goed recht wegzetten in het vriesvak. Als de blokjes bevroren zijn, druk ze er dan voorzichtig uit en verpak ze met 5 à 10 in zakjes. IJsblokjeszakjes zijn wat lastiger in het gebruik: het ingieten van de melk is een vak apart en gaat meestal met het nodige geknoei gepaard. Het is ook een hele kunst om de vakjes goed vol te krijgen: meestal blijft er een luchtbel in zitten die er niet uit te drukken is. Leg daarna een knoop in het zakje en leg het weg.

Let ook hier weer goed op dat het zakje niet rechtstreeks met de bodem van het vriesvak in aanraking komt in verband met vastvriezen en kapot gaan bij het uitnemen. Het ontdooien in de koelkast of onder de kraan is hetzelfde als met flesjes of speciale zakjes, maar daarna moet $u$ het allemaal weer over- of bijgieten in de fles. Het is wat extra werk, maar er zijn moeders die bij deze methode zweren.

\subsubsection{Bewaaradvies moedermelk}

Temperatuur en bewaaradvies. Bij onderstaande tijden en temperaturen is uitgegaan van een goed schone, stofvrije verpakking.

\begin{tabular}{lll}
\hline & Temperatuur & Houdbaarheid \\
\hline Colostrum & Kamertemperatuur & 12 tot 24 uur \\
Moedermelk & Kamertemperatuur & 6 tot 10 uur \\
Moedermelk & Koelkast & Tot 5 dagen \\
Moedermelk & Koelkast ziekenhuis & Niet langer dan 48 uur \\
Moedermelk & Vriesvak koelkast & Tot 2 weken \\
Moedermelk & (kleine) vriezer die vaak open en dicht gaat & 3 tot 4 maanden \\
Moedermelk & Diepvries constant max. $-18^{\circ} \mathrm{C}$ & 6 maanden of langer \\
Ontdooide moedermelk & Koelkast & Tot 24 uur \\
Ontdooide moedermelk & Kamertemperatuur & Zo snel mogelijk gebruiken \\
\hline
\end{tabular}


Wilt u meer informatie over het kolven en kolfapparaten, kijk dan verderop in deze brochure waar u meer informatie kunt krijgen.

Tenslotte:

De eerste keer dat u kolft zal er misschien nog niet veel uit komen. Dat geeft niets, kolven moet je leren. Het afkolven van moedermelk is namelijk een hele taak. In het begin zal het wennen zijn, en zal het extra inspanning vragen. Na verloop van tijd zult u er vertrouwd mee raken. Maar het is een dankbare taak. U geeft uw baby het beste dat er is!

\subsection{Introduceren van ander voedsel na zes maanden}

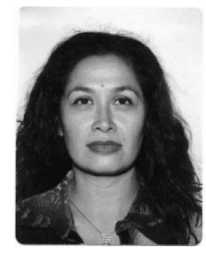

Sitia

over reacties

van anderen

over het

geven van

borstvoeding
Op een gegeven moment kreeg ik allerlei opmerkingen te verwerken vanuit mijn omgeving. "Je kind kun je toch niet zes maanden alleen maar borstvoeding geven?" Ik vond het erg vervelend om me constant te verdedigen tegen al die mensen die het allemaal beter denken te weten. Zelfs mijn huisarts begon mij te vertellen dat ik met vier maanden toch eigenlijk met het fruithapje moest gaan beginnen. Gelukkig heb ik me niet van de wijs laten brengen. Ik heb telkens uitgebreid uitgelegd waarom ik zes maanden uitsluitend borstvoeding geef aan mijn kind. De meeste mensen bleven het vreemd vinden, maar hielden uiteindelijk op met vragen te stellen. Het verbaasde me dat ik bijna een uitzondering was omdat ik zes maanden borstvoeding wilde gaan geven. Dat had ik niet verwacht.

Als $\mathrm{u}$ begint met het geven van vast voedsel, maakt het weinig uit in welke volgorde het vaste hapje geïntroduceerd wordt. Het is aan te raden om in het begin voorzichtig te zijn met sterk gekruide of zeer allergene voedingswaren (bijvoorbeeld het wit van een ei en aardbeien). Het is verstandig om nieuwe dingen apart te geven en niet een aantal dingen door elkaar te roeren. Dus puur bonen of alleen een gepureerde appel. Geef uw baby drie dagen achter elkaar hetzelfde en let goed op reacties of het verergeren van bestaande klachten. Zijn er geen andere reacties dan is het voedingsmiddel waarschijnlijk veilig. Zijn die er wel, dan stelt $u$ het geven van dit voedingsmiddel nog enige maanden uit en probeert $\mathrm{u}$ het daarna opnieuw. Varieer zo veel mogelijk met wat uw baby kan eten. Begin met zachte groenten als bietjes, worteltjes, bloemkool, witlof. Het is verstandig om niet vaker dan 1 keer per week spinazie en/of andijvie te geven. U dient de groenten in het begin goed te koken. Het geven van rauwkost komt pas later, want dat is moeilijk verteerbaar. Voor de eerste fruithapjes is geprakt vers fruit prima, zoals peer, appel, perzik, abrikoos, pruim, banaan en meloen.

\subsection{Alternatieven voor borstvoeding}

Het kan voorkomen dat het voor u niet mogelijk is om uw baby borstvoeding te geven. Het kan ondanks alle voordelen van borstvoeding ook een bewuste keuze van u zijn om uw baby niet met moedermelk te voeden. Wij adviseren $u$ echter in dat geval geen 'gewone' kunstvoeding te gaan gebruiken. Om de kans op het ontwikkelen van astma of koemelkallergie zo klein mogelijk te houden, is het beter uw kind te voeden met een hypoallergene flesvoeding (bijvoorbeeld Nutrilon Hypo Allergeen). In hypo-allergene voeding 
zijn de eiwitten speciaal behandeld, zodat de kans op het ontwikkelen van een allergie voor deze eiwitten nog maar heel klein is. Hypo-allergene flesvoeding is een voeding die geen stoffen bevat waardoor eventueel een allergie tot uiting zou kunnen komen. Door uw baby hypo-allergene flesvoeding te geven, kunt u dus de kans op het optreden van onder meer astma en koemelkallergie verminderen. De voeding ziet er anders uit en ruikt ook anders dan 'normale' kunstvoeding. Voor de baby maakt dit echter niets uit.

\section{Adressen voor informatie over borstvoeding en astma}

\section{Telefoonnummers}

Als $u$ een steuntje in de rug wilt en vragen heeft, dan kunt $u$ altijd contact opnemen met één van onderstaande organisaties:

Vragen over borstvoeding

- Vereniging Borstvoeding Natuurlijk, bereikbaar op telefoonnummer: 0343576626

- Borstvoedingsorganisatie La Leche League, bereikbaar op telefoonnummer: 0111413189

- Nederlandse Vereniging van Lactatatiekundigen, bereikbaar op telefoonnummer: 0900-5228284

Vragen over astma

- De advieslijn van het Nederlands Astma Fonds is bereikbaar op telefoonnummer: 0900-2272596 of via e-mail: advieslijn@astmafonds.nl.

Vragen aan dietiste

- De Nederlandse Vereniging van Diëtisten kan u informatie geven over namen en adressen van diëtisten bij $\mathrm{u}$ in de buurt. Deze vereniging geeft echter geen antwoorden op vragen over een persoonlijk dieet en voedingsvragen. De vereniging is bereikbaar op telefoonnummer: 030-6346222 of via e-mail: bureau@nvdietist.nl

\section{$\underline{\text { Bestellen folders }}$}

Zowel bij "Borstvoeding Natuurlijk" als bij "La Leche League" kunt u diverse folders bestellen over het geven van borstvoeding en alle daarbij komende zaken.

\section{Folders van "Borstvoeding natuurlijk"}

Nr. 1 Borstvoeding: een goed begin

Nr. 2 Borstvoeding: de eerste weken

Nr. 3 Voorkomen en genezen van pijnlijke tepels

Nr. 4 Borstvoeding en vaste voeding

Nr. 5 Huilen! Darmkrampjes?

Nr. 6 Te weinig melk

Nr. 7 Borstvoeding voor een meerling 
Nr. 8 Afkolven van moedermelk

Nr. 9 Borstvoeding en een baan

Nr.10 Moedermelk en het milieu

Nr.11 Te veel melk

Nr.12 Borstvoeding voor een couveusebaby

Nr.13 Borstontsteking

Nr.14 Borstvoeding na een keizersnede

Heeft $u$ interesse in een van deze folders dan kunt $u$ deze bestellen bij Borstvoeding Natuurlijk: 0343-576626 of via internet: www.vbn.borstvoeding.nl

\section{Folders van "La Leche League"}

Basisinformatie

De eerste weken

Goed aanleggen

Borstontsteking

Afkolven en bewaren

Borstvoeding, zo werkt het

Te veel of te weinig melk

Tepelproblemen, voorkomen en genezen

Stoppen met borstvoeding

Bijzondere omstandigheden

Te vroeg geboren

Spruw en candidas

Medicijnen voor de moeder

Schisis

Syndroom van Down

Meerlingen

Voedselovergevoeligheid

Borstweigeren

Keizersnede

Geelzucht

Overige onderwerpen

Huilen en troosten

Een baan buitenshuis

Seksualiteit en vruchtbaarheid

Introduceren van ander voedsel

Voor vaders

Voeding voor de moeder

Dragen van een kind (met gebruiksaanwijzing draagdoeken)

Heeft $\mathrm{u}$ interesse in een van deze folders dan kunt $\mathrm{u}$ deze bestellen via La Leche League. Telefoon: 0111-413189 of via www.lll.borstvoeding.nl 


\section{Informatiebijeenkomsten}

Iedere maand organiseren de leidsters van La Leche League informatiebijeenkomsten bij hen in de regio. Deze bijeenkomsten zijn voor aanstaande ouders en voedende moeders met hun baby's en andere belangstellenden. Onderwerpen zijn bijvoorbeeld "Voordelen van borstvoeding voor moeder en baby", "De kraamtijd", "Het voorkomen en oplossen van problemen" en "Als de baby ouder wordt". De leidster geeft informatie en er is gelegenheid ervaringen uit te wisselen.

Informatie kunt $\mathrm{u}$ verkrijgen via bovengenoemd telefoonnummer.

\section{Video's}

Voorbeeld video's om te downloaden vindt u op:

www.breastfeeding.com/helpme/helpme_video.html

Let wel. Dit is een Engelstalige video over het geven van borstvoeding.

Voorlichtingsvideo over borstvoeding geven:

Te bestellen bij Borstvoeding Natuurlijk, telefoonnummer: 0343-576626

\section{Internetadressen}

Informatie over borstvoeding en kolven

- www.borstvoeding.nl

- www.borstvoeding.com

- www.vbn.borstvoeding.nl

- www.lll.borstvoeding.nl

- www.zvb.borstvoeding.nl

- $\quad$ www.nvlborstvoeding.nl

Informatie over kleding voor borstvoedende vrouwen

- www.prettymum.nl

- www.beginnings.org

\section{Informatie over kolfapparaten}

- www.medela.nl

- www.avent.com

Informatie over het uitwisselen van informatie met andere ouders

- www.ouders.nl

Informatie over astma

- $\quad$ www.astmafonds.nl

Informatie over voedselovergevoeligheid

- www.voedingscentrum.nl

Informatie over diëtisten bij u in de buurt

- www.nvdietist.nl 
Let wel. Met nadruk willen wij u op onderstaande punten wijzen:

1. Aan deze brochure kunnen geen rechten worden ontleend.

2. Wij zijn niet verantwoordelijk voor de inhoud op de vermelde internetpagina's noch voor de diensten die geleverd worden door de instanties waarnaar wij verwijzen.

3. De verwijzingen naar de vermelde internetpagina's zijn gemaakt op het moment van samenstellen van deze brochure. Wij zijn niet verantwoordelijk voor het op een later moment niet meer beschikbaar zijn/ gewijzigd zijn van de vermelde internetpagina's.

4. Ondanks alle zorg die aan de samenstelling van de tekst is besteed, kan noch de auteur noch de uitgever aansprakelijkheid aanvaarden voor eventuele schade die zou kunnen voortvloeien uit een mogelijke fout die in deze uitgave zou kunnen voorkomen.

Bronvermelding:

In deze brochure zijn gegevens gebruikt uit onderstaande boeken, folders en websites:

- websites en folders van Vereniging Borstvoeding Natuurlijk

- website en folders van La Leche League

- E. Van Stokkom, Alles over Astma. Nederlands Astma Fonds. 1999. ISBN: 906608-027-2

- $\quad$ Standaarden Borstvoeding, NVJG, 1997

- Websites die vermeld staan in de brochure 



\section{Publications}





\section{Publications}

- Gijsbers B, Jongmans M, Katgert T, van Baar AL, de Kleine MJK. Temperament kenmerken bij prematuur geboren kinderen. TOKK 2002:27:66-77.

- Gijsbers B, Mesters I, Knottnerus JA, Legtenberg AH, van Schayck CP. Factors influencing breastfeeding practices and postponement of solid food to prevent allergic disease in high-risk children: results from an explorative study. Patient Educ Couns 2005;57:15-21.

- Kuiper S, Maas T, van Schayck CP, Muris JW, Schönberger HJ, Dompeling E, Gijsbers B, van Weel C, Knottnerus JA. The primary prevention of asthma in children study: design of a multifaceted prevention program. Pediatr Allergy Immunol 2005; $16: 321-331$.

- Gijsbers B, Mesters I, Knottnerus JA, Kester ADM, van Schayck CP. The success of an educational program to promote exclusive breastfeeding for 6 months in families with a history of asthma: A randomized controlled trial. Pediatr Asthma Allergy Immunol 2006;19:214-222.

- Gijsbers B, Mesters I, Knottnerus JA, van Schayck CP. Factors associated with the initiation of breastfeeding in asthmatic families: The Attitude-Social Influence-SelfEfficacy Model. Breastfeed Med 2006;1:236-246.

- Gijsbers B, Mesters I, Knottnerus JA, van Schayck CP. Factors associated with the duration of exclusive breastfeeding in asthmatic families. Health Educ Res 2007. doi:10.1093/her/cym013.

- Van der Meer A, Prakken BJ, Gijsbers B, Rademakers CMA, Wulffraat NM, Sinnema G. Psychological side effects of MTX treatment in juvenile idiopathic arthritis: a pilot study. Clin Exp Rheumatol 2007;25:480-485. 



\section{Dankwoord}





\section{Dankwoord}

Het is dan zover! Voor mij voor nu het laatste schrijfwerk, maar voor u als lezer mogelijk het eerste hoofdstuk dat $\mathrm{u}$ zult lezen. En dat is goed, want dit proefschrift is tot stand gekomen met de praktische en morele hulp van velen. Bedankt daarvoor en zonder iemand te kort te willen doen noem ik een aantal personen in het bijzonder:

Allereerst mijn promotoren, prof.dr. Onno van Schayck en prof.dr. André Knottnerus. Beste Onno, bedankt dat je mij 6 jaar geleden de kans en het vertrouwen hebt gegeven om een doorstart te maken met dit lopende onderzoek! Beste André, bedankt voor je kritische maar altijd opbouwende commentaar op de stukken en je betrokkenheid ondanks je drukke agenda. Daarnaast mijn co-promoter, dr. Ilse Mesters. Beste Ilse, ik ben blij dat jij mijn copromotor was. Ik kon altijd bij je terecht als er zich zo nu en dan een "probleempje" voordeed. Je verzekerde mij telkens dat het allemaal goed zou komen, bedankt daarvoor!

Mijn paranimfen Anita Legtenberg en Claudia Gijsbers. Beste Anita, samen hebben we de basis gelegd voor het project. Zonder jouw strakke en sterke organisatievermogen had het project nooit zo gladjes en professioneel kunnen verlopen. Super, dat jij samen met mijn zus mijn paranimf bent!

Een speciaal woord van dank voor Karin Manders. Beste Karin, jij was de sprankelende grondlegger van dit project. Met veel inzet heb jij de pilot-studie uitgevoerd en daarmee het meest intensieve onderdeel voor je rekening genomen. Bedankt daarvoor, en het ga je goed!

Verder statisticus, dr. Arnold Kester. Beste Arnold, bedankt voor je geduld en je heldere uitleg van de voor mij vaak ingewikkelde statistische technieken.

De deelnemende gezinnen wil ik heel hartelijk bedanken voor hun vrijwillige deelname aan dit project. Zonder hen had het onderzoek niet kunnen plaatsvinden.

De beoordelingscomissie wil ik bedanken voor de snelle beoordeling van het manuscript en hun nuttige aanbevelingen.

Tot slot, wil ik familie, vrienden, en collega's bedanken voor hun warme interesse en betrokkenheid al die jaren.

En Jeroen, je wilde het niet, maar dat kan ik natuurlijk niet maken, dus voor jou een aparte regel en nog wel de allerlaatste. 

About the author 



\section{About the author}

Barbara Gijsbers was born on July 31, 1975 in Nijmegen. In 1992 she graduated high school (HAVO) and completed Atheneum (van Maerlant Lyceum in Eindhoven) in 1994. In the same year she started her study Psychology at the University of Tilburg. She specialised in Child and Youth Psychology and graduated in 1999.

In 2000 she started as a research assistant at the department of General Practice (CAPHRI) of Maastricht University and in 2001 she was appointed as a junior-researcher and conducted the research presented in this thesis. Besides the research work she worked parttime as a psychologist-diagnostician at the department of Medical Psychology of the Academic Hospital Maastricht.

In 2005 she started to work fulltime in the Wilhelmina Children's Hospital of the University Medical Center Utrecht, and followed the two-year postdoctoral training to become a registered "gezondheidszorgpsycholoog; accent kinder- en jeugd" (Health Care Psychologist). Currently, she is working at the department of Medical Psychology in the Wilhelmina Children's Hospital.

Barbara lives happily together with Jeroen Rovers in Tilburg. They are expecting their first child in the beginning of 2008. Naturally, Barbara is already preparing herself to breastfeed exclusively for six months. 

